\title{
ASSESSMENT OF THE THERMAL-HYDRAULIC TECHNOLOGY OF THE TRANSITION PHASE OF A CORE-DISRUPTIVE ACCIDENT IN A LMFBR
}

\author{
G.A. Greene, T. Ginsberg, and M.S. Kazimi
}

\section{DO NOT MICROFILM COVER}

\section{DATE PUBLISHED — NOVEMBER 1982}

DEPARTMENT OF NUCLEAR ENERGY, BROOKHAVEN NATIONAL LABORATORY UPTON, LONG ISLAND, NEW YORK 11973 


\section{DISCLAIMER}

Portions of this document may be illegible in electronic image products. Images are produced from the best available original document. 
This report was prepared as an account of work sponsored by an agency of the United States Government. Neither the United States Government nor any agency thereof, nor any of their employees, makes any warranty, express or implied, or assumes any legal liability or responsibility for the accuracy, completeness, or usefulness of any information, apparatus, product, or process disclosed, or represents that its use would not infringe privately owned rights. Reference herein to any specific commercial product, process, or service by trade name, trademark, manufacturer, or otherwise does not necessarily constitute or imply its endorsement, recommendation, or favoring by the United States Government or any agency thereof. The views and opinions of authors expressed herein do not necessarily state or reflect those of the United States Government or any agency thereof.

NUREG/CR-3014

BNL-NUREG-51621

AN, $\mathrm{R}-7$

NUREG/CR--3014

DE83 009098

\title{
ASSESSMENT OF THE THERMAL-HYDRAULIC TECHNOLOGY OF THE TRANSITION PHASE OF A CORE-DISRUPTIVE ACCIDENT IN A LMFBR
}

\author{
G.A. Greene, T. Ginsberg, and M.S. Kazimi
}

\section{MANUSCRIPT COMPLETED — NOVEMBER 1982 DATE PUBLISHED - NOVEMBER 1982}

\author{
EXPERIMENTAL MODELING GROUP \\ DEPARTMENT OF NUCLEAR ENERGY \\ BROOKHAVEN NATIONAL LABORATORY \\ UPTON, LONG ISLAND, NEW YORK 11973
}

\section{NOTICE}

PORTIONS OF THIS REPORT ARE ILLEGIBLE.

It has been reproduced from the best available copy to permit the broadest possible availability.

Prepared for

UNITED STATES NUCLEAR REGULATORY COMMISSION

WASHINGTON, D.C. 20555

UNDER INTERAGENCY AGREEMENT DE-ACO2-76CH00016

NRC FIN NO. A-3024 
NOTICE

This report was prepared as an account of work sponsored by an agency of the United States Government Neither the United States Government nor any agency thereof, or any of their employees, makes any warranty, expressed or implied, or assumes any legal hability or responsıbılity for any third party's use, or the results of such use, of any information, apparatus, product or process disclosed in this report, or represents that its use by such third party would not infringe privately owned rights

The views expressed in this report are not necessarily those of the US Nuclear Regulatory Commission

Avarlable from

GPO Sales Program

Division of Technical Information and Document Control

US Nuclear Regulatory Commission

Washington, D C 20555

$$
\text { and }
$$

National Technical Information Service

Springfield, Vırginıa 22161 
The technology of thermal hydraulic aspects of the transition phase accident sequence in liquid metal fast breeder reactors has been reviewed. Previous analyses of the transition phase accident sequence have been reviewed and the current understanding of major thermal hydraulic phenomenology has been assessed. As a result of the foregoing, together with a scoping analysis of the transition phase accident sequence, major transition phase issues have been defined and research needs have been identified.

The major conclusion of transition phase scoping analysis is that fuel dispersal cannot be relied upon to rule out the possibility of recriticalities during this stage of the accident. The potential for fuel blowdown to a subcritical configuration immediately following fuel disruption has been greatly overestimated in much of the previous work. Material freezing in the subassembly blanket structure is the major factor expected to prevent blowdown. While our understanding of fuel motion and freezing phenomena is incomplete, the available evidence strongly suggests the likelihood of only limited fuel relocation prior to freezing.

As a result of fuel freezing, molten fuel and steel would remain temporarily entrapped in the core region. Molten pools of subassembly scale would grow to whole-core pools. During this process of pool growth, several mechanisms of pool collapse are conceivable and recriticality could occur. The accident progresses from a situation of incoherent fuel motion, imposed by the presence of subassembly duct walls, to progressively greater potential coherence. The possibility for significant energetics increases as the accident progresses towards the whole-core pool configuration. Estimation of accident energetics is beyond the scope of this work.

Considerable progress has been made in recent years relevant to major transition phase issues. Our state of knowledge is, however, incomplete. Recommendations for future research are presented. 
0

○ 
ABSTRACT. .......................... $i{ }_{i i}$

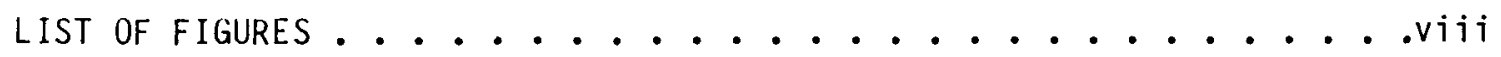

LIST OF TABLES. ......................... ix

NOMENCLATURE. ...................

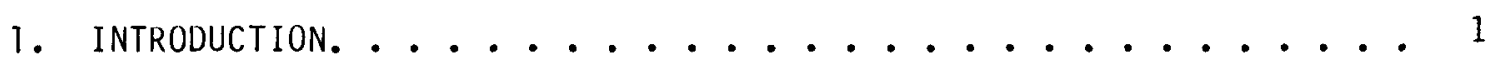

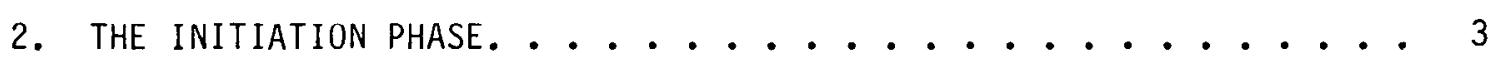

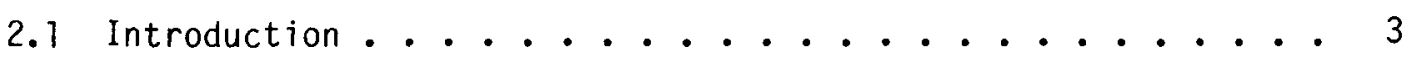

2.2 Mechanistic Assessment .............. 3

2.3 Phenomenological Uncertainties ........... 8

2.3.1 Sodium Voiding Incoherency. ........ 8

2.3.2 Clad Relocation............. 8

2.3.3 Fuel Motion Mode.............. 9

3. PREVIOUS TRANSITION PHASE ANALYSES. ............ 11

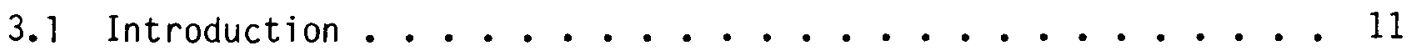

3.2 FfTf-Related Analyses. . . . . . . . . . . 11

3.2.1 Initiation Phase Results........... 11

3.2.2 Objectives and Methods of Analysis. ........ 12

3.2.2.1 Disrupted Core Analysis. ........ 12

3.2.2.2 Intact Core Disruption Analysis...... 13

3.2 .3 Results ................ . . 13

3.2.4 Potential Impact of Thermal Hydraulic Uncertainties . 14

3.3 CRBR-Related Analyses. . . . . . . . . . 16

3.3.1 Initiation Phase Results. . . . . . . . 16

3.3.2 Ubjectives and Methods of Analysis......... 16

3.3.2.1 Methods of Analysis. .......... 17

3.3 .2 .2 Results. ............ 18 
TABLE OF CONTENTS (Cont'd)

3.3.3 Potential Impact of Thermal-Hydraulic Uncertainties . $\frac{\text { Page }}{18}$

4. TECHNOLOGY ASSESSMENT .......................... 23

4.1 Cladding Melting and Relocation. . . . . . . . . 23

4.2 Hydrodynamic Behavior of Volume Boiling Pools. . . . . . 27

4.3 Boundary Heat Transfer from Volume Boiling Pools ....... 37

4.4 Fuel Relocation Dynamics . . . . . . . . . . . 44 44

5. TRANSITION PHASE ACCIDENT SEqUENCES ................... 59

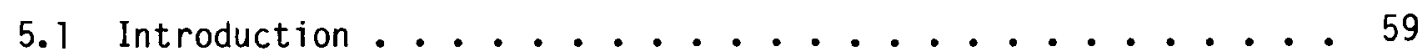

5.2 Accident Flow Chart and Discussion .......... 59

5.2.1 Initiation Phase.......................... 61

5.2.2 Transition Phase.............. 63

5.2.3 Termination Phase ............. 70

5.3 Summary. .......................... 70

6. ASSESSMENT OF RESEARCH NEEDS AND PRIORITIES . . . . . . . . 73

6.1 Initial Conditions of the Transition Phase . . . . . . 73

6.1 .1 Sodium Voiding Dynamics in Multi-Channels . . . . 73

6.1 .2 Clad Relocation Dynamics. ........... 77

6.1 .3 Fuel Dispersal Modes. ............. 77

6.2 Material Behavior During the Transition Phase. . . . . . 78

6.2.1 Solidification of Fuel-Steel in Pin Bundles..... . 78

6.2.2 Multi-Component (Fuel-Steel) Pool Thermal and Hydrodynamic Characteristics. ....... 79

6.2.3 Boiling Pool Collapse Mechanisms. . . . . . . 79

6.3 Termination Phase. . . . . . . . . . . 80

6.3.1 Fuel Two-Phase Blowdown Through Pin Bundles...... 80 
7. SummarY AND CONCLUSIONS. . . . . . . . . . . . . . 81

7.1 Accident Analysis ......................... 81

7.2 Transition Phase Phenomenology. . . . . . . . . 82

8. ACKNOWLEDGEMENTS . . . . . . . . . . . . . . 85

9. REFERENCES . . . . . . . . . . . . . . . . 86

APPENDIX A: ANALYSIS OF KEY TRANSITION PHASE PHENOMENOLOGY $• . \cdots 5$

A.1 Development of Steel Vapor Source. . . . . . . . . . . 95

A.2 Blockage Development . . . . . . . . . . . . . 98

A.3 Blockage Melt-Through. . . . . . . . . . . . . . 99

A.4 Duct Wall Melt-Through . . . . . . . . . . . . 103

A.5 Small Scale Pool Energy Balances . . . . . . . . . . 109

A.6 Whole Core Energy Balances . . . . . . . . . . . . 113 


\section{LIST OF FIGURES}

Figure

Page

2.1 Accident Sequence Diagram ............ 4

2.2 Chronology and Sequence of Events in a CRBR LOF . . . . 6

2.3 Power and Reactivity Vs. Time . . . . . . . . . 7

4.1 Pool-Average Void Fraction Measurements....... 35

4.2 Natural Convection Correlation of Boundary Heat Transfer from Volume Boiling Pool

(a) $\mathrm{Nu}(\mathrm{x})$ vs. $\operatorname{Ra}(\bar{\alpha}, \mathrm{x})$ (b) Nu vs. $\operatorname{Ra}(\bar{\alpha}, \mathrm{L}) \ldots 42$

5.1 Transition Phase Accident Sequence Paths. . . . . . . 60

5.2 Disrupted Core Criticality Calculation Results. . . . 69

A.1 Melting Time of Pure Fuel Blockage,

Thickness $=0.1 \mathrm{~m}$, Zero Subcooling. ......... 101

A.2 Melting Time of Fuel-Steel Blockage,

Thickness $=0.1 \mathrm{~m}$, Zero Subcooling,

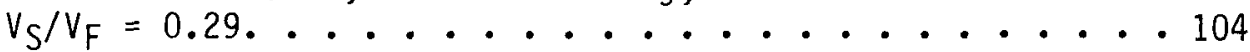

A.3 Melting Time of Fuel-Steel Blockage, Thickness $=0.1 \mathrm{~m}$, Subcooling $=528 \mathrm{~K}$,

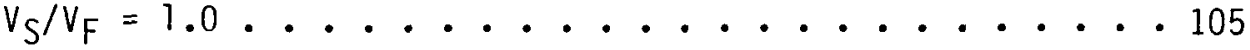

A.4 Duct Wall Melting Time. ............. 107

A.5 $v_{2}$ Crust Thickness . . . . . . . . . . 108

A.6 Boiling Fuel-Steel Pool Heat Losses.......... 110 


\section{LIST OF TABLES}

Table

$\underline{\text { Page }}$

4.1 Single-Component Volume-Heated Boiling and Gas Injection

Experiments.......................... 30

4.2 Summary of Correlations of Heat Transfer from Internally

Boiling Liquids to Boundaries........... 40

4.3 Fuel Freezing Experiments.............. 51

5.1 Timing of Initiation Phase Events . . . . . . . 62

5.2 Comparison of Transition Phase Events Under

Low- and High-Power Conditions. . . . . . . . . 66

6.1 Summary of Further Research Needs . . . . . . . . . . 74

A.l Computed Dimensionless Steel Vapor Generation Rates . . . 97

A. 2 Results of Whole-Core Energy Balances . . . . . . 114 


\section{NOMENCLATURE}

A

$A_{\text {fs }}$

$c_{f}$

$c_{p}$

$c_{S}$

$\mathrm{d}_{H}$

D

f

g

geff

$\mathrm{Gr}, \mathrm{Gr}$ *

h

$n_{f s}$

$h_{f g}$

$n_{s}$

$h_{f}$

$h \star$

H

$\mathrm{H}_{\mathrm{O}}$

jg

$j_{g}$ *

$j_{g b}$

$j_{g j}$

jgk

$j_{g \infty}$

k blockage area

fuel-steel interfacial area

specific heat of fuel

specific heat

specific heat of steel

hydraulic diameter

fuel pin diameter

friction factor

gravitational acceleration

component of gravitational acceleration

Grashof number

heat transfer coefficient

heat of fusion

latent heat of vaporization

enthalpy of steel

enthalpy of fuel

enthalpy of molten steel entering pool

pool height

collapsed pool height

superficial vapor velocity

dimensionless vapor flux

bubbly flow transition vapor flux

drift flux

dispersed flow transition vapor flux

vapor flux at top of pool

thermal conductivity 


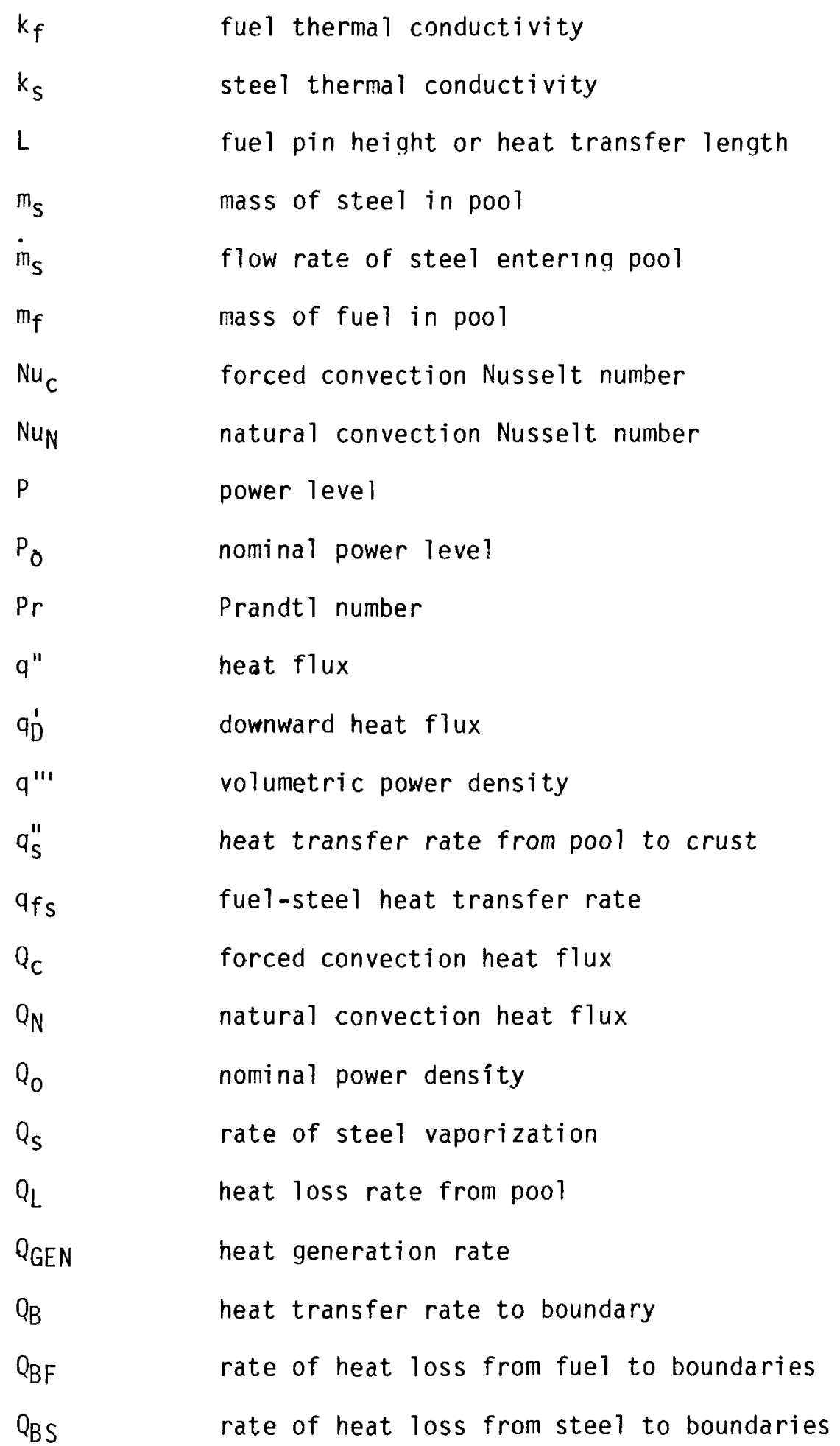


NOMENCLATURE (Cont'd)

\begin{tabular}{|c|c|}
\hline $\mathrm{Q}_{\mathrm{BOT}}$ & pool bottom heat loss rate \\
\hline$Q_{S I D E}$ & pool side heat loss rate \\
\hline QTOT & total heat loss rate \\
\hline Qup & upward heat loss rate \\
\hline QuP & heat flux from pool to blockage \\
\hline $\mathrm{Ra}, \mathrm{Ra}$ * & Rayleigh number \\
\hline $\operatorname{Re}$ & Reynol ds number \\
\hline$t$ & time \\
\hline$t_{1 \text { ife }}$ & crust lifetime \\
\hline$T_{f}$ & fuel temperature \\
\hline TPOOL & pool temperture \\
\hline$T_{m}, v_{2}$ & melting point of $\mathrm{UO}_{2}$ \\
\hline $\mathrm{T}_{\mathrm{m}, \mathrm{s}}$ & melting point of steel \\
\hline $\mathrm{T}_{\mathrm{S}}$ & steel temperature \\
\hline$T_{w, m}$ & wall melting temperature \\
\hline$T_{W}$ & wall temperature \\
\hline$U_{g}$ & gas velocity \\
\hline$U_{\infty}$ & bubble rise velocity in infinite medium \\
\hline$v_{g}$ & vapor velocity \\
\hline V & blockage volume \\
\hline$V_{B}$ & equivalent free stream velocity \\
\hline$v_{f}$ & volume fuel in blockage \\
\hline$V_{S}$ & volume steel in blockage \\
\hline$v_{T c}$ & thermal convection reference velocity \\
\hline$x$ & distance along heat transfer boundary \\
\hline
\end{tabular}


NOMENCLATURE (Cont'd)

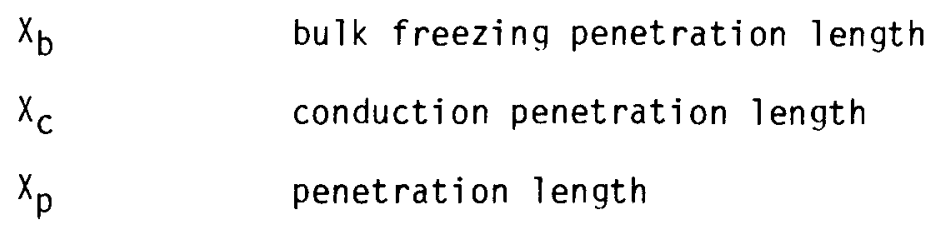

Greek Symbols

$\begin{array}{ll}\alpha & \text { local void fraction } \\ \bar{\alpha} & \text { pool-average void fraction } \\ \alpha_{f} & \text { fuel thermal diffusivity } \\ \gamma & \text { volume fraction of steel in pool } \\ \Gamma_{v} & \text { rate of steel vaporization } \\ \zeta & \text { crust thickness } \\ \theta & \text { boundary wall angle of inclination } \\ \mu_{f} & \text { fuel viscosity } \\ \nu & \text { kinematic viscosity } \\ \nu_{f} & \text { liquid kinematic viscosity } \\ \rho_{f} & \text { fuel density } \\ \rho_{q} & \text { vapor density } \\ \rho_{W} & \text { liquid density at wall temperature } \\ \rho_{v} & \text { vapor density } \\ \sigma & \text { surface tension }\end{array}$




\section{INTRODUCTION}

Mechanistic analyses of the loss-of-flow (LOF) accident without scram in loop-type LMFBRs led to the conclusion that core-wide fuel disruption could not be avoided (Stevenson, 1974). Much of the attendant analyses of the consequences of the LOF accident initiator focused on predicting the energy releases from neutronic excursions occurring during the "initiation phase" of the accident. As a result primarily of analyses related to FFTF, however, it was recognized that the initiation phase need not terminate energetically (Stevenson, 1974; Jackson, 1974b). Instead, an alternate accident progression path was postulated in which fuel disruption and melting would occur "gradually" on a subassembly scale. This would lead to a growing molten core configuration as subassembly duct walls melt and individual "pools" coalesce. This stage of the accident was labelled the "transition phase" (Ostensen, 1974b) of the loss-of-flow accident without scram.

A major factor in the analyses which led to the postulate of a transition phase is the low (negative) sodium void coefficient characteristic of the FFTF. The postulate of a transition phase in the CRBR is more tenuous than for the FFTF due to the large positive sodium void coefficient of the CRBR core (Theofanous, 1978). Nevertheless, a transition phase for the CRBR has also been postulated (Boht, 1975).

Early (FFTF-related) assessments (Ostensen, 1974a, 1974b) of the transition phase relied on mechanistic models of perceived key safety phenomenology supported, to a limited extent, by experimental evidence. Integrated accident analysis methods were not available at the time. The independent phenomenological models, however, were pieced together to provide plausibility arguments pertaining to the sequence of transition phase events leading to accident termination. Subsequent analyses, related to the CRBR, relied heavily on fundamental "behavior principles" (Fauske, 1977b) which were to be verified experimentally. Basic heat transfer and multiphase flow principles were applied to transition phase safety issues, generally with little detailed mechanistic analysis and, again, supported by only limited experimental evidence.

More recently, important developments have occurred in the areas of: (i) phenomenological modeling and supporting experiments and (ii) integrated, mechanistic accident analysis modeling. Experimental evidence has been developed pertinent to major transition phase phenomena. This evidence has improved our understanding of the phenomena and has led to improved mathematical models of them. Integrated, mechanistic computer codes have been developed to enable one to track the transition phase accident progression to termination (Smith, 1978; Muraoka, 1975; Hakim, 1979). These developments led to initiation of this report, which provides an updated assessment of the state of the art of transition phase technology.

This assessment report focuses on the thermal hydraulic phenomena which strongly influence potential transition phase accident sequences. The adequacy of the present understanding of the relevant phenomena is addressed, and the impact of these phenomena on the transition phase is assessed. 
The development of calculational tools such as the SIMMER code (Smith, 1978) to integrate the material motion phenomena with the tightly coupled neutronic characteristics of the LMFBR is essential for tracking potential transition phase accident sequences. It is, however, beyond the scope of this report to review and assess the adequacy of such integral computational methods. This report is relevant to these methods, however, insofar as the phenomena addressed here are also characterized in the computer codes by mathematical models.

The objectives of this report are:

(i) to review previous analyses of the transition phase accident sequence,

(ii) to assess the current understanding of transition phase phenomenology,

(iii) to provide an updated scoping analysis of the transition phase in the light of recent developments in phenomenology,

(iv) to assess the research needs related to major transition phase issues and to assign priorities to these needs.

The work reported here was carried out in conjunction with the homogeneous core design of CRBR. It is felt, however, that much of the analysis and conclusions also apply to transition phase issues of the heterogeneous core CRBR.

Chapter 2 reviews the results of previous initiation phase analyses, in particular with respect to definition of initial conditions for the transition phase. Chapter 3 is a summary of previous transition phase analyses, focusing particularly on those studies which attempted to trace the accident through to termination. An assessment of currently available analytical methods and experimental data relevant to major thermal hydraulic phenomena relevant to the transition phase is presented in Chapter 4. An updated scoping analysis of possible transition phase accident progressions is described in Chapter 5. Finally, Chapter 6 is an assessment of research needs projected from the reviews and analyses of the prior chapters of this report. 


\section{THE INITIATION PHASE}

\subsection{Introduction}

The initiation phase of LMFBR core-disruptive accidents has been widely studied in the last decade. The studies have, in general, focussed on conditions representative of small reactors (FFTF) and intermediate reactors (CRBR). It is intended here to review the results of this phase of the accident which have a direct bearing on the transition phase of the accident.

Historically, two types of transients have been addressed: the coolant disturbance transients and the overpower transients. In both cases, control rod insertion is assumed to fail to occur. More recently, the loss of heat sink accident has also been mentioned (Bari, 1977) as a potential core-disruptive accident. The loss-of-flow accident due to pump power failure has been regarded as generally enveloping the consequences of other postulated HCDAs and received the most attention. The initiation phase of this accident involves coolant flow rate decay, heat up and voiding of the hottest channels up to clad dryout, clad melting and relocation, and early fuel melting. Beyond this point, it has become practice to identify this sequence of events with the "transition phase". The transition phase involves the stage of the accident between the time when substantial deviation of reactor core geometry begins to the time a large amount of the fuel is finally removed from the core (or equivalently, the core becomes subcritical permanently). The behavior of the dispersed material outside the core is described in the termination and post accident heat removal stages of the accident.

\subsection{Mechanistic Assessment}

In gerieral, the mechanistic analyses of the progression of the initiation phase of the accident have relied on the SAS3A code (Dunn, et al., 1975). Besides the transition phase, the analyses have identified two other possibilities for the accident progression: early termination and mechanical disassembly (see Fig. 2.1). Early termination is possible if enough negative reactivity is introduced at an early stage when very little damage has been done to the core. Current designs do not permit this to occur under unprotected loss-of-flow conditions. Under transient overpower conditions, small amounts of fuel may be removed initially to shut down the reactor. There is a concerted effort to define core design conditions under which enough negative reactivity will be initially injected to shut down the reactor while the core is essentially intact.

On the other hand, if initially a large amount of positive reactivity is inserted by sodium voiding and clad relocation, the accident may progress directly to hydrodynamic disassembly. Such a possibility can be ruled out for a small core size, where the net sodium worth (due to both spectral shift and leakage effects) is negative (- $\$ 3.5$ for FFTF). However, for a larger core, the net sodium voiding worth is positive $[+\$ 3.5$ for the homogeneous CRBR design (Bohl, 1975)]. Hence, reactivity addition associated with spectral hardening and decreased neutron absorption due to initial clad relocation may bring about a prompt criticality condition. Thus, the clad and fuel 


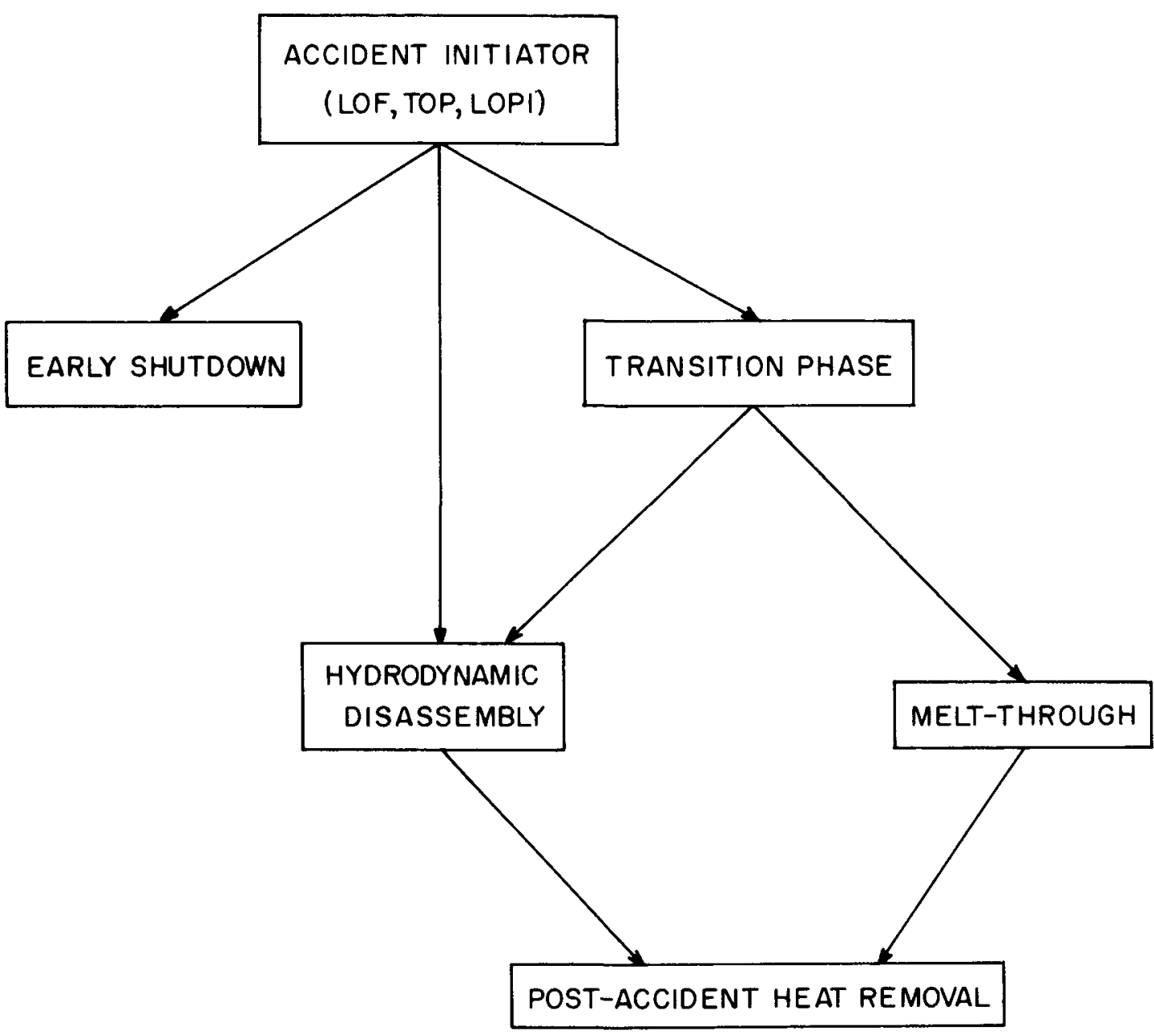

Figure 2.1 - Accident Sequence Diagram 
relocation is a more sensitive area of concern for large cores than it is for small cores with regard to accident progression.

The analysis of FFTF LOF accident sequence by ANL (FFTF FSAR) indicates that boiling inception occurs about 14 seconds into the accident. Cladding dryout, as calculated by SAS3A, follows by about one second, and cladding melting and initiation of relocation in another 2 to 3 seconds. Fuel melting occurs in 3 to 4 seconds following clad melting. At the time of fuel melting and initiation of fuel motion, the power has risen to twice the nominal power. The fuel slumping begins which results in near prompt critical conditions at about 10 to 50 times the nominal power level. The negative reactivity due to Doppler effects, axial expansion and fuel dispersal leads to shutting off the initial burst with about 20-25 fuel assemblies in the fuel motion stage. The accident is then predicted to "gradually" proceed to full core involvement with one or two additional neutronic bursts. The core pressure is predicted to stay at about 5 atmospheres with a peak fuel temperature of $4000^{\circ} \mathrm{C}$. The descriptions of fuel assembly duct melting and fuel plateout at the core extremities are part of the transition phase assessment.

In NRC's analysis for the CRBR (Meyer, et al., 1977) with a homogeneous core, flow decay lasts 10 seconds before initial boiling. Cladding dryout follows by one full-power second (see Fig. 2.2). Initiation of clad melting follows by about 0.5 seconds. When fuel motion occurs within about 0.15 seconds of clad melting, the power level in the lead subassemblies is 10-30 times nominal power and the power level in the remaining assemblies is up to 130 times nominal power. This range of power at the onset of net fuel motion is due to core-wide incoherency effects. About 50 percent of the assemblies have not yet voided when the high power causes the fuel pins to fail. The reactivity resulting from fuel dispersal into the coolant and motion within the clad or outside the clad is uncertain. This has been assessed to lead to an increase in the reactor power to over 100 times the nominal power (see Fig. 2.3). The reactivity ramp rates have been estimated by NRC to be significant in that they will lead to significant energetics (hydrodynamic disas semibly).

In the analyses performed at ANL for the homogeneous core CRBR conditions (Bohl, et al., 1977) all the fuel pins are disrupted at the termination of the SAS3A calculations. A variety of cases were analyzed to account for uncertainties in key phenomena. However, in all cases but one, the reactor shuts down without production of high fuel temperatures. Thus it was assumed that hydrodynamic disassembly was unlikely for the CRBR. The main differences between the NRC assumption and the ANL assumptions are:

(i) Different SAS3A channel arrangements for the core.

(ii) The use of a clad relocation rate of $80 \mathrm{~cm} / \mathrm{sec}$ in the NRC base case whereas the clad relocation in the ANL best estimate core was suppressed until fuel motion occurs.

(iii) Allowance for fuel axial expansion in the ANL base case but not in the NRC base case. 


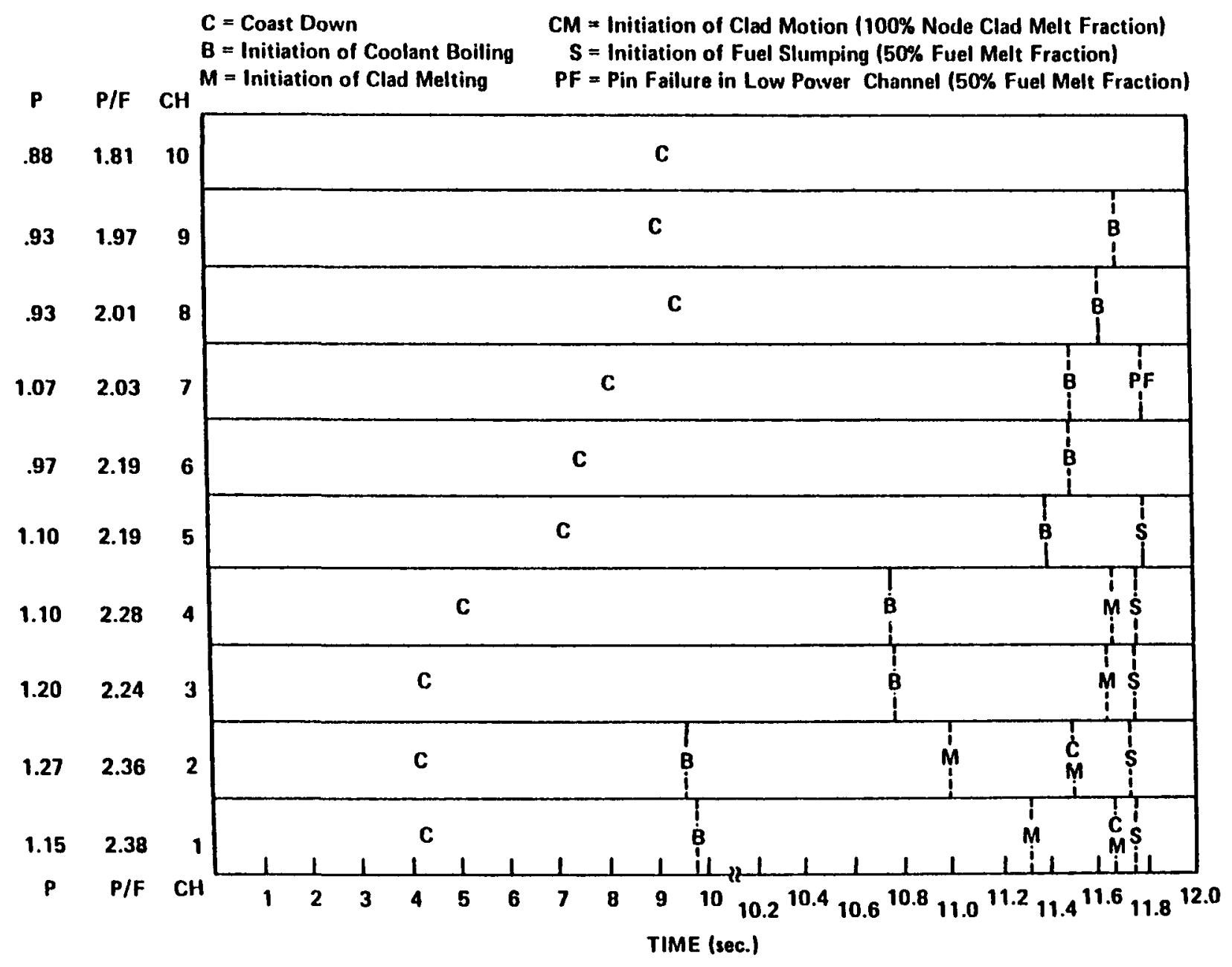

Figure 2.2 - Chronology and Sequence of Events in a CRBR LOF (Meyer, et a 7,1977 ) 


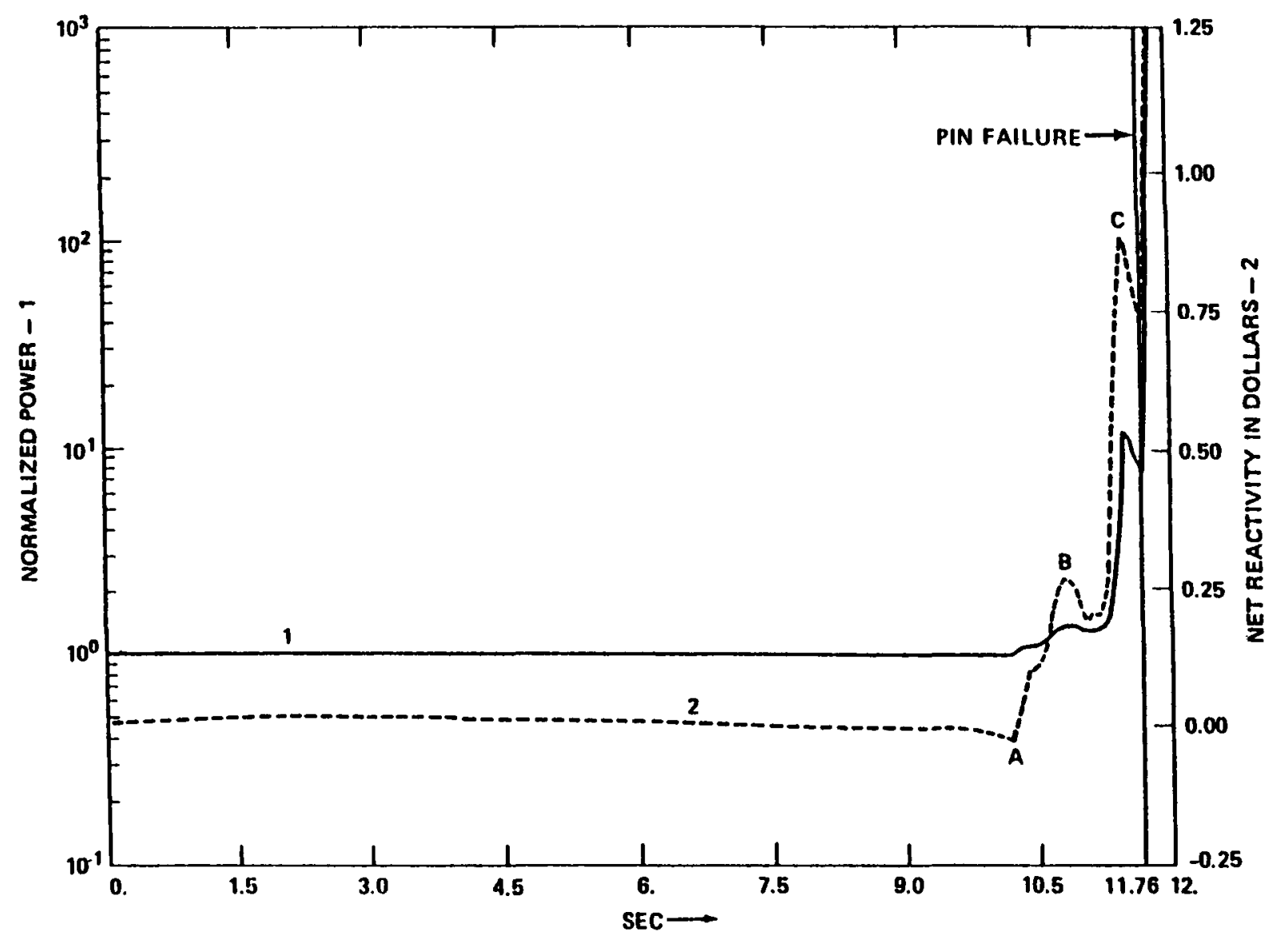

Figure 2.3 - Power and Reactivity vs. Time (Meyer, et a1, 1977) 
(iv) Variations in the amounts of fission gases that are assumed immediately available to disperse the fuel with less gas assumed available in NRC cases. This leads the ANL analyses to become closer to NRC analysis for the Beginning of Equilibrium Cycle case, with little fission gas available in the fresh fuel.

\subsection{Phenomenological Uncertainties}

Of the various phenomena involved in the above analyses of FFTF and CRBR LOF accident, three items require some elaboration.

\subsubsection{Sodium Voiding Incoherency}

Limited work has been done in this area. HEV -20 is the only code which has been used so far for assessment of the incoherency effect (Theofanous, 1978). For CRBR conditions, the comparison between one dimensional and two dimensional voiding histories indicates that there may be an increase in the time between boiling initiation and flow reversal by a factor of 2 . This prolonged time for sodium voiding will be associated with increased sodium boiling potential in the low power fuel pins. At the time of fuel pin failure, less sodium will be available in the core. This result may be significant in assessment of the rate at which reactivity is being added to the core at fuel failure time, as well as the eventual energetics of the accident. Work at MIT (THERMIT) (Kazimi, 1979) and ANL (COMMIX) (Sha, et a1., 1978) is in progress on codes utilizing the two-fluid approach which will relax the $H E V-2 D$ assumption of a homogeneous two-phase flow regime. That should further decrease the voiding rate in the assemblies up to the flow reversal condition (one-dimensional behavior follows).

\subsubsection{Clad Relocation}

For cores with high voiding reactivities, clad relocation plays an important role in determining the potential for prompt critical conditions before voiding the entire core. The current understanding (based on 37 pin bundle experiments) (Kraft, et al., 1979) is that some clad will be flooded via sodium vapor streaming and perhaps fission gas streaming. The time elapsed between clad melting and fuel melting may be too small in high-power reactor conditions to allow for coherent clad behavior. Due to the interchannel vapor and gas flow instability, the clad is expected to remain largely in the core. This conclusion further decreases the potential for mechanical dissassembly and enhances the potential for a transition phase following the initiation phase. The plugging formed by clad relocation would also be expected to be incomplete which should allow fission gas passage from the core.

On the other hand, if long times are available between fuel melting and steel melting (times $>1$ second), substantial clad blockages may be formed above and below the core. The above core blockages may not be complete but will be extensive. The bottom blockages may be thick (6-7 cmi) and coniplete. 


\subsubsection{Fuel Motion Mode}

An assessment of fuel motion under LOF accident conditions has been given by Deitrich and Ostensen (1977). They list five modes of fuel motion:

(i) buckling of pellet stack,

(ii) large scale swelling of solid fuel,

(iii) melting and draining of molten fuel inside a solid shell,

(iv) melting and frothing of molten fuel with breakup of the outer shell,

(v) breakup of solid fuel into small particles (dust cloud breakup).

It should be noted that the above fuel motion modes are not mutually exclusive. The factors determining the behavior are:

(i) radial pressure gradients across the fuel possibly due to fission gases in the central void and the pores, fission gases retained in the grains, and fission product vapors.

(ii) the pressure sources not dissipating in fuel motion prior to melting (particularly swelling).

(iii) sufficient gases and vapors available to ensure dispersal and prevent fuel collapse.

It appears that (results of TREAT test $\mathrm{Fl}$ ) when the power remains near the nominal level, fuel swelling can occur. Some frothing may also occur and the gas bubbles may escape from the fuel allowing for some slow downward motion of the molten fuel within the center. Gross slumping was not observed in the LOF simulation tests. At high power levels (ten times nominal power level), fuel will swell, froth and initially disperse in a chunk breakup mode (result of L5). For high rates of fuel heating at high burnup, breakup cannot be excluded. The dust cloud breakup mechanism appears less probable than the mechanisms in ( $i i i$ ) and (iv) above.

Due to the effect of dispersal on reactivity, this area of LOF fuel behavior needs further attention. The early dispersal due to fission gas will reduce the power levels during the accident below what will be achieved if dispersal had to await generation of fuel vapor.

\subsection{Summary}

The initiation phase for small core LMFBRs can be reasonably analyzed with the current methods and experimental knowledge. However, for large cores further work is needed in order to improve modeling of the following phenomena:

(i) intra-assembly sodium voiding incoherencies, 
(ii) clad relocation potential under high power generation rates in the fuel pins,

(iii) modes of initial fuel dispersal. 


\section{PREVIOUS TRANSITION PHASE ANALYSES}

\subsection{Introduction}

Mechanistic analysis of the initiation phase of the LOF accident in the FFTF led to the conclusion that the accident sequence would more likely develop toward the direction of a gradual core meltdown rather than of an energetic disassembly (Jackson, 1974b). The ensuing period of core disruption was termed the "transition phase" of the accident sequence. The recognition that the accident could develop in this direction marked a significant departure in accident analysis and led to the "transition phase" accident progression path shown in Fig. 2.1.

It was recognized that analysis of the transition phase required development of methods to deal with a growing molten disrupted core in which a portion of the core would be geometrically intact and the remainder would be molten. Methods of the initiation phase analysis, such as the SAS computer code, could not be applied to developing molten regions. Hydrodynamic methods such as used in disassembly calculations could not be applied to the yet geometrically intact regions of the core. The lack of an integrated method of analysis applicable to this phase of the accident led to the development of a number of models of physical phenomena perceived as fundamental to the accident progression. These models were then employed to piece together a picture of the perceived transition phase accident sequence. This method of analysis has been used exclusively for both FFTF safety analysis and for CRBR licensing-related studies. Only recently have more integrated methods of analysis been developed (Smith, 1978; Muraoka, 1975).

\subsection{FFTF-Related Analyses}

\subsubsection{Initiation Phase Results}

At the termination of initiation phase calculations performed with SAS3A, sodium boiling is predicted in all subassemblies, most of the core is partially voided, clad melting has been initiated in a portion of the subassemblies, and steel blockages are predicted in the hottest subassemblies (Jackson, 1974a). Fuel disruption and motion is predicted in 21 subassemblies. Fuel slumping following pin disruption leads to mild excursions which are not sufficiently energetic to disperse the fuel beyond the axial extremities of the core. These excursions do, however, drive the disrupted fuel, via fuel vapor pressure, against the steel blockages that were predicted to have been developed earlier in the accident sequence. The upward-dispersed fuel is in an unstable configuration, and must fall back to the core region. Subsequent recriticality analysis indicated no disassembly due to fall-back into the core. The subassembly duct walls are heating up and will shortly melt through. At this point, SAS calculations were terminated. The "transition phase" was defined to begin at this point.

The above sequence of events is tied to the existence of integral steel blockages which retard dispersion of the fuel beyond the core region. Significantly different conclusions could be potentially reached if the plugs 
did not exist and if the fuel could be dispersed well beyond the core into the sodium plena. It was, therefore, alternately assumed that the steel blockages did not exist and that the molten fuel was free to be driven into the upper subassembly pin structure. The penetration of the fuel into the structure was evaluated using a "bulk freezing" model (discussed in more detail in Section 4). The model and supporting thermite injection experiments (0stensen, 1974b) supported the conclusion that the fuel would rapidly freeze in the channels and channel plugging would take place without significant dispersion of fuel from the core. Since the time of this early work, much conflicting evidence with respect to fuel freezing has been generated, and theories supporting short and long penetration have been proposed. The issue, still not settled, is discussed in Section 4. Nevertheless, the "transition phase" accident sequence evaluation was continued by Jackson (1974a) assuming that the initial fuel disruption was accompanied by plugging of the flow passages, whether by fuel or by steel.

\subsubsection{Objectives and Methods of Analysis}

The objectives of the analysis of Jackson (1974a) were to continue the analysis of the LOF accident beyond the initiation phase, to scope out possible accident progression paths as the disrupted molten region propagated through the reactor core, and to follow the motion of the fuel until dispersion to a subcritical configuration. A most important concern was to identify potential modes of recriticality. Scoping calculations were performed to assess the energetics at those points where recriticality was indicated.

An integrated method of transition phase analysis (one which would couple the initiation phase to the transition phase, and which would couple the disrupted and intact core regions) was unavailable. The approach adopted was to divide the core into a central 12-subassembly disrupted molten region, and the remainder of the core. Separate analyses were performed for each of the two regions. The results were then used to provide plausibility arguments for the behavior of the entire system to accident termination (permanent subcriticality).

\subsubsection{Disrupted Core Analysis}

Initiation phase analysis indicated that the initially disrupted fuel would form a blockage at the axial extremities of the disrupted zone. The subassembly walls would still be intact. The reactivity insertion rate due to reentry of the fuel was estimated assuming coherent slug reentry of the fuel under gravity. The resulting reactivity insertion was judged to be insufficient to force a disassembly.

During the excursion(s) described above, fuel would transfer energy to the steel component. As the steel approaches the fuel melting temperature, it was argued, the steel would begin to boil. Steel vaporization would cause the fuel-steel mixture to boil up. The events occurring between pin disruption and fuel-steel boiling were not mechanistically modeled. This "transition to the transition phase" (Theofanous, 1978) domain remains one of the 
largest uncertainties in the accident sequence. It was assumed that if the fuel-steel mixture would be vigorously boiling, and if the mixture would fill the entire core region, then the probability for recriticality would be diminished. Thus, steel vapor boilup would terminate the excursion due to fuel collapse in the central subassemblies. The remaining part of the core would subsequently undergo similar disruption and boilup sequences. A boiling pool model was developed to analyze the behavior of the disrupted core region.

The model assumes that a spatially uniform homogeneous mixture of fuel and steel is confined in a closed volume (subassembly scale or larger). A global energy balance on the system was written which, taken together with an equation of state for the volatile steel component, was used to compute the system pressure, temperature and average static vapor quality. Molten steel flow into the pool from duct walls was computed assuming that the steel enters the pool at its melting point. Heat transfer to the boundaries was through a fuel crust. The heat sink temperature was the melting point of the fuel.

The boiling pool model was used to assess whether the pool remains in a "vigorously boiling" state. This was judged by comparing the pool pressure with a system pressure which was defined as the sum of the cover gas pressure and the sodium and fuel-steel hydrostatic heads. The pool was assumed boiled up if the pool pressure was greater than the system pressure. The model was also used to compute duct wall melt-through times, and upper and lower meltthrough times.

A molten fluid blowdown model was developed, in conjunction with the boiling pool model. This model was developed to compute the time for fluid ejection once leakage paths out of the core developed. This calculation was also used to determine the inventory of fuel remaining after blowdown was complete. The blowdown calculation assumes homogeneous two-phase flow, limited by choked flow conditions at the outlet of the flow path.

\subsubsection{Intact Core Disruption Analysis}

The SAS code was used to estimate the time scale for disruption to spread across the entire core. Since the power level and reactivity are not known at this point in the accident, SAS was run assuming constant, full power conditions. It was estimated that within 5 seconds the entire core would be disrupted and would contain no remaining fuel pin structure. During this period of time, recriticality due to fuel breakup and slumping are possible.

\section{2 .3 Results}

The results indicate that at full power conditions the entire core could be disrupted and molten within 5 seconds, that hexagonal duct wall meltthrough would take about 2-3 seconds, and that melt-through of the upper steel blockages could take 5-15 seconds. Melt-out of the thicker lower steel blockages is predicted to take 30-60 seconds. Thus, open passages appear more likely to develop in the upward direction rather than downward. Following 
steel blockage melt-out, the authors predict that the fuel-steel mixture would be ejected upwards and would refreeze, thereby preventing continuing blowdown. The authors conclude that the entire core would be in a core-wide molten configuration before blowdown to the upper sodium plenum could occur.

The boiling pool model results were interpreted to imply that (i) at full power the pool would continue to boil vigorously at all times, including during the time for duct wall melt-in; ( $i$ i) at 5-10 percent power, steel melt-in makes a strong impact on the pool energy balance, and can potentially collapse the pool; ( $i j i$ ) after duct wall melt-in (upon formation of a subassembly pool) the molten region would remain boiled up, (iv) pool pressurization rate is a strong function of system energy losses.

The conclusion that the disrupted assemblies continue to boil was used to support the contention that during the continuing disruption of the core, only mild recriticalities are to be expected. The boiling process keeps the system from compacting and attaining larger reactivity levels.

A number of possible termination paths were projected by the authors. The most likely path was felt to be via blowdown of a core-wide pool through passages created by melt-out of the upper subassembly structure. The fuel ejection model predicts that upon establishment of flow paths, blowdown would be completed within less than 10 seconds. The final in-core molten fuel mass inventories were judged to be below critical masses.

Several potential modes of recriticality were analyzed. These included:

(i) fuel slumping upon initial pin disruption,

(ii) fuel reentry from initially dispersed (axially) fuel,

(iii) disrupted fuel collapse, e.g., boiling pool collapse,

(iv) large-scale reentry due to either gravity fall-in of initially ejected fuel or pressure driven reentry.

The first two modes of recriticality were judged to lead, due to incoherencies, to mild ramp rates which would not result in disassembly. The fourth mode was shown to possibly lead to disassembly, depending on the extent of initial upward fuel relocation, and the degree of coherence of reentry under gravity. The authors believe that incoherencies would prevent reaching ramp rates at the upper limit of their scoping calculations. The third mode of recriticality assumes loss of vapor production, and hence eventual collapse as the vapor within the fuel separates out due to bouyancy. This collapse mode leads to relatively mild ramp rates.

\subsubsection{Potential Impact of Thermal Hydraulic Uncertainties}

The FFTF transition phase analysis led to the conclusion that while energetic hydrodynamic disassembly could not be ruled out, a more probable accident termination path would proceed via boilout of fuel-steel boiling 
mixtures from a whole-core molten pool configuration through the upper pin structure. The main arguments which led to this conclusion are:

(i) Fuel disruption and resultant fuel slumping are incoherent. In addition, reentry of initially disrupted fuel is also incoherent. These incoherencies prevent disassembly during the disruption stage of the accident.

(ii) Stainless steel plugs bottle-up the core. If these steel plugs do not develop, then initially disrupted fuel would plug the flow channels. The plugs prevent immediate blowdown of the subassemblies as disruption occurs, resulting in bottled fuel configurations.

(iii) The boiling fuel-steel pools remain fully dispersed. This helps keep neutronic events mild as the entire core undergoes disruption.

(iv) Boiling pool collapse is limited by the characteristic vapor transport velocity.

Major uncertainties in the course of events are (i) the behavior of the CLIRA assemblies and ( $i j)$ the potential for large energetics due to either coherent gravity driven fuel compaction or pressure driven fuel compaction mechanisms.

The above sequence of events is closely tied to the physics of molten fluid freezing and multiphase hydrodynamics. Uncertainties exist with respect to the physics of molten fuel and steel relocation and also with respect to multi-phase, multi-component boiling pool dynamics. The technology with respect to these areas is reviewed in Section 4 of this report.

If upper steel plugs do not develop, or if they are incomplete, then a multi-phase mixture of fuel and steel would penetrate the pin structure. The extent of penetration is uncertain. Models to accurately predict the extent of penetration of molten fuel into pin structure geometries have not been developed or confirmed (see Section 4). Evidence, however, suggests that the available fuel will form blockages in the pin structure region. The extent of penetration of the fuel, however, is still uncertain.

The boiling pool model used in the FFTF analysis provides an indication of the sensitivity of the system to the magnitude of available heat sinks. A more detailed model, however, is needed to assess the extent of boilup or dispersal. The extent of dispersal is directly dependent upon the rate of vapor generation and upon the vapor-liquid slip characteristics. A model is required which couples the vapor generation rate to the liquid-vapor void dynamics. It is expected that if the pool system is likely to pressurize, then much of the heat generated would be consumed in sensible heating, and would not be available for vaporization. Thus, the extent of fuel boilup may not be as extensive as assumed in the analysis. The impact of the extent of fuel dispersal on the accident sequence is difficult to predict. It is clear, however, that if the disrupted channels are not fully boiled up, then the reactivity could be greater than implicitly assumed. Subsequent recriticalities due to slumping in the channels undergoing disruption could be more energetic. 
A mode of boiling pool collapse was analyzed which postulated an instantaneous loss of vapor source. The rate of compaction was assumed to depend on the rate of rise of pre-existing vapor. This leads to a computed relatively mild recriticality $(\$ 23 / \mathrm{s})$ which would not disassemble the core. The dynamics of a boiling pool of fuel and steel with simultaneous steel melt-in have not been analyzed in detail. The results of the boiling pool analysis presented by Jackson (1974a), however, indicate that molten steel is a potentially strong pool heat sink. Analysis and supporting experiments related to multi-component boiling pools with simultaneous addition of subcooled molten fluid of one component are required in order to determine the rate of collapse under these conditions.

\subsection{CRBR-Related Analyses \\ 3.3.1 Initiation Phase Results}

The ANL analysis (Bohl, 1975) which leads to the postulated transition phase behavior indicates that the coherent core and high power at disruption result in predicted fuel pin failure and fuel motion in all subassemblies in a fraction of a second following the first failure. The average core temperature is near the fuel melting point. During this time period, and until duct melt-through or rupture occur, the fuel would be confined within distinct subassembly walls, and initial dispersal of fuel to the axial blankets would occur. The mode(s) of pin failure during this period of time would determine the strength of any recriticalities due to fuel motion which would occur. The ANL analysis does not address this period of the accident, which has been called the "transition to the transition phase". Instead, the analysis jumps over this period, and assumes that rapid steel vaporization and fuel dispersal occur, thereby preventing any potential for molten fuel collapse at this stage of the accident.

The ANL initiation phase analysis led to the conclusion that steel blockages at the axial extremities of disrupted subassemblies are unlikely to occur or would be incomplete. Thus, at the onset of the transition phase, the core was assumed completely disrupted, with steel boiling imminent in the hottest channels. The subassembly blanket structure flow paths are assumed unobstructed by frozen steel blockages, and the average core temperature is near the fuel melting point.

\subsubsection{Objectives and Methods of Analysis}

The objectives of the analysis made by Bohl (1975) were to follow the course of the LOF disruptive core analys is beyond the pin disruption stage, to identify the most probable path to accident termination, to identify possible modes of recriticality, and to bound the ramp rates associated with them.

An integrated transition phase analysis tool was not available for use in the computations. Instead, several physical phenomena, perceived to be the key issues in transition phase accident behavior, were identified. Models describing these phenomena were then discussed and applied to transition 
phase accident conditions. Arguments were pieced together in order to characterize the transition phase sequence to accident termination.

\subsubsection{Methods of Analysis}

The ANL "best estimates" analysis of the molten core behavior of the CRBR was initially based upon two fundamental notions:

(i) Upon fuel disruption, rapid steel vaporization would occur, thereby "fluidizing" and maintaining a vigorously boiling, dispersed fuel-steel mixture.

(ii) Freezing of molten fuel and subsequent plugging of the axial blanket flow channels is unlikely.

These two physical arguments were cited to justify the contention that fuel dispersal is "monotonic" and nonenergetic, and that accident termination would occur rapidly following disruption via blowdown to the sodium plena.

The assumed rapidity of steel vaporization was based upon the wetting characteristics of steel on wet oxide fuel, and on equilibrium thermodynamics for computation of steel vaporization. The projected dispersal of fuel by steel vapor was based upon flow regime transition criteria. The volumetric rate of steel vapor production was not, however, computed. The dispersion mechanism is discussed in Section 4.

The "Conduction Model" for fuel freezing (discussed in detail in Section 4) which assumes that heat transfer rates and, hence, freezing rates, are 1 imited by heat transfer through a stable crust, was used to justify the notion that fuel would flow through the axial blankets without plugging the channels.

The possibility of fuel plugging was recognized (although considered unlikely). An alternate accident progression path was also considered, therefore, which postulated complete core plugging. The consequences of a corewide bottled pool were examined.

The power and reactivity levels of the core-wide pool system were not specified. It was argued, however, that the system would be stable against either pressurization at high power or collapse at low power. This argument was based upon (i) flow regime transition criteria which were used to justify the notion that the bottled pool would be in a dispersed flow regime at power levels to decay heating, ( $i i)$ the heat loss mechanism from such a pool would be similar to "nucleate boiling on a heated surface," (iii) a fuel crust would be present at low power levels, providing a surface temperature for heat losses equal to the fuel melting point rather than the steel melting point. Pool pressurization would not be significant at high power, since a fuel crust would not be present, and the heat losses would bal ance the heat generation rate. Void collapse at low power would be precluded since the crust would insulate the pool and hence reduce the heat transfer rates.

In the above analyses of molten pool behavior, mechanistic evaluations, 
which coupled the flow dynamics to the thermodynamics and heat transfer characteristics of the system, were not employed.

Two other modes of fuel collapse were discussed: (i) quenching by cold material fall-in and ( $i j)$ pressure-driven collapse. The former mechanism, it was argued, would not lead to large heat transfer rates due to the development of fuel crusts on the object. The latter was judged to be improbable, based upon the "Upper Plenum Injection" experiments (Henry, 1976b).

Termination of the bottled pool accident sequence, it was argued, would occur in blowdown through openings in the pin structure. A homogeneous, twophase, choke flow limited model was used to compute the rate of fuel relocation under blowdown conditions.

\subsubsection{Results}

The two alternate accident progression paths were judged to lead to the same accident termination conclusion: nonenergetic blowdown through meltedout passageways. The ejection of fuel into the axial blankets, together with the postulated fuel dispersion by boiling steel, was argued to prevent energetic recriticalities. The authors recognized the possibility of delayed steel vapor production following pin disruption, but concluded that the subsequent recriticalities would be mild and insufficiently energetic to disassemble the core.

The "best estimate" analyses led to the judgement that blowdown would occur immediately upon disruption. The alternate plugged-structure analysis led to the estimate that a whole-core pool would develop within 5 seconds following disruption, that the system would be subcritical due to fuel dispersion and fuel relocation to the pin structure region, and that blowdown from a whole-core pool would be complete within 10 seconds following development of an open passageway of subassembly duct size.

\subsubsection{Potential Impact of Thermal Hydraulic Uncertainties}

The analysis of the CRBR, summarized above, relied upon several basic thermal hydraulic arquments which were applied to the conditions peculiar to the transition phase accident sequence. Large uncertainties exist with respect to these principles and, moreover, recent evidence indicates that some of the basic arguments were inaccurate.

The pin disruption stage of the transition phase accident sequence is highly uncertain due to a lack of knowledge of the modes of fuel pin breakup. The process may be initially dispersive or compactive (Deitrich, 1977). In addition, the role of steel vaporization in dispersal of fuel during this period of time is also uncertain. During this "transition to transition phase" of the accident sequence, the duct walls are likely to be intact, and some fuel is likely to be relocated to the axial blankets if steel blockages do not retard the flow. Information is needed on the modes and time scales of pin disruption, and on the rate of development of the dispersive steel vaporization source during this portion of the accident. 
The existing data suggest that molten fuel ejected into the axial blankets could freeze and plug the flow channels before penetration of sufficient fuel to neutronically terminate the accident sequence. The dominant mechanisms of flow and freezing of two-phase molten mixtures of fuel and steel within pin structure are not clear, and the extent of penetration under transition phase accident conditions is uncertain. Thus, the "best estimate" analysis of the transition phase for CRBR appears to have been overly optimistic in the conclusion that the disrupted molten core would immmediately blow down upon disruption, with no plugging of the flow channels.

While it now appears that plugging of flow channels would occur as a result of fuel flow into the pin structure, the timing of plugging and the mass of fuel displaced both into the pin structure and through to the plena, is uncertain. The mass of fuel displaced could be a significant factor during the accident stage where multiple distinct pools are distributed across the core and are in the process of merging due to duct wall melt-through. It has been shown that if fuel and steel in their original core proportions were displaced from the core to fill the upper axial blanket channel structure, with remaining fuel and steel homogenized through the core, the system would be subcritical by approximately - $\$ 40$. This could have a strong impact on the potential for fuel compaction recriticalities that might occur during the multiple pool duct melt-in phase of the accident. A mechanistic model for the fuel relocation problem is required, together with supporting experimental evidence.

The fuel freezing data, as discussed above, support the conclusion that molten fuel and steel mixtures would likely be contained in bottled pools a short time after pin disruption. Multiple pools, separated by hexagonal duct walls, would initially be formed. These pools would begin to merge by meltthrough. As shown by Jackson (1974a) the steel entering the pool may act as an efficient heat sink. Pool collapse, and hence, recriticality at this point is possible, depending upon the power level and magnitude of heat losses. The potential for pool collapse during this accident stage was not considered in the CRBR analysis.

An integrated treatment of the characteristics of whole-core pools in dual enrichment zone reactors must account for the possible large reactivity insertions and concomitant high power levels during this period. Fuel zone homogenization in CRBR could lead to a reactivity insertion of $\$ 14$; control material separation can lead to another $\$ 10$. Superimposed on the preexisting sodium voiding worth of approximately $\$ 2.5$, these possible additional insertion mechanisms must be weighed against the reactivity losses due to fuel motion away from the core. The potential for significant reactivity removal by fuel relocation is substantial. Fuel plugging of the subassembly pin structure, however, is likely during the initial dispersal stage. The power and reactivity levels of whole-core pools, cherefore, are highly uncertain. This uncertainty must be considered in the evaluation of potential ramp rates from postulated whole core collapse conditions.

The CRBR analysis assumed that if a fuel blockage were to develop and prevent permanent fuel dispersal to the sodium plena, the fuel relocated to form the plugs would remove sufficient reactivity to make up for the reactivity addition due to fuel homogenization. Thus, reactivity levels would re- 
main low during the whole-core pool period. It was concluded that recriticality would be unlikely due to the large reactivity loss via fuel ejection into the blankets. The arguments used in the analysis are qualitative, and do not rely on mechanistic understanding of initial fuel motion into the pin structure. The qualitative prediction of large reactivity loss due to fuel dispersal should, therefore, be viewed with caution.

Analysis of the stability of whole-core pools should consider potential mechanisms for collapse against those for dispersal. Pool collapse due to heat losses was considered in the CRBR analysis. The analysis was qualitative. Pool energy balances and vaporization rate analysis were not performed. The conclusion that at "high" power the heat losses would match the heat generation were not supported by quantitative arguments. Similiarly, the conclusion that at low power the insulating crusts limit the heat transfer and thereby prevent collapse is also qualitative, with no numerical justification. The "self-regulating" nature of pools of boiling fuel and steel is, therefore, unsubstantiated. Mechanistic evaluations of pool stability are required which carefully consider the heat losses to the pool boundaries and to entrained subcooled steel.

The postulate that boiling fuel-steel mixtures are dispersive down to decay-heating power levels was a major argument which led to the conclusion that the transition phase in the CRBR would terminate without significant energetics. The dispersion mechanism was used to justify the following arguments:

(i) Boilup of fuel by vaporizing steel to the full extent of the available volume aids in keeping the reactivity levels down during the course of the accident. This argument was implicit, i.e., the extent of dispersion was not used to make a quantitative estimate of the reactivity or power during the accident sequence.

(ii) The postulated dispersed flow regime was used to justify a mechanism of heat transfer to boundaries of bottled pools similar to "nucleate boiling heat transfer."

(iii) Steel boiling and fuel dispersal would result in two-phase fuel blowdown to the sodium plena, either immediately upon fuel disruption if no plugs developed, or upon plug melt-through if plugs do develop.

The extent of dispersion was related to the pool flow regime characteristics. Flow regime maps were constructed based upon two-phase flow transition criteria which relate the vapor flux to the existing flow regime. The vapor flux was computed assuming all the energy generated was used to produce steel vapor. This computation of vapor flux does not account for heat losses to the boundaries, heat transfer to entrained steel, sensible heating and nonequilibrium fuel-steel heat transfer, and can seriously overestimate the available steel vapor flux. As a consequence, the ability to disperse fuel was overestimated. In addition, recent data (Ginsberg, 1977) have shown that the transition criteria used to construct the flow regime maps are inaccurate. Data now available indicate that the transition from churn-turbulent to 
the dispersed droplet fl ow regime occurs at higher vaporization rates (by at least a factor of 5) than assumed in constructing the flow regime maps. Another set of conflicting data (Farahat, 1976) indicate that a foam flow regime is dominant under some conditions. In both the churn flow regime and the foam flow regime, the liquid and vapor are more tightly coupled, and tend to generate higher void fractions, than does the dispersed droplet flow regime. The assumption of dispersed flow, therefore, underestimates the tendency to keep the fuel in a boiled-up configuration.

The extent of dispersal and the neutronics characteristics of whole core pools must be evaluated using an integrated model which couples the thermodynamics, heat transfer and fluid dynamics behavior together with the neutronics performance of the system. It is expected that the heat transfer and fluid dynamics behavior of the system will depend upon the structure of the flow, i.e., flow regime, and on the steel vaporization rate which, to a large extent, governs the extent of dispersion. The vaporization rate can only be computed from system energy balances which permit one to estimate heat losses, nonequilibrium transfer of energy from fuel to steel and sensible heat addition to the fuel. 
-

- 


\section{TECHNOLOGY ASSESSMENT}

Of all the thermal hydraulic phenomena related to the transition phase, the following seem most important in determining the specific accident path and the resultant energetics:

a) Cladding melting and relocation,

b) Hydrodynamic behavior of volume boiling pools,

c) Boundary heat transfer from volume boiling pools,

d) Fuel relocation dynamics.

Although all of these phenomena impact upon the progression of the accident scenario, some phenomena are well understood as a result of extensive research and model development efforts. In this category, the authors would place clad relocation and boiling pool heat transfer. Although not as clearly understood, boiling pool hydrodynamics have benefitted greatly from recent studies and lag not far behind. In the area of fuel relocation dynamics, however, considerable uncertainty and disagreement still prevail. An attempt has been made to review the literature with respect to each of these general classes of phenomena. Although the review cannot cite each and every contribution over the years due to the volume of the LMFBR CDA literature, an attempt has been made to highlight the most prominant work, as well as more obscure papers which point out conflicting data or unresolved issues. An attempt is made to identify areas of disagreement or gaps in the technology where appropriate.

\subsection{Cladding Melting and Relocation}

In the event of an unprotected LOF in the FTR or CRBR, it has been shown in the L\&R series TREAT tests, in particular the R-7 test, that coolant voiding should occur in the active core region within approximately 10-15 seconds after flow decay (Epstein, 1977a; Spencer, 1976). The coolant outlet temperature has been observed to increase towards saturation with coolant boiling and voiding occurring first at the top of the active fuel region. Local boiling occurred for one second prior to net voiding, and net voiding continued for approximately another second prior to flow reversal. Voiding began as unidirectional annular flow until pressure buildup due to increasing vapor generation caused inlet flow reversal. Subsequent voiding proceeded as bidirectional annular flow. The remaining sodium film on the pins was estimated to be on the order of $0.1 \mathrm{~mm}$ average thickness. Film dryout and cladding heat-up at a rate of $300-400^{\circ} \mathrm{C} / \mathrm{s}$ subsequently occurred, and clad failure began one second after flow reversal. In the case of pressurized pins, release of fission gas products into the sodium flow paths accelerated the sodium slug downward from the active core region.

Contact between the lower sodium pool and the fuel pins resulted in sodium vaporization and upward streaming past the melting steel cladding. Estimated vapor velocities are approximately $90 \mathrm{~m} / \mathrm{s}$; this velocity has been 
shown to be sufficient to flood the molten clad by cocurrent annular flow into the upper pin structure (Dickerman, et al. 1977).

Once in the upper pin structure, the molten clad will freeze and block further sodium vapor streaming. The upper blockages have been measured to be approximately 3-5 mm, significantly thinner than SAS calculations based on CLAZAS subroutine predictions. Nevertheless, these clad blockages appeared to present sufficient hydraulic resistance to the upward flooding and/or entrainment of clad so that further clad motion was achieved by downward draining and solidification in the lower blanket (CRBR) or reflector region (FTR). In contrast to the upper blockages, these lower blockages appeared to be complete and massive $(10 \mathrm{~cm}$ thick). Their presence will prevent resumption of coolant flow and early fuel dispersal into the inlet plenum region. Due to the nature and time scales of the LOF accident, early fuel dispersal into the upper plenum appears not to be a viable termination path due to the initial formation of the clad blockages. These upper clad blockages, however, may not form at all in the case when pressurized pin failure causes early termination of sodium vapor streaming and prevents clad flooding altogether. Nevertheless, these blockages are estimated to be able to withstand only 2-3 bars differential pressure and may not present an efficient mechanism to sustain high core pressures (Dickerman, et al. 1977; Spencer, et al. 1976)

The ability to accurately calculate the rate and quantity of relocated clad material by sodium vapor flooding and/or entrainment is important since it is an indication of the strength of clad blockages, and may in fact determine if clad blockages form or not. Most phenomenological models have been developed on the basis of out-of-pile experiments. Available correlations for film flooding and droplet entrainment have indicated that sodium vapor velocities of $20 \mathrm{~m} / \mathrm{s}$ and $120 \mathrm{~m} / \mathrm{s}$ will result in clad flooding and entrainment, respectively. Grolmes, et al. (1975) proposed an incipient clad flooding velocity for sodium vapor over a stainless steel melt of approximately 16 $\mathrm{m} / \mathrm{s}$. Ishii, et al. proposed a similar criteria for droplet entrainment in cocurrent annular flow in which the mechanism responsible for droplet entrainment was identified as roll wave formation. The sodium vapor velocity for entrainment was found to be $120 \mathrm{~m} / \mathrm{s}$. Recall that from the TREAT R-7 test, sodium vapor velocity was calculated to be $90 \mathrm{~m} / \mathrm{s}$. This indicated that film flooding should occur but not entrainment. Henry, et al. (1976a) addressed these issues experimentally and analytically in a program using argon gas and molten Wood's metal to simulate sodium vapor and molten clad. Single and ten-pin bundles were utilized. Critical gas velocities for sustained flooding and entrainment were identified, and comparisons of calculations were in good agreement with photographic observations. Extension to the sodium-clad system of interest predicted sustained flooding and entrainment velocities of 82 and $101 \mathrm{~m} / \mathrm{s}$, respectively, supporting the calculation of Grolmes and in general agreement with the observations of TREAT tests. The utility of the Kutateladze criteria for flooding and entrainment critical gas velocities was verified, although the Kutateladze criteria were developed to explain data acquired with water, glycerine, and ethyl alcohol. The incipient flooding criterion (Henry 1976a) was expressed as

Incipient Flooding:

$$
U_{g}=1.15\left[\frac{\rho_{\ell}}{\rho_{g}} \frac{g \delta}{0.006+200 \delta^{2}}\right]^{1 / 2}
$$


and the critical gas velocities for sustained flooding and entrainment were given as

Sustained Flooding:

$$
U_{g}=3\left[\frac{g \sigma\left(\rho_{\ell}-\rho_{g}\right)}{\rho_{g}^{2}}\right]^{1 / 4}
$$

and

Entrainment:

$$
U_{g}=3.7\left[\frac{g \sigma\left(\rho_{\ell}-\rho_{g}\right)}{\rho_{g}{ }^{2}}\right]^{1 / 4}
$$

Spatial incoherency effects were investigated by Henry, et al. (1976) and Theofanous, DiMonte, and Patel (1976). It was proposed that although sodium vapor flow diversion into outer subchannels where clad is not yet molten may allow clad to unflood and drain, maximum vapor flow will be quickly reestablished in the molten region, and the flooding process will begin again. Henry, et al. (1976) performed experiments similar in concept to the singleand 10-pin clad relocation tests but in a 28-pin bundle. The results were in general agreement with Henry's earlier tests.

Incoherency effects in clad relocation have been examined extensively by Theofanous, et al. in several papers (Di Monte, 1975; Theofanous, 1976; Prather, 1976; Marrotte, 1978; Marrotte, 1979). Clad flooding was generally observed to be in agreement with the previously mentioned flooding criteria, both with and without bypass flow. Theofanous concluded that sustained upward clad relocation was adequately characterized by the Wallis criterion, $j_{g}^{*} \sim 1$, but that the Kutateladze scaling overpredicted the available data by a factor of two. Transient two-phase friction multipliers were found to be less than those for nonmetallic steady systems by a factor of four, and maximum upper plug thicknesses based on these data may be expected to be up to $10 \mathrm{~cm}$. However, he stated that plugging may not be complete, and the remaining molten clad would chug at flow velocities in the range below

$$
0.5<j_{g}^{\star}<1.0
$$

and would subsequently drain.

It is generally agreed that in the LOF accident sequence the upper blockage will be thinner than the lower blockage, and for the R-7 test, it was found to be several millimeters thick. Utilizing a one-dimensional single channel model in which clad film flow is formulated in terms of a continuous film and includes gravity, interfacial shear, and clad freezing dynamics, Ishij, Chen, and Grolmes (1976) predicted this blockage to be $2.5 \mathrm{~cm}$ thick in the reflector region of FFTF but predicted no blockage for CRBR due 
to the presence of the low conductivity axial blanket region. This prediction for FFTF is an order of magnitude greater than TREAT observations indicate, but is in good agreement with SLSF test P3.

Several other codes have been used to compare to available quantitative data from in-pile TREAT tests. Among these are the CMOT code (Angerer; 1977, 1979) and the SIMMER-I I code (Smith, 1978). CMOT, developed at KFK, assumes good wettability of the $\mathrm{clad}$ and fuel and models clad motion as annular film flow. SIMMER, on the other hand, represented clad motion as a two-phase droplet flow. CMOT was compared to R-5 test data while SIMMER was compared to R-7 data (for calculation of fuel motion as well as clad). CMOT appeared to give a good representation of the overall scenario of clad motion as interpreted in the R-5 test. The upper blockage was calculated to develop first and was thin (however, not porous as in R-5). The lower blockage was found to form subsequently and was thicker. The author concluded that the assumption of wettability was a reasonable one for computation of clad motion, based solely on agreement between CMOT calculations and R-5 post-test results. SIMMER (Bohl, 1979b), however, calculated a reverse scenario of events. First clad droplets in the channel were found to fall and freeze in the lower pin structure. This was followed by increased sodium vapor flow, driving periodic upward clad wave motion followed by freezing in the upper regions of the channel. The axial penetrations of the upward and downward clad motion were calculated to be much greater than R-7 test data. This comparison of SIMMER to $R-7$ was found to be in quantitative disagreement with respect to clad motion.

More recently, Ishii, et al. (1979) have reported on a multi-channel cladding motion model, MULCLAD, based on wavy film flow and upper and lower plugging. Incoherent clad melting and interconnected channel effects are taken into account. Comparisons to the R-4 and R-5 TREAT tests and the P3A SLSF test were favorable. They concluded that thermal incoherency in a subassembly has the effect of accelerating the initiation of voiding and clad motion, reducing the mass of the central blockage, and may cause wall channel clad to penetrate further into the upper pin structure. However, incoherency was found to have little effect on clad downward relocation.

Theofanous, et al. (1976b) reported non-wettability effects in simulant tests. These effects were found to accelerate the process of entrainment into the streaming sodium vapor flow from the clad film leading edge. Steps were taken to eliminate non-wetting in further experiments. In fact, nearly all non-reactor materials tests on clad motion have "suffered" from conditions under which wettability was ensured. This fact has been pointed out by ostensen, et al. (1977). They demonstrated that molten steel, under conditions that the fuel is below its disruption temperature, will in fact not wet the urania substrate. Presenting evidence from various TREAT tests, they demonstrated that liquid metals do not wet $\mathrm{UO}_{2}$ or mixed oxide fuels. In fact, the Sandia FD-1 test films explicitly demonstrate that the molten steel "beads up and peels away from the urania." They further conclude that the impact of this behavior may be manifested in flooding and entrainment models that are different from those developed in wetting systems. Since the models that are currently applied to clad motion are derived from systems that wet, and since all experiments and codes to date presume wettability, this poses a significant uncertainty with respect to prototypicality of available experi- 
mental data and calculational tools.

Although this point with respect to wettability is well taken, the preponderance of analytical and experimental evidence, both in- and out-ofpile, points to a reasonably unified picture of clad relocation and blockage formation for low void worth cores. The codes that have been developed to analyze this behavior appear for the most part to be in qualitative agreement with TREAT tests, in particular, R-7. Although disagreement with respect to thickness of the upper blockage may exist, the conclusion reached is that thin porous upper blockages should be expected as well as substantially thicker lower blockages. These blockages may prevent early downward fuel motion and present a significant hydraulic resistance to upward sodium vapor flow, at least temporarily retarding clad motion. The obstacle presented to subsequent fuel motion by the upper clad blockages has been assessed as minor by some but represents a continuing uncertainty.

A general conclusion may be reached that sustained clad motion into the upper blanket or reflector region is unlikely. This is due to early freezing of clad due to its high thermal conductivity and the increase in hydraulic friction across the upper pin structure. This may create an effective impediment to sodium vapor streaming, causing the sodium vapor velocity to fall below that for clad flooding; subsequent chugging and/or draining of clad is expected to result in massive lower blanket blockages as observed in TREAT tests.

\subsection{Hydrodynamic Behavior of Volume Boiling Pools}

The transition phase of the (hypothetical) loss-of-flow core disruptive accident in an LMFBR may be characterized by the temporary entrapment of pools of molten oxide fuel and boiling steel within the confines of the original core volume (Ostensen, et a1., 1974a; Boh1, et al., 1975). The potential for compaction of the unsupported molten fuel and, hence, for nuclear recriticality, during this stage of the accident has been the subject of much discussion (Fauske, 1977a; Dhir, et al., 1976). It has been suggested that fuel-steel mixing with steel vaporization and fuel holdup may prevent fuel collapse or may mitigate its consequences (Fauske, 1975; Ostensen, et al., 1976). Experimental verification of this dispersion mechanism with prototypic materials is lacking.

The development of pools of boiling mixtures of fuel and steel during a whole core meltdown accident in an LMFBR was first hypothesized by Ostensen and Jackson (1974a). This hypothesis was based upon the recognition that upon core disruption, molten core components would be relocated into the upper and lower fuel pin structure. In oxide fuel systems, the melting temperature of the fuel is close to the boiling point of steel. It has been proposed, therefore, that upon fuel melting, the steel would begin to vaporize and would keep the molten fuel-steel system in a boiled up, or dispersed, configuration. Permanent subcriticality may not be achievable under such conditions. Potential mechanisms for pool collapse must be identified and quantitative estimates for fuel compaction rates must be developed.

In the absence of detailed mechanistic models, it has been assumed 
(Fauske, 1977b; Ostensen, 1976) that the oxide fuel-steel system will act as a saturated, homogeneous mixture of heat source (molten fuel) and vapor source (boiling steel), subject to volumetrically distributed heating. Predictions of the extent of fuel dispersal have been based upon flow regime transition criteria and associated vapor-liquid void dynamics models. These criteria and models had been developed from early experimental data from systems characterized by either surface heating or surface gas (or light liquid) injection (Kutateladze, et al., 1960; Wallis, 1969).

On the basis of this information, it has been argued that the molten fuel would be in a boiled up configuration and would be dispersive. Fauske (1975b) has suggested that there are three flow regimes of interest in volume heated boiling pools: bubbly, churn turbulent, and dispersed.

Bubbly flow is predicted to break down to churn turbulent flow at the superficial vapor velocity corresponding to (Wallis, 1969).

$$
\frac{j_{g b} \sqrt{\rho_{\ell}}}{\left(g \sigma\left(\rho_{\ell}-\rho_{g}\right)\right)^{1 / 4}}=0.3
$$

Dukler (1977) derived a simiTar relationship, with a constant equal to 0.46 , assuming that the transition occurs at a void fraction of 0.3 . This transition is probably caused by the mechanism of bubble agglomeration. The agglomeration mechanism, however, is a strong function of system constituents, in particular, contaminants. Bubbly flows have been observed to break down at void fraction as low as 0.1 , and have been observed to be stable at void fraction greater than 0.5 (Wallis, 1961; Zuber, 1962). The relationship given by Eq. (4.5), therefore, should be approached with the recognition that system behavior may be strongly influenced by impurities or contaminants.

The transition from the churn turbulent regime to the dispersed flow regime has been predicted to occur according to the Kutateladze relationship (Kutateladze, 1960).

$$
\frac{j_{g k} \sqrt{\rho_{g}}}{\left(g \sigma\left(\rho_{\ell}-\rho_{g}\right)\right)^{1 / 4}}=0.14
$$

This transition criterion, as stated earlier, was developed from data obtained in isothermal experiments in which light liquids were injected through planar surfaces into pools of heavier liquids. Wallis (1961) independently developed a similar dispersal criterion, based upon the concept of minimum fluidization velocity. The constant in his relationship is $0.15-0.18$. Dukler (1977) suggested that churn or slug flow will break down into annular flow when the vapor velocity is great enough to lift the entrained droplets. This 
led Dukler to the relation

$$
\frac{v_{g} \sqrt{\rho_{g}}}{\left(g \sigma\left(\rho_{\ell}-\rho_{g}\right)\right)^{1 / 4}}=3.08
$$

If one allows the void fraction at dispersal to be 0.5 , this relation predicts one order of magnitude greater vapor velocity for transition to a dispersed flow regime than the Kutateladze dispersal criterion. From his extended two-phase flow stability criterion for predicting changes in flow regimes due to a boiling system with internal heat generation, Fauske constructed a flow regime map for the boiling fuel-steel pool. His observation was that a critical configuration of the fuel was only possible below 1 percent of nominal reactor power. Since he deduced that the fluidization limit for the dispersed droplet regime would be exceeded for very small power levels, his conclusion was that the boiling fuel-steel mixture in the reactor core region would exist as dispersed fuel-steel droplets suspended in a continuous steel vapor. Subsequently, experiments have been performed at vapor superficial velocities approaching or exceeding that believed to be required for the dispersed flow regime. Under no experimental conditions has this dispersed flow regime been conclusively identified in the laboratory.

Experimental data with boiling molten fuel-steel mixtures and volumetric heating have not been developed. Numerous single component volume heated boiling experiments as well as gas injection studies have been reported. Table 4.1 summarizes these experiments. The vapor generation rates have generally been lower than may be expected in transition phase conditions. Only recently have experiments with gas injection been able to approach what appears to be a dispersed flow regime. These experiments will be discussed in detail below.

Farahat's (1976) experiments were performed using microwave heating. Water, seeded with small, neutrally buoyant plastic particles, was boiled in vessels of various dimensions. The static liquid level and the boiled up liquid level were recorded for each set of conditions. A pool-average void fraction was computed and reported as a function of the superficial vapor velocity. The results indicated that for a dimensionless vapor velocity greater than 0.25 , a stable, high void fraction regime existed. Visual observation of the two-phase flow field indicated a bubbly flow for $j_{g_{\infty}} / N_{\infty}<$ 0.25 , a foam flow regime for $j_{\infty} / U_{\infty}>0.25$. It is noted that $\mathrm{Eq} .(4.5)$ predicts a transition from bubbly flow to churn-turbulent (or slug) flow at $\mathrm{j}_{\mathrm{g}} / \mathrm{U}_{\infty}=0.20$. While a transition did apparently occur at roughly this velocity value, the flow regime changed from bubbly to foam but not from bubbly to churn flow. In addition, it was noted that the superficial vapor velocity exceeded the Kutateladze velocity Eq. (4.6) by a factor of three. Dispersed flow was not observed, nor was the slug flow regime. The test results revealed that a transition from the bubbly flow regime to the churn turbulent flow regime was not observed even at superficial vapor velocities up to 50 times the transition velocity. A transition to the dispersed flow regime was not observed, even at superficial vapor velocities up to three times the 
TABLE 4.1

SINGLE-COMPONENT VOLUME-HEATED BOILING POOL EXPERIMENTS

\begin{tabular}{|c|c|c|c|c|c|}
\hline REFERENCE & TEST FLUIDS & $\begin{array}{l}\text { HEATING } \\
\text { MODE }\end{array}$ & GEOMETRY & $\begin{array}{l}\text { FLOW } \\
\text { MEASUREMENT }\end{array}$ & $\begin{array}{l}\text { MAXIMUM } \\
j_{g_{\infty}} / U_{\infty}\end{array}$ \\
\hline $\begin{array}{c}\text { Farahat, et al. } \\
(1976)\end{array}$ & $\begin{array}{l}\text { water/dyed } \\
\text { particulate } \\
\text { additives }\end{array}$ & microwave & $\begin{array}{l}\text { cylindrical } \\
\text { vessels; } \\
\text { diameters: } \\
0.8-12 \mathrm{~cm}\end{array}$ & $\bar{\alpha}$ & 13 \\
\hline $\begin{array}{l}\text { Gustavson, et al. } \\
\text { (1977) }\end{array}$ & $\begin{array}{l}\text { water/zinc } \\
\text { sulfate }\end{array}$ & electrical & $\begin{array}{l}\text { rectangular } \\
\text { vessel; } \\
17 \mathrm{~cm} \times 23 \mathrm{~cm}\end{array}$ & $\frac{\alpha(z)}{\bar{\alpha}}$ & 1.8 \\
\hline $\begin{array}{l}\text { Gabor, et al. } \\
(1976)\end{array}$ & $\begin{array}{l}\text { water/zinc } \\
\text { sulfate }\end{array}$ & electrical & $\begin{array}{l}\text { rectangular } \\
\text { vessels; } \\
15.2 \mathrm{~cm} \times 19.1 \mathrm{~cm} \\
15.2 \mathrm{~cm} \times 28.1 \mathrm{~cm}\end{array}$ & $\bar{\alpha}$ & 2.0 \\
\hline $\begin{array}{c}\text { Ginsberg, et al. } \\
(1977 \mathrm{~b})\end{array}$ & $\begin{array}{l}\text { water/zinc } \\
\text { sulfate }\end{array}$ & electrical & $\begin{array}{l}\text { rectangular } \\
\text { vessel; } \\
6.4 \mathrm{~cm} \times 8.9 \mathrm{~cm}\end{array}$ & $\bar{\alpha}$ & 19 \\
\hline $\begin{array}{l}\text { Greene, et al. } \\
(1977 \mathrm{a}, \mathrm{b})\end{array}$ & $\begin{array}{l}\text { water/zinc } \\
\text { sulfate }\end{array}$ & electrical & $\begin{array}{l}\text { rectangular } \\
\text { vessel; } \\
18 \mathrm{~cm} \times 33.5 \mathrm{~cm}\end{array}$ & $\begin{array}{l}\bar{\alpha} \\
\alpha(x)\end{array}$ & 2.0 \\
\hline Koontz (1977) & water & microwave & $\begin{array}{l}\text { rectangular } \\
\text { vessels; } \\
7.62 \mathrm{~cm} \times 3.81 \mathrm{~cm} \\
16.51 \mathrm{~cm} \times 3.81 \mathrm{~cm}\end{array}$ & $\frac{\alpha(z)}{\alpha}$ & 2.0 \\
\hline $\begin{array}{l}\text { Orth, et al. } \\
\quad(1980)\end{array}$ & $\mathrm{N}_{2} /$ water & $\begin{array}{l}\text { gas injection: } \\
\text { volumetric, surface }\end{array}$ & $\begin{array}{l}\text { square vessel; } \\
5.08 \mathrm{~cm} \times 5.08 \mathrm{~cm}\end{array}$ & $\bar{\alpha}$ & 12 \\
\hline $\begin{array}{l}\text { Leung, et al. } \\
\quad(1981)\end{array}$ & $\mathrm{N}_{2} /$ water & $\begin{array}{l}\text { surface } \\
\text { gas injection }\end{array}$ & same as above & $\bar{\alpha}$ & $\sim 50$ \\
\hline
\end{tabular}


Kutateladze (1960) dispersal velocity; however, a stable, high void fraction, bubbly flow regime characterized as a "foam" regime was observed at vapor velocities exceeding the bubbly-churn turbulent transition velocity. The above behavior has not yet been rationalized with respect to prior two-phase flow experience; it is possible that the particulate additives, with their associated red, water-soluble coloring agent, may have enhanced the stability of bubbles against coalescence and, hence, led to a foam regime which has not been reproduced in subsequent experiments.

Gustavson, et al's. (1977) experiments were carried out in an electrically heated boiling system, using water doped with zinc sulfate. Void fraction profiles were measured using a traversing pressure probe. Heat fluxes to the vertical boundaries were the primary measurement of this work. Average void fractions were also measured using the static and boiled up pool heights. The superficial vapor velocities were less than half the Kutateladze velocity. One flow regime was visually identified as a foam regime. Large scatter was evident in the foam data, perhaps indicating that the regime was unstable with respect to some undefined parameter. Another flow regime was identified visually as dense (bubbly or churn turbulent). The foaming behavior was suppressed by addition of small quantities of surface active agent. These results did not reveal a change in flow behavior with velocity which could be identified as a flow regime transition. It was apparent, however, that the foam regime was characterized by a considerably larger average void fraction than either bubbly or churn turbulent flow regimes. The authors noted that a characteristic feature of the pool appearance was a stratified two-layered structure: the lower portion of the pool was relatively devoid of bubbles, whereas the upper portion was characteristically two-phase.

The experiments reported by Gabor, et al., (1976) were also performed with electrical heating of solutions of water and zinc sulfate. Boundary heat fluxes were measured. In addition, the average void fraction was measured using the static and boiled up pool heights. According to the authors, the visual appearance of the pool was associated with bubbly and churn turbulent flow (Gabor, 1977). The authors reported a two-layered stratified flow regime structure similar to that described by Gustavson.

The experiments of Luk, et al. (1976, 1977) were non-condensible gas injection simulations of volume boiling, in which air was injected into water through a bank of vertical hypodermic tubes with holes drilled along their length. These experiments did not precisely simulate the volumetric production of vapor on a per unit mass of liquid basis. In addition, gas bubbles did not grow, and they may have been more stable than vapor bubbles generated during boiling. The superficial gas velocities studied were low, with $j_{g_{\infty}} / U_{\infty}<0.3$. Void profiles were measured via vertical static pressure traverses. In addition, average void fractions were measured with the method described previously. A two-layered structure was observed, similar to the boiling system observations reported both by Gustavson (1976) and Gabor (1976). The observed flow regime at the lower gas flow rates was bubbly. Individual bubbles of about $0.32 \mathrm{~cm}(1 / 8 \mathrm{inch})$ in diameter were observed. At larger superficial velocities, the pool became turbulent, perhaps some coalesence occurred, but individual bubbles were still observed. The increased pool turbulence may have indicated a transition from bubbly to 
to churn turbulent flow, although this is not apparent from the void data.

Koontz' (1977) experiments were performed to evaluate flow regime transition criteria for bubbly to churn turbulent and churn turbulent to dispersed flow regimes. Single and multicomponent fluid mixtures were utilized. The single component boiling pool tests demonstrated a relatively uniform volumetric vapor generation. However, the multicomponent bottom injection boiling tests demonstrated that if the injection rate was low enough and the power density high enough, nearly all the vapor would be generated at the pool bottom; behavior would be more like bottom gas injection studies previously performed. The multicomponent pools were observed to be well mixed and behaved as a homogeneous mixture. It was found that the bubbly to churn turbulent transition criterion, Eq. (4.5), approximately described the flow regime transition if the value of $k$ used was 0.6 instead of the value 0.3 as suggested by wallis. The 0.3 value always gave earlier transition than observed experimentally. This is in reasonable agreement with the observations of Greene (1979) and Ginsberg (1977b, 1978, 1979). No transition to a dispersed droplet flow regime was observed.

An experimental study was carried out by Ginsberg (1977b) with the objectives to provide visual observations of the two-phase flow behavior of volume heated boiling pools and to provide a preliminary quantitative measure of the void distribution in volume heated pools, with vapor production rates large enough to produce superficial vapor velocities considerably in excess of the Kutateladze dispersal limit. Observations of two-phase, single component volume heated boiling pool behavior were made in an electrically heated water-zinc sulfate system. Photographic observations were made of the poolaverage void fraction. Experiments were carried out for the superficial vapor velocity up to 19 times the characteristic bubble rise velocity and approximately five times the Kutateladze dispersal velocity. A bubbly flow regime was always observed for dimensionless superficial velocity up to approximately unity. In most of the experimental runs, a transition from bubbly to churn turbulent flow was observed at this point. The average void fraction data in this regime were characterized reasonably well by the bubbly flow drift velocity formulation.

In the range of $j_{g_{\infty}} / U_{\infty}$ between 1 and 4 , the flow regime appeared to be markedly influenced by the presence of contaminants. A foam flow regime was observed in instances where system contamination by particulate impurities was observed. This regime always gave way to the churn turbulent flow regime for $j_{g \infty} / U_{\infty}$ greater than 4 . The average void fraction data in the churn flow regime were also described reasonably well by the churn-turbulent drift flux model. The churn turbulent regime was observed at vapor velocities up to nearly five times the Kutateladze dispersal limit (Kutateladze, 1960). This observed stability of the churn turbulent regime was consistent with the dispersal limit proposed by Dukler (1977).

Greene's (1979) experiments were performed in an open boiling system in which joule heating was used to generate volumetric boiling. The average void fraction was measured and compared to the dimensionless superficial vapor velocity based upon total vaporization power. It was found that there existed a threshold velocity, below which the pool would not boil. This point defined a transition to volumetric boiling from natural convection. Subsequently 
a net boiling superficial vapor velocity was defined as the difference between the two. The incipient boiling, bubbly flow data and the churn turbulent data were compared to the predictions of the one dimensional drift flux model based upon net vaporization power and an appropriate drift flux function. The model was in fair agreement with the bubbly flow and incipient boiling data for small values of superficial velocity and improved considerably as this value increased. The transition data, due to the nature of the onset of flow instability, demonstrated poor agreement with both the bubbly and churn turbulent flow models. For the churn turbulent flow data, good overall agreement between experiment and analysis was achieved. The sensitivity of the void fraction in the churn turbulent flow regime to the vaporization power was considerably less than in the bubbly flow regime. The following conclusions were drawn from these data. The pool-average void fraction in bubbly flow never exceeded 0.60 . In churn turbulent flow, the average void fraction was approximately 0.40 in the range $1.0<j_{g_{\infty}} / U_{\infty}<2.0$. Transition from bubbly flow to churn turbulent flow occurred for the total dimensionless superficial vapor velocity in the range 0.8 to 1.0 , in reasonable agreement with Ginsberg et al. (1977b). This transition was accompanied by an immediate and sudden collapse in pool average void fraction from approximately 0.55-0.60 to 0.40. The thin foaming layer which existed for some of the bubbly flow runs invariably was destroyed during transition to churn turbulent flow. This was interpreted to mean that foaming flows were unstable for dimensionless superficial velocity greater than unity. Once again, stratification was observed in the pool for both bubbly and churn flow.

Two sets of steady two-phase flow behavior have been observed. One set is characterized by relatively low average void fraction, and has been identified with the bubbly and churn turbulent flow regimes. These are the experiments of Gabor, (1976), Luk, (1977), Greene, (1979a,b) and a portion of Gustavson's (1976) and Ginsberg's $(1977 \mathrm{~b}, 1979)$. The second set of results, including those of Farahat (1976) and a portion of Gustavson's (1976) and Ginsberg's $(1977 b, 1979)$ are characterized by relatively high average void fractions. The flow regime here has been identified with a foaming twophase flow behavior. In Farahat's (1976) experiment, the superficial vapor velocity exceeded the Kutateladze velocity by a factor of three. The predicted (Fauske, 1975b) transition to dispersed flow was not observed. Neither the dispersed flow nor the slug flow regime was observed in any of these studies. The most significant difference in results is the apparent persistence in Farahat's microwave experiments of the foam regime to relatively large vapor fluxes. The consequence of this is that for comparable vapor fluxes, the average void fraction was greater than 0.9 in Farahat's experiments, compared with 0.6-0.7 in other tests. It is believed that the foam regime observed in Farahat's experiments was associated with bubble stability enhancement caused by the presence of the red, plastic particulates used in the experiment to promote bulk nucleation. A major unresolved issue is the question of the reasons for the unusual persistence of bubbly flow and the influence of system contamination on the observed behavior.

The above results indicated the importance of flow regime on the boil up in volume heated boiling pools. The results suggested, moreover, that the dominant system flow regime might be dependent upon system constituents, the presence of chemical impurities, and particulates. 
Subsequently, Orth, et al. $(1979,1980)$ and Leung, et al. (1981) investigated the hydrodynamics of simulated boiling pools with distributed or bottom noncondensable gas injection. Emphasis was placed upon the high gas velocity regimes. Orth reported observing bubbly, churn turbulent, and "fountain" flow. The fountain flow was observed under some circumstances to coexist with churn turbulent. No dispersed droplet flow was observed, even to dimensionless superficial velocities up to 12. Leung (1981) simply modified Orth's apparatus to include a bottom gas injector. An electrical conductance probe was employed to infer flow regime. They concluded that at a superficial velocity of $5 \mathrm{~m} / \mathrm{s}$ (dimensionless gas velocity $=20$ ), a transition to dispersed flow was achieved, at approximately ten times the Kutateladze limit. On the basis of these results, they remarked that for a fuel/steel pool, approximately 15\% nominal power would be required to achieve such a dispersed flow. It should be remarked that Orth's conclusions were that churn turbulent flow was observed although the average void fractions began to approach the dispersed limit. At any rate the data from both investigations in the high gas velocity limit were certainly bounded by the limits of the churn turbulent flow regime and the dispersed droplet regime.

Although the distributed and bottom (noncondensible) gas injection average void fraction data from these high gas velocity tests appear to qualitatively agree, several papers have presented results warning of the dangers of applying results from adiabatic gas injection studies to volume boiling conditions. Ginsberg (1981) performed experiments in a gas injection apparatus and compared his results to prior boiling results. He reported that the two-phase distribution parameter, $C_{0}$, could be arbitrarily varied to improve the comparison between experimental data and the churn turbulent mode1. Moreover, the churn turbulent behavior was detected visually for dimensionless gas velocity up to 15 .

In comparing to his previous internally boiling data, Ginsberg noted that, whereas transition from bubbly to churn turbulent flow occurred for dimensionless vapor velocity in the range unity to four, for adiabatic gas injection in a similar geometry this transition occurred at a value of 0.25 , a factor of four to 16 lower. This suggests that a flow regime transition criterion based on gas injection data may not be applicable to an internally boiling system. Greene (1981) examined boiling inception and stratification effects in volume boiling liquids. Local void fraction was measured with a pressure probe and compared to drift flux models. It was found that significantly thick nonboiling layers could be found at the pool bottom in bubbly and churn turbulent regimes which could not be predicted by the drift flux models and which were not found in adiabatic studies with gas injection. Although the average void behavior was in reasonable agreement with the drift flux models, alarmingly poor agreement was found on a local basis. However, it was found that if this nonboiling layer was accounted for, subsequent vapor generation in the boiling layer was in better agreement with the $\mathrm{drift}$ flux model. The average void fraction results of all these experiments are presented in Figure 4.1.

Several codes have been developed to deal with integral transition phase phenomena including boiling fuel/steel pool hydrodynamics. Among these are FUM0-T (Martin, 1979) and SIMMER-II (Smith, 1978). Martin, et al. (1980) examined the condition of the bottled transition phase pool. They examined the 


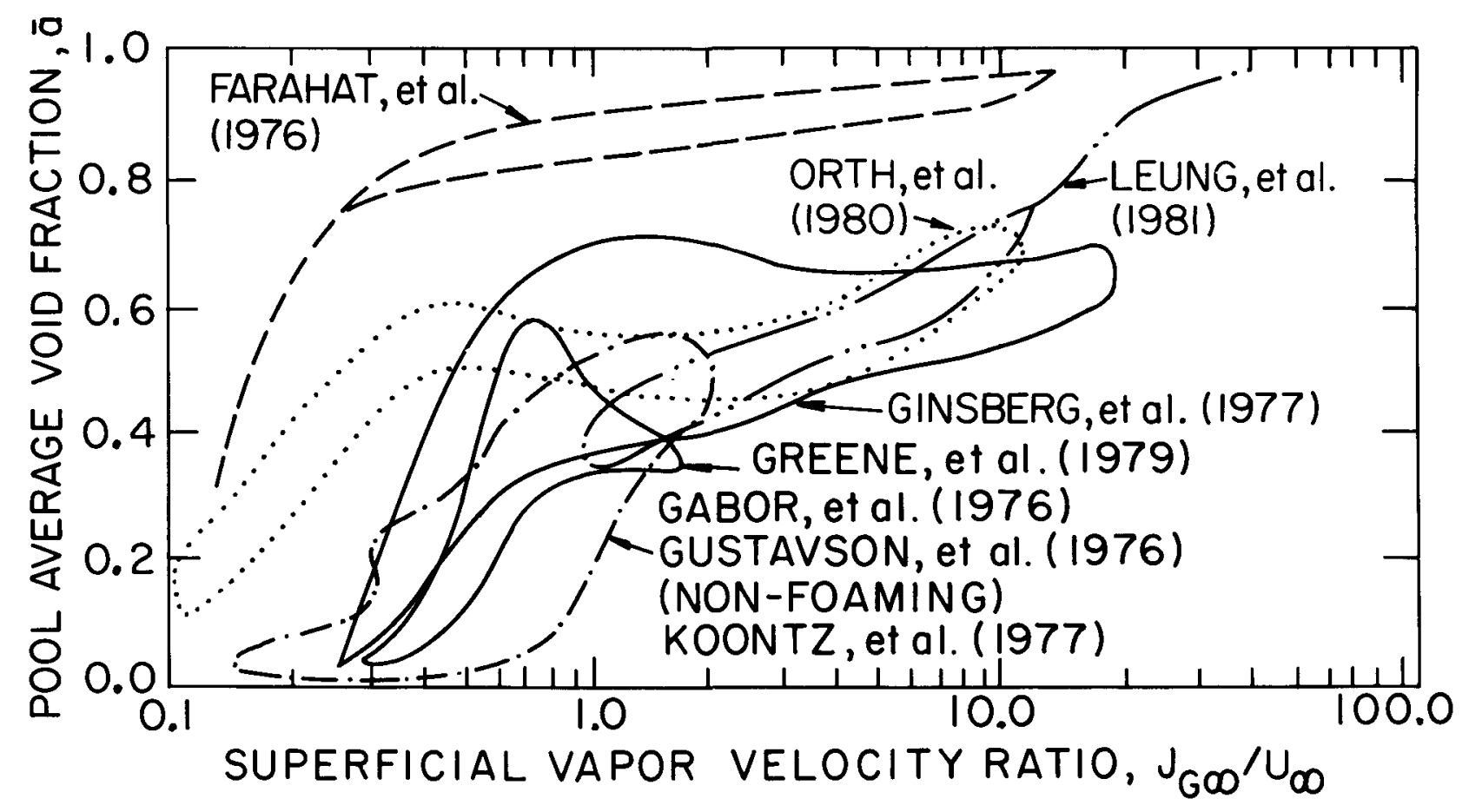

Figure 4.1 - Pool Average Void Fraction Measurements 
behavior of a confined boiling pool with respect to flow regime, power profile, mixing and bottom and lateral heat losses. Based upon his studies with FUMO-T, Martin concluded that the dominant flow regimes would be bubbly (and foam) and churn turbulent. The principal effect of a fuel crust was determined to be regulation of maximum pool temperature as opposed to degree of boilup. The boundary heat losses were observed to stratify the temperature in the pool, causing accumulation of nonboiling superheated liquid at the bottom. The separate effects method of modeling transition phase phenomena in an integral tool such as FUMO-T has the advantage that new models of phenomena can be easily incorporated into the code as they become available.

SIMMER-I I was developed to predict the transient behavior of an LMFBR during an HCDA, coupling fluid dynamics, heat transfer and neutronics models in two dimensions. The hydrodynamics of two-phase boilup of a molten core is modelled by assuming that the core is in the dispersed droplet flow regime. Although designed to calculate whole core accidents in LMFBRs, its versatility has allowed calculation of small scale experiments in geometry other than whole core geometry. In this regard, the code was used to predict boilup or average void fraction of a series of simulant experiments as a function of the superficial gas velocity (Bel1, 1981). The experimental data were in the bubbly, churn turbulent and "dispersed" flow regimes and included data from internally heated, distributed gas generation, and bottom gas generation experiments. Calculations with SIMMER-II predicted the average pool void fraction for superficial velocities up to $2.5 \mathrm{~m} / \mathrm{s}$ that essentially passed within the band of available data over the entire range of superficial gas velocity. Although only modeling the dispersed flow regime, this kind of quantitative agreement is very encouraging, indeed. It is expected that accomodation of alternate flow regimes would significantly improve the code performance.

Ginsberg, et al. (1979b) reported some implications of volume boiling hydrodynamics with respect to the transition phase. They pointed out that for most experimental investigations, the bubbly and churn turbulent flow regimes were the dominant regimes. They ruled out the foam flow and dispersed flow regimes as being applicable, based upon available experimental evidence. However, they added observations that although average void fraction may be characterized well by drift flux formulations (Ginsberg, et al., 1977b; Greene, et al., 1977a), local void distributions may not be adequately predicted (Koontz, 1977; Greene, 1980). They recommended future work with respect to the influence of heat losses, sensible heating and cold material addition to the pool.

At present, the codes appear to be doing an adequate job of calculating the steady state boilup of internally boiling pools in comparison to the available models and experimental data with simulant materials. The discrepancies noted may represent fine points which are not essential for the integral codes such as FUMO and SIMMER. Nevertheless, future work should address internally heated pools at superficial velocities sufficiently high enough to verify (or disprove) the transition criteria that have been widely quoted. It is doubtful if this can ever be done with reactor materials such as $\mathrm{UO}_{2}$ and steel. In addition, transient effects such as pressurization and sensible heating, as well as cold material addition, should be examined in order to develop the next generation of hydrodynamic models for boiling 
pool behavior.

\subsection{Boundary Heat Transfer from Internally Boiling Liquids}

Numerous studies exist in the literature concerning heat transfer from liquids with an internal heat source. However, investigations into the heat transfer and hydrodynamic behavior of volume heated boiling liquids have been few. The earliest known attempt to consider the heat transfer from volume heated boiling liquids was the work performed at Argonne National Laboratory by Stein, et al. (1974). In this work, a solution of $\mathrm{NaCl}$ and water was boiled in an open container by joule heating. The average downward and horizontal heat fluxes were measured by themocouples soldered in small dead end holes in the plates making up the electrodes and base, and in the coolant system.

The boundary heat transfer was separated into a natural convection and forced convection regime. For the lower limit of the boiling heat flux, the data was shown to agree with natural convection while for an upper limit of the boiling heat flux, the data were well characterized by forced convection based on the bubble velocity. A thermal convection reference velocity, $V_{T C}$, was defined as

$$
V_{T C}=(g B \Delta T L)^{1 / 2}=\left(g\left(\rho_{\omega}-\rho_{\infty}\right) L / \rho_{f}\right)^{1 / 2}
$$

and an equivalent free stream velocity, $V_{B}$, was defined as below:

$$
V_{B}=40 Q^{0.72}
$$

It was reported that for $V_{B} / V_{T C} \leq 0.2$, natural convection heat transfer was applicable and for $V_{B} / V_{T C}>3.0$, forced convection was applicable. For intermediate ratios, mixed convection was suggested to exist.

The next attempt to experimentally characterize boundary heat transfer from volume boiling liquid was the work of Gabor, et al. (1976). They used solutions of $\mathrm{ZnSO}_{4}$ in water. The volumetric boiling power was supplied by resistance heating as in the previous work. The electrodes and base plate were used as the heat transfer surfaces; thermocouples were buried halfway into the copper plates for temperature measurements, seven into the base plate, and two in each of the electrodes. Boundary heat losses were measured by calculating the enthalpy increase of the water coolant flowing in coils of copper tubing brazed to the backs of the electrodes. In these tests, one of the vertical electrodes was split into two segments in order to estimate the heat flux distribution along the vertical axis of the boundary. The opposite electrode was unsegmented. The ratios of the boundary heat fluxes, Qupper Qlower, were measured as a function of the boiling heat flux. It was found that for low boiling heat flux the ratio Qupper/Qlower was in the 
range of 1.5 to 2 , in agreement with the prediction from thermal convection theory. For high boiling heat flux, the heat flux ratio was nearly equal to unity and equal to the heat flux to the unsplit electrode. The data were correlated in terms of a Nusselt number and Reynolds number based on the superficial vapor velocity. The Prandtl number was assigned separate exponential weight of $0,1 / 3$, and $1 / 2$ powers. A new model was suggested for heat flux to a vertical boundary based on bubble induced laminar forced convection of the form

$$
\overline{\mathrm{Nu}}=\mathrm{C} \mathrm{Re}^{1 / 2}
$$

where the constant $C$ included the effect of the Prandtl number. This model does not reduce to the lower limit of natural convection in the case that the vapor generation rate goes to zero.

In so much as the previous studies had contributed to the understanding of some heat transfer processes occurring in internally heated boiling liquids, they did not provide a mechanistic model for predicting local boundary heat transfer or void fraction in such liquids. Recognizing this shortcoming, Gustavson, et al. (1977) undertook an investigation into the local distribution of boundary heat transfer and void fraction in internally heated boiling liquids. They employed a rectangular pool of $\mathrm{ZnSO}_{4}$ and water with resistance heating. Instead of using the electrode as the heat transfer surface, an instrumented test plate was installed with which to measure local heat transfer to themally isolated segments. The local heat flux was measured by measuring the temperature rise and the flow rate of the coolant for each individual segment. The surface temperature of each segment was determined by extrapolating the interior thermocouple reading at the segment centerline to the test wall surface across $0.38 \mathrm{~mm}$ of aluminum and $0.76 \mathrm{~mm}$ insulating Teflon sheet. The accuracy of the measured local heat transfer coefficient in these tests was reported to be +40 percent. It was proposed that boundary heat transfer from volume heated boiling liquids was a mixed convection heat transfer phenomenon in which the effects were superimposable. They proposed that the behavior of an internally boiling pool was bounded by asymptotes of natural and forced convection similar to Stein.

The method they used to model the combined natural/forced convection heat transfer was a non-linear interpolation curve fit between the asymptotic limits, a technique developed by Churchill and Usagi (1972).

The functional form of the correlation was

$$
\frac{N u}{N u_{N}}=\left[1+\left(\frac{N u_{C}}{N u_{N}}\right)^{n}\right]^{1 / n}
$$

where $n$ was determined by a "best fit" evaluation of the data. Alternate forms of the natural and forced convective heat transfer correlations are required depending upon the laminar or turbulent behavior of the boundary layer. The correlation was tested against the measured heat transfer data. 
The best agreement was obtained using the laminar relations and a value of $n=1$.

The data of Gustavson, et al. (1977) represented the first data available for local convective heat transfer from internally boiling liquids. Greene, et al. (1977) conceived from the available data that the mode of heat transfer, instead of resembling mixed convection in which the effects were approximately superimposed, more closely approximated an enhanced mode of natural convection boundary layer flow and heat transfer. It was assumed that the vapor rising through the pool caused a net liquid drift upward, which encountered the free surface and was forced to return downward al ong the cold boundary. In this case, the net bouyancy effect was due to the liquid-to-two-phase density difference. The heat transfer distribution from the volumetrically boiling liquid to the boundary exhibited behavior not unlike a single phase natural convection boundary layer, enhanced by the flow of net liquid recirculation due to upward vapor drag through the central liquid and downward along the walls. On this basis, single phase natural convection boundary layer theory coupled with the bouyancy effect of the two phase flow in the bulk liquid was used by Greene, et al. (1977) to correlate the Nusselt number to a modified Rayleigh number. A modified Grashof number based on the void fraction weighted liquid density, including wall inclination effects, was developed.

$$
\operatorname{Gr}^{*}(x, \alpha, \theta)=g \alpha x^{3} \cos \theta / \nu_{f}^{3}
$$

The experimental data of Gustavson, et al. (1977) and Gabor, et a . (1976) were correlated on the basis of modified single phase natural convection theory utilizing the average and local void fraction where available and the forms of the local and/or average heat transfer correlations are indicated in Table 4.2. The form of the correlation of Gustavson's data was found to be insensitive to whether the average or local void fraction was used. The use of the average void fraction was attractive since the computation of local heat flux would not require knowledge of the local void distribution which is more difficult to measure and compute. The experimental data of Gabor, et al. (1976) and Gustavson, et a1. (1977) and the analytical modeling of Greene, et al. (1977) based on their data strongly suggest that the boundary heat transfer was in fact dominated by natural convection behavior. However, the uncertainty in the available data made it difficult to differentiate the degree of agreement with the various models proposed, as well as to identify the heat transfer behavior associated with various flow regimes. As a result, it was difficult to extrapolate these results to other heat transfer systems of interest. For these reasons, Greene, et al. (1979) undertook the experimental effort to be described next.

An open boiling pool was constructed with electrodes recessed into the lexan walls for Joule heating. An inclinable test wall was designed with a boron nitride (BN) test plate machined and recessed to be flush with the lexan. Precision microthermocouples $(0.010 \mathrm{in}$. diameter) were cemented into the test plate in 19 locations flush with the wall surface. Determinations of vaporization power and superficial vapor velocity were made based upon makeup flow rate. Experiments were performed over a range of dimensionless power, $j_{g_{\infty}} / U_{\infty}$, approximately up to two, and wall angles of $90^{\circ}$ (vertical), $75^{\circ}$, and $60^{\circ}$ where $j_{g_{\infty}}=q^{\prime}{ }^{\prime \prime} H_{0} / \rho v^{h g}$. The local distribution of 
TABLE 4.2

SUMMARY OF CORRELATIONS OF HEAT TRANSFER FROM INTERNALLY BOILING LIQUIDS TO BOUNDARIES

\begin{tabular}{|c|c|c|c|c|c|}
\hline AUTHOR & $\begin{array}{l}\text { BOUNDARY } \\
\text { ANGLE }\end{array}$ & $\begin{array}{l}\text { LOCAL OR AVERAGE } \\
\text { CORRELATION }\end{array}$ & CORRELATION & $\begin{array}{l}\text { STANDARD } \\
\text { DEVIATION }\end{array}$ & $\begin{array}{c}\text { RANGE OF } \\
\text { APPLICABILITY }\end{array}$ \\
\hline $\begin{array}{l}\text { Gustavson } \\
\text { (1977) }\end{array}$ & Vertical & $\begin{array}{l}\text { Local } \\
\text { Average }\end{array}$ & $\begin{array}{l}\mathrm{Nu}(x)=.78 \operatorname{Ra}(x, \bar{\alpha}) 0.25 \\
\mathrm{Nu}(x)=.76 \mathrm{Ra}(x, \alpha(x)) .25 \\
\overline{N u}=1.07 \operatorname{Ra}(L, \bar{\alpha}) .25\end{array}$ & $\begin{array}{l} \pm .35 \\
\pm .56 \\
\pm .30\end{array}$ & $\begin{array}{l}\mathrm{Ra}<10^{12} \\
\operatorname{Ra}<10^{12} \\
\mathrm{Ra}<2 \times 10^{12}\end{array}$ \\
\hline $\begin{array}{l}\text { Gabor } \\
(1976)\end{array}$ & Vertical & Average & $\overline{\mathrm{Nu}}=1.58 \mathrm{Ra}(L, \bar{\alpha}) \cdot 25$ & \pm .33 & $\mathrm{Ra}<2 \times 10^{12}$ \\
\hline $\begin{array}{l}\text { Greene } \\
\text { (1979) }\end{array}$ & $\begin{array}{l}\text { Vertical }\left(90^{\circ}\right), \\
75^{\circ}, 60^{\circ}\end{array}$ & $\begin{array}{l}\text { Local } \\
\text { Average }\end{array}$ & $\begin{array}{l}\mathrm{Nu}(x)=1.41 \mathrm{Ra}(x, \bar{\alpha}, \theta) .25 \\
\mathrm{Nu}(x)=.0234 \mathrm{Ra}(x, \bar{\alpha}, \theta) \cdot 40 \\
\overline{N u}=1.54 \mathrm{Ra}(L, \bar{\alpha}, \theta) \cdot 25 \\
\overline{\mathrm{Nu}}=.0314 \mathrm{Ra}(L, \bar{\alpha}, \theta) \cdot 40\end{array}$ & $\begin{array}{l} \pm .24 \\
\pm .002 \\
\pm .08 \\
\pm .002\end{array}$ & $\begin{array}{l}\mathrm{Ra}<1.9 \times 10^{11} \\
\mathrm{Ra}>1.9 \times 10^{11} \\
\mathrm{Ra}<1.9 \times 10^{11} \\
\mathrm{Ra}>1.9 \times 10^{11}\end{array}$ \\
\hline
\end{tabular}

$\mathrm{Nu}=k(\mathrm{Gr} P r)^{n}$ where $\mathrm{Gr}=g a x^{3} / \mathrm{v}^{2}$ 
boundary heat transfer coefficient was integrated to determine the average heat transfer coefficient. The average void fraction was determined from pool boil-up measurement. The superficial vapor velocity, $j_{g_{\infty}}$, was determined by converting the flow rate of make-up water into an average vapor flux.

Local and average heat transfer correlations were calculated and are indicated in Table 4.2 for the bubbly flow regime. The scatter in the data was less by a factor of 4-6 than observed in previous investigations. The assignment of the exponents to the data correlation, similar to single phase natural convection, was done only on the justification of observation of the marked change in the behavior of the data in the vicinity of $\operatorname{Ra}^{\star} \sim 1-2 x$ $10^{11}$ and should not be interpreted to indicate laminar to turbulent transition.

The churn turbulent regime data, however, deviated sharply from the above observed behavior. For the same Rayleigh number, the churn turbulent data was observed to lie significantly above the correlation for bubbly flow. There is insufficient data at this point to make any quantitative statements to correlate the data to particular model assumptions. The magnitude of the temporal fluctuations in the wall temperature, as well as the significantly higher boundary heat transfer coefficient (by a factor of 2-4 or more) was interpreted to indicate that the multidimensional hydrodynamic nature of the churn turbulent boiling pool was interfering with the formation of the wall boundary layer, if not intermittently destroying it.

The best fit modified natural convection correlations derived from analyzing the average heat transfer data of Gustavson, et al. (1977), Gabor, et a1. (1976), and Greene, et al. (1979) are summarized in Table 4.2, and the relationships for local and average heat transfer coefficient from internally boiling liquids from Greene, et al. (1979) are given below:

and

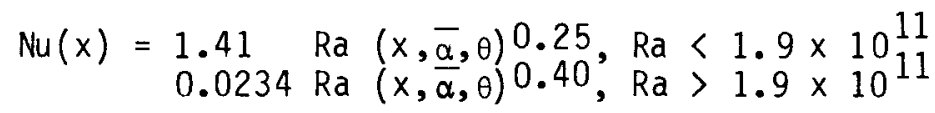

$$
\begin{array}{ll}
\overline{N u}=1.54 & \operatorname{Ra}(L, \bar{\alpha}, \theta) 0.25, \\
0.0314 & R a(L, \bar{\alpha}, \theta) 0.40, \operatorname{Ra}>1.9 \times 1011 \\
0.9 \times 10^{11}
\end{array}
$$

These data are plotted in Figures $4.2 \mathrm{a}, \mathrm{b}$. The local correlations were found to be insensitive to the use of the local or average void fraction. These relationships are to be preferred in the calculation of boundary heat transfer from internally boiling pools to vertical or inclined boundaries.

The following conclusions were made concerning heat transfer from volume boiling pools to vertical and inclined structural boundaries:

In the bubbly flow regime, boundary heat transfer from volume boiling pools in the bubbly flow regime behaved similar to but greater than natural convection boundary layer heat transfer. The spatial variation in the local heat transfer coefficient was as great as a factor of 3-5 along the wall, with the greatest heat transfer at or near the pool surface. The data of Greene, et al. (1979) for local convective heat transfer coefficient exceeded 

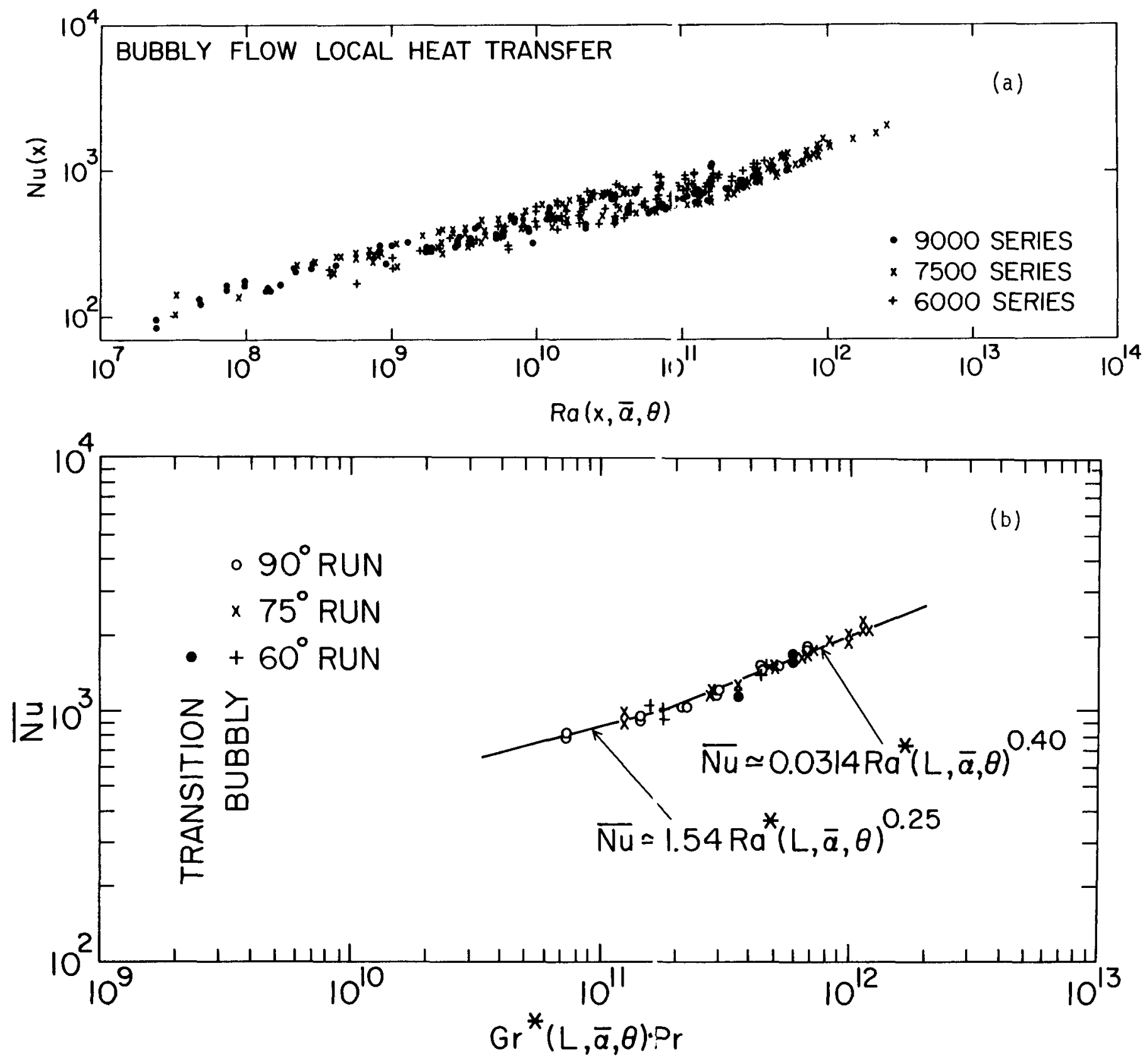

Figure 4.2 - Natural Convection Correlation of Boundary Heat Transfer from Volume Boiling Pool $\begin{array}{ll}\text { (a) } \mathrm{Nu}(\mathrm{x}) \text { vs. } \operatorname{Ra}(\bar{\alpha}, \mathrm{x}) & \text { (b) } \overline{\mathrm{Nu}} \text { vs. } \operatorname{Ra}(\bar{\alpha}, \mathrm{L})\end{array}$ 
those previously reported by Gustavson, et al. (1977) by a factor of 2 or more but agreed with the earlier average pool data of Gabor, et al. (1976) within the scatter in their data. The heat transfer behavior of the foaming data from Gustavson (1977) did not demonstrate a marked difference from the dense regime data of the same work. For boundary layer-type heat transfer from volume boiling pools in the bubbly flow regime, the effect of small angle of inclination of the boundary from vertical was modeled by the component of the gravitational acceleration along the wall. For the data described herein with inclinations up to $30^{\circ}$ from the vertical, this correlation proved adequate.

In the churn turbulent flow regime, large temporal fluctuations were observed in the standard deviation of the local wall temperature fluctuations. In some instances, the fluctuations were of the same magnitude as the difference between the pool temperature and the time-averaged wall temperature, indicating partial or complete local destruction and renewal of the wall boundary layer. It is this mechanism that is believed responsible for the increased boundary heat transfer coefficient in churn-turbulent flow. The profile of local heat transfer coefficient was more uniformly distributed along the wall, exhibiting large spatial variations.

Recently, a model was developed to compute heat transfer from the sides of a volume boiling pool for application to the TRANSIT-HYDRO code (Chawla, et al., 1981). The basis of the modeling assumed single phase natural convection with combined buoyancy due to themal and two phase effects. Similarity analysis of the boundary layer equations assuming turbulent single phase flow was performed. Comparison to the experimental data of Greene, et a1. (1979) and Gabor, et a1. (1976) yielded excellent agreement. It should be pointed out that the assumption of combined thermal and two phase buoyancy in a single phase natural convection approach is identical to the assumptions inherent in the method of correlation of these data by Greene, et al. (1977).

The previous studies of boundary heat transfer from internally boiling liquids all employed open pools with aspect ratio close to one. For application to transition phase conditions, however, both of these conditions may represent severe limitations on the applicability of this work to bottled, subassembly scale pools with aspect ratio greater than ten and possible pressurization effects. It is not expected that the heat transfer rates in high aspect ratio pools would be the same as those presented in the correlations in Table 4.2. However, there are currently no alternative correlations available for large aspect ratio pools to the best knowledge of the authors and the quoted correlations represent the present state-of-the-art.

In addition, thermal radiation effects in a boiling $\mathrm{UO}_{2}$ pool have been suggested as being as important as convective heat losses at $3000^{\circ} \mathrm{C}$ (Ostensen, 1980). The experiments performed thus far and quoted have not modeled this effect nor is it included in any analyses currentiy available. Presently, there are widespread conflicting opinions concerning internal radiation effects in molten $\mathrm{UO}_{2}$ pools. Stein (1979) claims there is evidence from his experiments that downward heat transfer in molten $\mathrm{U0}_{2}$ exceeds the predictions of thermal convection theory by a factor of four based upon the known thermal conductivity of $\mathrm{UO}_{2}$. In addition, there are data that indi- 
cate the thermal diffusivity of $\mathrm{UO}_{2}$ increases substantially as it increases in temperature through its liquidus. These data have been interpreted to indicate an effect of internal radiation enhancing the conduction heat transfer (Kim and Liebowitz, 1977). Both Stein and Kim reported good agreement between their data and calculations including thermal radiation in the form of the Rosseland optically thick limit.

On the other hand, Bober, et al. (1980) have reported spectral reflectivity and emissivity measurements of solid and liquid $\mathrm{UO}_{2}$ at high temperature which indicate little effect of internal radiation on the thermal conductivity of molten $\mathrm{UO}_{2}$. A detailed discussion of their work will not be presented except to mention that they conclude that the "penetration depth of radiation is about $0.1 \mu \mathrm{m} . "$ In view of this conflicting evidence with respect to the importance of internal radiation in molten $\mathrm{UO}_{2}$, no fim conclusions can be made at this time.

\subsection{Fuel Relocation Dynamics}

A great many studies have been reported in the literature concerning flow and freezing of fluids in channels whose walls are cooled below the solidification temperature of the fluids. Until recently, the majority of these studies have addressed conditions in which the mass flow rate was constant or the freezing was not complete. It was only recently that reporting began on studies relating to conditions of more interest and applicability to reactor safety. These generally involve transient flow from reservoirs, penetration lengths, plugging times, wall melting, multiphase effects, and frozen crust instability. This review will concentrate on the literature addressing those issues related to freezing processes that may occur under conditions applicable to the flow and freezing of molten core material.

Early studies of fuel flow and freezing were performed under conditions that may occur during flow through the lower shield block region in an LMFBR. These tests generally involved single phase liquids freezing in tubes which were not melting. Cheung and Baker (1976) performed a very early study in which the penetration distance of various fluids into cooled copper coils was measured. A parametric study was performed, and an empirical correlation of the transient freezing data was obtained. The authors reported that the results were in good agreement qualitatively with a model based upon conduction 1 imited freezing. The model would apply to the conditions that a stable frozen layer forms along the walls of an infinitely long cooled channel, and freezing is limited by a transient growing crust. Chun, et al. (1977) reported a similar study in which flow and freezing of single phase liquids in circular tubes were investigated. Wood's metal and paraffin liquids were allowed to flow through a short test section and the amount of liquid that could flow through the channel was measured until complete frozen plugs formed preventing further flow. It was concluded that for fuel at low decay power levels suddenly flowing through the lower axial shield structure into the lower plenum, plugging of single phase fuel would not occur for fuel initially above $2900^{\circ} \mathrm{C}$. If two of the seven channels in the lower support structure of a subassembly were open and fuel entered at the freezing temperature (conservative estimate), it could be shown that the entire subassembly would relocate into the lower plenum in less than eight seconds. In a series of papers, Epstein, Yim, and Cheung (1977) and Epstein and Hauser 
(1977) analytically studied the penetration length of a liquid into an initially empty cold tube. In the first paper, the fluid temperature was fixed at the freezing temperature and a shape for the frozen layer was assumed. In the second paper, this assumed crust profile method was verified. Epstein and Hauser (1977) later compared the predicted penetration lengths with experimental data for water, freon, and benzene flowing into tubes cooled by liquid nitrogen. Good agreement was found between predictions and data, giving support to the idea of using the crust profile method for predicting penetration and freezing with stable crusts.

This work was subsequently improved upon (Epstein et al (1977b)), taking into account frictional resistance in addition to flow constriction effects in determining the penetration distance before freezing. This analysis was extended to consider the amount of liquid displaced into or through rod bundle geometry before freezing shut (Epstein, et al, 1979). Considering turbulent flow of liquid at its freezing point and accounting for constriction and friction losses, the final liquid penetration length due to conduction freezing was found to be given by

$$
\frac{X_{c}}{D_{h}}=0.085\left(\frac{v}{\lambda^{2} \alpha_{s}}\right)^{7 / 11}\left(\frac{\Delta P D_{h}}{\rho v^{2}}\right)^{4 / 11}
$$

and the amount of liquid mass that would emerge from the rod bundle exit before complete solidification was given by

$$
\frac{M_{p}}{\rho L C D_{h}}=3.33 \times 10^{-3}\left(\frac{D_{h}{ }^{\nu}}{\lambda^{2} \alpha_{s} L}\right)\left(\frac{\Delta P D_{h}^{3}}{\rho v^{2} L}\right)^{4 / 7}-0.159
$$

where $\lambda$ is the growth constant, $C$ is the wetted perimeter of the bundle, $X_{c}$ is the conduction limited penetration length, and $M_{p}$ is the displaced mass exiting the rod bundle. When Equation (4.14) was used to predict penetration length of thermite in pin bundles, $X_{c}$ was calculated to be $130 \mathrm{~cm}$. However, the authors remarked that this improved agreement with the thermite freezing tests should be taken with caution, since this equation does not model the effect of sensible heat in the flowing liquid, nor does it account for the effect of entraining liquid steel into the flowing fuel. Accounting for these effects would certainly alter the calculated results.

The papers considered up to this point have dealt with single phase $1 i-$ quids flowing from a reservoir into an initially empty and cold tube, and the results have supported the applicability of the conduction freezing model to the experimental conditions. In most cases, the experimentally observed penetration lengths or integrated mass flow rates agreed substantially with the analytical models developed to predict them. However, flowing core debris is likely to consist of a two-phase mixture of molten fuel and the vapor void content may be substantial. Greene, et al. (1977; 1978a,b,c) studied the problem of the solidification of two-phase noncondensable mixtures as they flow and freeze in circular tube geometry. The fluids were simulant mixtures of Wood's metal and paraffin with nitrogen gas as the dispersed phase, and flow was initiated downwards through an initially empty cold tube 
from a reservoir. The vapor fraction was varied by changing the gas flow rate. The results of these tests indicated that as the dispersed phase (i.e., gas void fraction) in the flow increased, the two-phase mass flow rate, as well as the crust growth plugging times decreased markedly. An empirical expression relating the ratio of the two-phase plugging time, $t_{2 \phi}$, and the single-phase plugging time, $t_{1 \phi}$, to the average void fraction was given. This type of calculation offered an upper limit on the fuel flow rate during the transient fuel motion with freezing. It was demonstrated that if the fuel was heated above its fusion temperature, freezing rates would be even slower due to convection heat transfer from the flowing fluid to the crust.

Petrie et al. (1980) also examined the two-phase effect on freezing rates. In their experiments, instead of tube flow, they employed a planar natural convection boundary layer with rising gas bubbles from below. At the freezing point, they reported no two-phase effect on crust growth rate; at liquid temperature above the freezing temperature, they reported slower crust growth rates and attributed this effect to enhanced convective heat transfer to the bubbling action. This result appears to be in direct contradiction to the previously reported results of Greene et al. who reported faster twophase freezing rates, not slower.

In an analytical effort, Sienicki and Spencer (1981) recently reported on some analyses of two-phase effects on freezing and plugging models. They reported that for two-phase flow, representing the heat transfer coefficient by the forced convection part of Chen's correlation (1963) for single phase flow multiplied by $(1-\alpha)^{0.8}$ would result in lower convective flux than for the single phase case. For the conduction freezing model, the penetration distance is reported increased by $21 \%$ (in the absence of convective heat transfer), while bulk freezing and thin film predictions of penetration distance decrease by 7 and $28 \%$, respectively. They concluded that this perturbation to the penetration length due to two phase flow was not significant for reactor safety purposes.

At first glance, these results (Petrie, 1980; Greene, 1977; Sienicki, 1981) seem to be contradictory with respect to the magnitude of the two phase effect on the freezing rate as well as the trend. For fluids at their $1 i-$ quidus, convective heat transfer from the fluid to the crust is zero and as such plays no role in the crust growth rate. This observation is certainly in agreement with the results of Petrie and Sienicki. Greene, however, observed that with increasing void fraction the freezing rate increased and the mass flow rate decreased even for fluids at their liquidus. Established two phase flow principles dictate that for experiments with constant pressure drop at low quality, the two phase effect should decrease the total mass flow rate, and thus the convective heat transfer coefficient should al so decrease. One possible explanation for the data of Greene is that his fluids were not exactly at their liquidus but had some finite sensible heat content. In this case, the void effect would tend to reduce the mass flow rate due to the two phase friction (with constant pressure drop) and the reduced mass flow rate would tend to lower the convective heat transfer to the crust (Sienicki, 1981), thus increasing the freezing rate in the direction of that for a fluid at its liquidus, which should represent the fastest freezing rate. Petrie, 
however, reports that the two phase nature of his pool-type natural convection flow enhanced the boundary convective heat transfer resulting in slower growing crusts. This type of heat transfer enhancement in bubbling pools has been observed previously in volumetric boiling pools (Stein, 1974; Gabor, 1976; Gustavson, 1977; Greene, 1979a) and by Luk and Bankoff (1977) in pools with gas injection. It is not inconsistent that these two sets of data (Greene, 1977; Petrie, 1980) should behave differently since the two phase nature of the experiments is so different. The hypotheses offered above still need to be conclusively verified by further experiment and analysis. For similar discussions of the two phase effect on the bulk freezing and thin film models of fuel freezing, the reader is referred to the report of Sienicki (1981).

Fuel penetration through cold fuel pin structures may involve the complicated combination of melting and freezing of wall and fuel simultaneously. Submerged crust has been proposed as an effective insulating mechanism for preventing intimate mixing of melting steel surfaces and flowing molten fuel. In the presence of a melting substrate, it has also been argued that since the crust does not have a solid surface on which to adhere, mechanical instabilities may prevent the frozen crust from insulating the surface. The presence of the crust could reduce the heat transfer driving temperature difference from $\sim 1500{ }^{\circ} \mathrm{C}$ to approximately $150{ }^{\circ} \mathrm{C}$. Dhir, et al. (1976, 1977) presented a theory in which downward heat transfer from a molten pool to a melting subsurface caused large droplets from the melt layer to rise and interfere with stable crust formation. Film boiling considerations were used to predict the minimum temperature drop across the melt layer necessary to allow a crust formation of fuel over the molten steel. Temperature differences above this limit would drive the system unstable from the point of view of stable crust formation. The pseudo-film boiling hypothesis was tested in a water-dry ice experiment. Failure of an ice crust to form over the melting (sublimating) dry ice surface was interpreted to substantiate the hypothesis. Epstein (1977d) suggested that instead of the film boiling arguments employed by Dhir, et al. $(1976,1977)$ a fuel crust would invariably form when molten fuel and steel meet, and the "fate of the crust depends on a race between the fuel crust growth process and the rate of development of buoyancy forces due to the presence of the underlying lighter steel melt." The interface disturbance was envisioned as similar to Taylor wave formation with surface tension and elastic forces. Experimental results from pouring hot, heavy liquid onto cold, lighter liquid were in good agreement with the crust stability predictions. It was calculated for the case of a core-wide fuel pool, the minimum unstable disturbance wavelength would be greater than 2.0 $\mathrm{m}$, indicating fuel-steel pools would be separated by stable crust, and boiling pool collapse due to addition of steel as a heat sink could be avoided. However, this result was quite sensitive to the temperature of the hot, overlying liquid. If that liquid were sufficiently above its solidification point, freezing would not be possible and intermixing would occur.

Fuel crust breakup due to thermal stress has been proposed as a potential mechanism for the removal of insulating crusts which may form between molten fuel/steel mixtures and structural steel, thus promoting the mixing of fuel and steel. This mechanism could limit the penetration of molten fuel during pressure driven expulsion from a molten core through axial blanket 
regions as well as cause boiling pool collapse due to higher convective heat losses and cold material entry into the flow. Ostensen et al. (1977) reported on the effect of thermal stresses on the mechanical integrity of oxide fuel crusts. Assuming the crust surface temperatures to be bounded by the fuel melting temperature on the hot side and the steel melting temperature on the cold side, it was concluded that based upon available physical property data that $75 \%$ of the crust would be penetrated by cracks. For a single FFTF subassembly at full power (or a 100 subassembly pool at $10 \%$ power) the uncracked crust thickness was calculated to be $63 \mu \mathrm{m}$; for the same case at $10 \%$ power, the uncracked crust thickness would be $0.6 \mathrm{~mm}$. The ability of such thin crusts to insulate the pool from cold boundaries was considered doubtful, especially if the fuel is above its freezing point, leading to cold material entry and high heat losses, pool subsidence, and possible recriticality.

In addition to pool crust stability considerations, crust stability in the presence of ablating jets and melting walls (in the case of convectively flowing liquids) has been investigated by Swedish, et al. (1978), Yim, et al. (1977, 1978) and Epstein, et al. (1978), extensively. It has been shown that for freon flowing through a thick ice pipe, the ice wall melting rate is controlled by the growth and decay of the frozen freon layers on the ice pipe wall. It was postulated that a freon crust would grow until convection became greater than conduction through the crust, at which time the crust would recede and disappear. When the crust disappeared entirely, the freon would again be exposed to the underlying solid ice surface after the melt layer was removed and crust growth would begin again. If the crust growth and decay period were small compared to the flow time, the ice melting and removal would repeat at a rate proportional to the difference between the flow temperature and the crust melting point. If the fluid flow temperature were equal to the interfacial crust melting temperature, crust removal would be prevented.

Epstein, et al. (1978) and Swedish, et al. (1978) demonstrated that, in addition to fuel crust stability in pool geometry and tube flow, an insulating crust could be stable in the impingement region of a nomal liquid jet. Since the rate of melting of solid surface was found to be dependent on the difference between the liquid jet temperature and the melting temperature of the jet material (similar to the melting tube experiments), it was concluded that the jet freaze layer controlled the melting rate. The presence of the frozen jet material between the jet and ablating wall was demonstrated photographically. The dependence of the presence of the crust on the temperature of the jet was further evidence of the sensitivity of crusts to the thermal conditions.

More recently, Ganguli and Bankoff (1978, 1979) investigated the growth and decay of an ice crust in boundary layer flow over a melting decane flat plate. The leading edge of the crust was observed to melt and move downstream, while the exposed wall melt layer was ablated upstream. Refreezing of the ice crust was not observed; this was explained by the low thermal conductivity of the decane resulting in the instantaneous interface temperature being greater than the liquid freezing temperature after one crust growth cycle. 
The issue of crust stability is of central importance in determining the rate and amount of fuel motion from the core (and hence reactivity loss) once leakage paths appear in the above-core clad blockages. The experiments described so far were performed with simulant fluids flowing over or inside cold structures; the fluids were generally at or near their fusion temperature and the driving pressure was generally low. Even in the cases in which wall melting was allowed, crusts were demonstrated to be stable and the freezing processes were rate limited by conduction through the solid crusts (Epstein et al). None of the previously described tests used materials which would occur in an actual core melt situation for reasons that physical measurements in that environment are severely limited. It is inevitable that such tests have to be performed in order to determine if the phenomena previously (or simultaneously) observed in simulation tests will actually represent the processes which may occur under the actual core melt conditions expected.

A series of tests have been performed which utilize an exothermic thermite reaction (Ostensen, 1974b; Jackson, 1974a; Epstein, 1976b, c; and Spencer, 1978, 1979) to generate a high temperature $\left(\sim 3200{ }^{\circ} \mathrm{C}\right)$, high pressure ( 3-6 MPa), and high void fraction (75 percent) two-phase fuel mixture. The high pressure and gas fraction are a result of the release of nitrogen gas from the solid uranium during ignition. For most thermite tests performed to date, the only measurements made during the transient fuel freezing have been the injector pressure and initial test section temperature, and post-test analysis.

The first study of the motion of fuel in the upper subassembly pin structure was conducted by Ostensen and Jackson (1974a). A bulk freezing model was developed (Jackson, 1974a), which assumed that no stable crust would form due to underlying steel melting. The crust would break up and be swept away with the fuel. Heat transfer from the flow was modeled by Deissler's turbulent heat transfer correlation. In this fashion, the fuel would travel a distance necessary to remove all the sensible heat and latent heat of fusion. A simple formula was presented to predict this bulk freezing penetration distance, $Z$, given as

$$
z=\frac{\rho c_{p} d_{h}{ }^{6 / 5} u^{1 / 5}}{0.111} \ln \left[\frac{T_{0}^{*}-T_{w}}{T_{f}-T_{w}}\right]
$$

where $\rho$ is the density, $C_{p}$ is the specific heat, $d_{h}$ is the hydraulic diameter (given as $0.51 \mathrm{~cm}$ inside pins and $0.25 \mathrm{~cm}$ between pins), $U$ is the fuel velocity, $T_{0}$ is the initial fuel temperature, $T_{0}\left(=3200{ }^{\circ} \mathrm{C}\right)$, plus the equivalent temperature rise to represent the latent heat release, $h_{f s} / C_{p}$ $\left(\sim 450{ }^{\circ} \mathrm{C}\right), \mathrm{T}_{\mathrm{W}}$ is the wall temperature (= steel melting temperature, 1450 $\left.{ }^{0} \mathrm{C}\right)$, and $\mathrm{T}_{\mathrm{f}}$ is the fuel melting temperature $\left(=2770{ }^{\circ} \mathrm{C}\right)$. Experiments were performed with mixtures of thermite injected into 7-pin hollow pin bundles to simulate 7 pins of fuel subassembly. The thermite was injected into the test assembly at $15 \mathrm{~m} / \mathrm{s}$ and $3200{ }^{\circ} \mathrm{C}$. The experimental results (see Table 4.3) indicated that for initial steel temperature in the range 400-900 
${ }^{0} \mathrm{C}$, thermite penetrated between the pins an average of $23 \mathrm{~cm}$ and inside the pins an average of $39 \mathrm{~cm}$. (The hydraulic diameter between pins was approximately $.250 \mathrm{~cm}$ and inside was $.508 \mathrm{~cm}$ ). Ostensen, et al. (1974b) reported that the results of the bulk freezing model calculations compared very well with the observed fuel penetration distances (see Table 4.3). Calculations with Equation $(4.16)$ (letting $T_{w}=1450^{\circ} \mathrm{C}$ ) predict average penetration inside and between pins of 35 and $15 \mathrm{~cm}$, respectively. For the experimental runs in which the instantaneous contact temperaure would predict wall melting (Tests 3 and 4 ) resulting in $T_{w} 1450{ }^{\circ} \mathrm{C}$, the average penetration distances measured were 39 and $23 \mathrm{~cm}$ inside and between pins, respectively. ostensen (1974b) was led to the conclusion that for $3000^{\circ} \mathrm{C}$ fuel entering the plenum structure driven by 12 bars pressure (for FFTF), fuel would penetrate only $20 \mathrm{~cm}$ upward between the pins. The results were observed to be insensitive to the pressure. Epstein, et al. (1976b) attempted to develop a set of mechanistic models to describe the scenario of the fuel freezing process. Freezing modes were identified as conduction freezing, bulk freezing, and ablation freezing. For conduction freezing the conduction penetration length, $X_{c}$, can be predicted by Equation (4.14). For bulk freezing, a relationship essentially identical to that derived by Ostensen was developed.

Assuming mechanical stability, a thermal stability criterion was derived on the basis of a growing and decaying crust. It was found that the lifetime for a stable mechanical crust due to thermal decay was predicted by

$$
t_{1 i f e}=\frac{16 \lambda_{f}^{2}{ }^{\alpha_{f}}}{(f U)^{2}}\left[\frac{T_{f}-T_{w}}{T_{0}-T_{w}}\right]^{2}
$$

The maximum equilibrium crust thickness could be represented by

$$
\delta_{\max }=\frac{k\left(T_{f}-T_{W}\right)}{h\left(T_{0}-T_{f}\right)}
$$

The corresponding penetration length upon crust disappearance was

$$
x_{p}=u t_{1 \text { ife }}
$$

For $\mathrm{T}_{0} \rightarrow \mathrm{T}_{\mathrm{f}}$, note that both mechanical and thermal crust instability mechanisms would become inoperative, and for this case, crusts are unconditionally stable.

Assuming that crust removal will occur in fuel freezing situations involving high fuel velocities and hot steel temperatures, it was postulated that fuel freezing by mixing with cold ablated steel will occur after a delay time equal to the sum of the thermal lifetime of the crust (assuming mechanical stability for the crust) and the time for the steel melt layer to equal the thickness of the laminar sublayer. By an enthalpy balance, equating the 


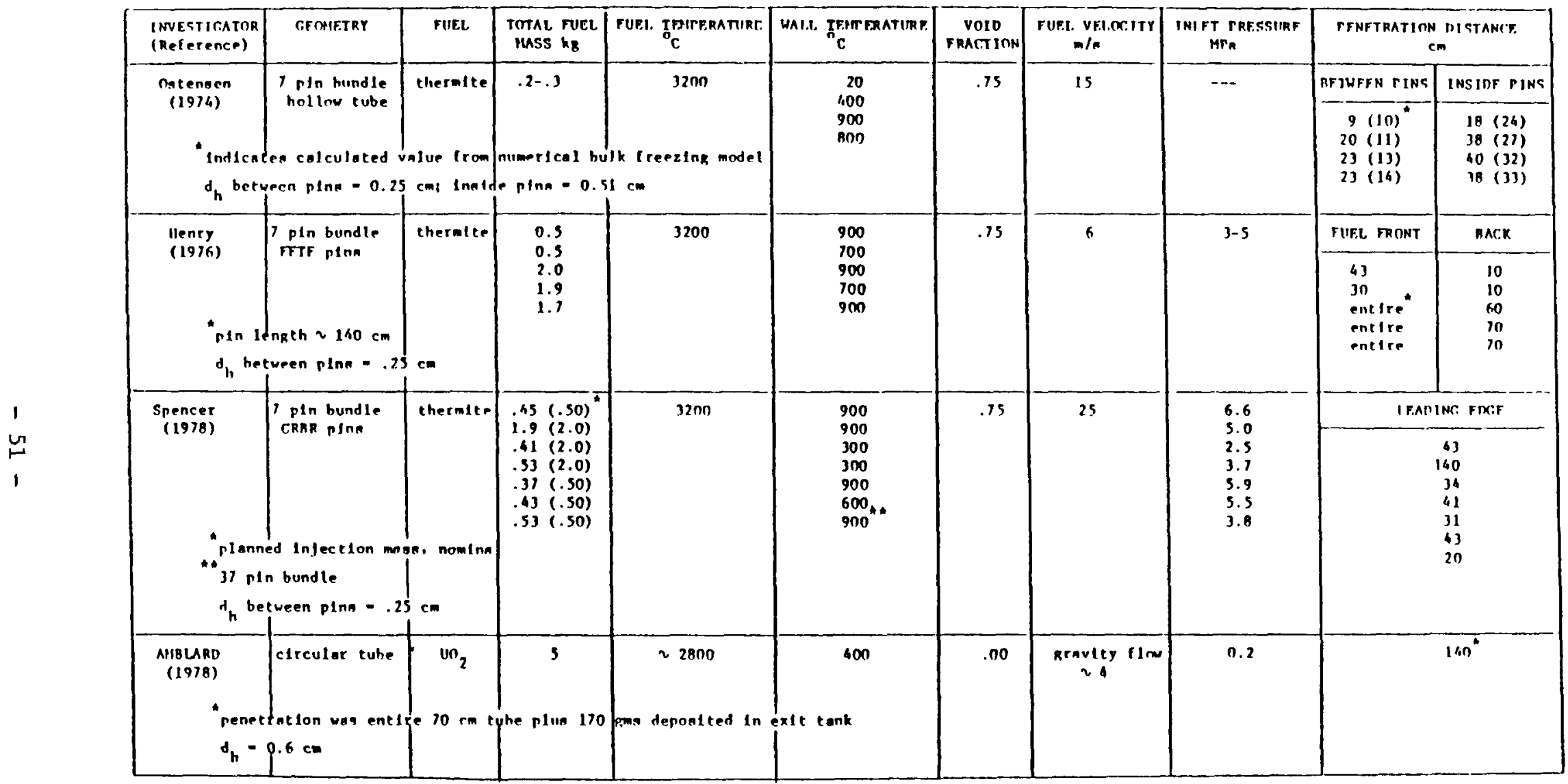

Table 4.3 - Fuel Freezing Experiments 
mass of steel and fuel to be mixed to cool the fuel to freezing, it was shown that the penetration distance (ablation model) of the fuel mixing zone (not the leading edge) could be calculated from

$$
x_{a}=x_{b}\left[1+\frac{T_{f}^{-T} w, m}{h_{f s} / c_{p}+T_{w, m}{ }^{-T_{w}}}\right]
$$

For the analysis of the 7-pin thermite tests of 0stensen, et al. (1974b), mechanical crust stability was assumed since the computed critical flow velocity was $\sim 54 \mathrm{~m} / \mathrm{s}$ and the measured velocity $\sim 15 \mathrm{~m} / \mathrm{s}$. The penetration of the leading fuel edge can be expected to be the sum of Equations (4.19) and (4.20). It was found that the results agreed substantially with the results from the early thermite freezing tests. It was concluded that "fuel cannot penetrate far into the upper subassembly structure," due to fuel crust removal, steel ablation, and fuel-steel freezing.

A second series of thermite 7-pin injection tests were reported by Epstein, et al. (1976c) in which the hollow tubes employed previously were replaced by FFTF fuel pins, the first $15 \mathrm{~cm}$ of which were solid steel (Inconel reflector). Both 0.5 and $2.0 \mathrm{~kg}$ injections were performed. The $0.5 \mathrm{~kg}$ injections agreed with the earlier hollow tube injection tests (Ostensen, $1974 \mathrm{~b}$ ) and penetrated approximately $30-40 \mathrm{~cm}$. The $2.0 \mathrm{~kg}$ injection, however, penetrated almost the entire pin bundle length $(135 \mathrm{~cm})$ and the leading edge came to rest in the end cap region (see Table 4.3). It was observed that this was inconsistent with the bulk or ablation freezing concepts previously presented. An explanation was made that a slurry of fuel and steel was formed and that the presence of steel "lubricated" the flow; complete plugging and freezing would now depend upon conduction limited freezing in the steel fraction and freezing of the leading edge would occur in the end cap region. The short penetration distances observed with the $0.5 \mathrm{~kg}$ thermite releases were explained to be due to the limited amounts of thermite employed. A scenario of events to explain the observed test results was presented as follows: (i) ablation and entrainment of the cladding occurred in the inlet region; ( $i i)$ melted steel became the continuous phase in the leading edge; ( $i i j$ ) the flowing steel-thermite mixture fell below the steel ablation temperature, and conduction limited steel crust growth began. From the conduction penetration formula, this predicted penetration of $50 \mathrm{~cm}$ (not the observed $135 \mathrm{~cm}$ ). However, there is independent evidence that slurries or two component solid-liquid mixtures undergoing transient freezing solidify and plug much more rapidly than liquid-vapor mixtures under identical conditions (Greene, 1980). The conclusions of the authors was that "fuelsteel mixtures under sustained pressure penetrate far into subassembly structure and even travel distances which exceed the dimension of the LMFBR subassembly", a conclusion significantly different than the previous position that "fuel cannot penetrate far into the upper subassembly structure."

Spencer, et al. $(1978,1979)$ reported the results of a series of thermite freezing tests in 7-pin CRBR-type fuel pins. These pins were different from the FFTF pins in that they had $36 \mathrm{~cm}$ of depleted $\mathrm{UO}_{2}$ to simulate the blanket region instead of $15 \mathrm{~cm}$ of steel to represent the reflector. The 
hydraulic diameter of the flow path was $0.286 \mathrm{~cm}$. The fuel initial velocity was nominally $25 \mathrm{~m} / \mathrm{s}$ for both 0.5 and $2.0 \mathrm{~kg}$ injections (see Table 4.3). In test 2, fuel-steel mixture penetrated $140 \mathrm{~cm}$ and was stopped by frozen stainless steel at the leading edge. However, in tests 3,4 , and 6 , in which the initial wall temperature was below that expected for crust instability, penetration distances on the order of $30-40 \mathrm{~cm}$ were measured, al though conduction freezing modeling predicted stable crust formation and sustained flow. It was suggested that stable crusts did form and "choked off" the flow, resulting in the short distances observed. It was suggested that since the circular tube shotgun thermite tests (Epstein, et al., 1976c) at $T_{W}=300$ ${ }^{\circ} \mathrm{C}$ formed a stable crust $0.53 \mathrm{~cm}$ thick and this would result in a reduction of hydraulic diameter from $2.86 \mathrm{~mm}$ to $0.63 \mathrm{~mm}$ in the 7-pin CRBR thermite tests, that stable crust formation caused the short penetrations and limited injection (20-25 percent of available thermite) observed. However, from Epstein's (1976b) maximum crust thickness criterion (allowing the heat transfer coefficient to be approximately $17 \mathrm{~W} / \mathrm{cm}^{2} \mathrm{~K}$ ), one can calculate an expected maximum crust thickness approximately $0.1 \mathrm{~mm}$ thick, reducing the hydraulic diameter from $2.86 \mathrm{~mm}$ to $2.66 \mathrm{~mm}$. This casts some doubt upon the identification of the actual fuel freezing mechanism at work. The results of these seven tests are shown in Table 4.3. Regardless, Spencer $(1978,1979)$ was led to the conclusion, unlike Epstein (1976c) previously, that "molten fuel is not likely to penetrate completely through the $1.5 \mathrm{~m}$ length of upper pin structure to disperse into the upper plenum during a transient pressure driven expulsion from the core." This conclusion is essentially similar to the conclusion reached after the 7-pin thermite tests of 0stensen, et al . (1974).

Several approaches to explaining the observed penetration distances of molten thermite into rod bundles have appeared. The previous approaches, bulk freezing, ablation, and conduction models, have not enjoyed good agreement with the observed data on their own. In most instances, the bulk freezing model (Ostensen, 1974) which models turbulent heat transfer from the leading edge consistently underpredicts the penetration length. The ablation model (Epstein, 1976c) which accounts for thermal crust decay and molten steel ablation predicts about the same penetration length as the bulk model. Conduction freezing models which assume unconditionally stable crusts invariably predict significantly longer penetration lengths than the observed thermite data. As a result, alternate approaches based upon completely different sequences of events, or modifications to the previously mentioned models have appeared. The predominant objective of these modeling efforts has been to explain the themite freezing data.

One such attempt was performed by Spencer et al. (1979). In reporting the results of 7-pin (CRBR) thermite freezing tests, they observed invariably that insulating $\mathrm{UO}_{2}$ crusts were absent from the cladding surfaces, similar to the claims of 0stensen (1980). An energy balance was performed based upon the mixing of molten $c l a d$ and the fuel, in which the penetration distance was determined by equating the energy to reduce the thermite mass to its solidus to the energy required to raise the distributed steel heat sink to its liquidus. It was shown that if the mass of thermite injected into the bundle was known, the penetration distance could be predicted rather well. The inference from these results is that the mechanism of heat transfer from the fuel involves high rates and gross melt entrainment, although the model 
ignores virtually any mechanistic treatment.

Another more mechanstic approach to modeling the penetration and freezing of molten fuel in pin structures is the thin film model developed at Sandia (Eisenhawer, 1979; Lee, 1979; Eisenhawer, 1981). Motivated by the apparent inability of the bulk and ablation freezing concepts to accurately predict the penetration of thermite generated fuel into prototypic pin bundies, an experimental and analytical study of heat transfer to a melting wall with film flow was initiated. Concern over the applicability of conventional turbulent heat transfer models for heat transfer to a melting wall was expressed since no data or analyses of convective heat transfer in liquidliquid systems with boundary melting were available.

An experiment was developed using R-11 refrigerant as the flowing fuel simulant and an ice pipe as the structural simulant. On the basis of the density ratio, these materials were chosen to represent the hydrodynamic behavior of the fuel-steel system. With this fluid pair, the development of a crust was prevented, enabling investigation of just the heat transfer as af fected by the wall melting process and the film flow. It was considered desirable to eliminate crust formation since insulating fuel crusts did not appear to form in thermite freezing tests. Hydrodynamic observations during the experiments revealed the presence of a wavy film flow of water along the wall between the flowing $R-11$ and the ice pipe. No entrainment of the film into the bulk flow was observed, in contradiction to the assumptions made in the bulk and ablation freezing models. Heat transfer measurements were made which revealed that the Nusselt number for the melting process was essentially constant and independent of the bulk flow Reynolds number, indicating that the rate of heat transfer to the melting wall was controlled by the thin water film. This would tend to increase the resistance to heat transfer greatly over the simple turbulent heat transfer resistance that had previously been assumed.

A mathematical model was developed based upon these observations called the thin film model which agreed well with the results of the $R-11 /$ water film melting experiments. This model was applied to the analysis of freezing and melting for the urania/steel system of interest in reactor safety. The thin film model was used to calculate the effective heat transfer coefficient through the film to the wall, assuming a stable molten steel film forms along the clad wall. This heat transfer coefficient was input into the bulk freezing model to predict the fuel penetration length into the axial pin structure for Spencer's thermite freezing tests. These calculations with the thin film model predict penetration in the range 0.7 to 1.0 meter, a significant improvement to the 0.1 and 0.3 meter penetration distance previously calculated with the ablation and bulk freezing models, respectively.

In a recent analysis, Sienicki and Spencer (1982) attempted to extend the original bulk freezing model by including the damping effect of fuel particles on turbulent eddy transport of heat in the flow. Turbulent transport of energy and momentum was modeled according to the Prandt 1 mixing length theory, including a damping of eddy transport due to partcles which exceed the local mixing length. It was found that the diffusion of energy to the cladding was significantly reduced by the solid particles, resulting in longer calculated penetration lengths at plugging for the thermite freezing 
test with this modification to the bulk freezing model.

Concern has been expressed about the prototypicality and applicability of the thermite freezing tests to the conditions of fuel relocation dynamics during transition phase. Under the conditions of the thermite reaction, a high void fraction, dispersed flow is created at pressure in excess of 50 bars. These conditions may be more representative of energetic disassembly conditions than of transition phase blowdown. The pressure for transition phase blowdown may be an order of magnitude less and the flow regime is expected to be churn-turbulent in accordance with present experimental evidence.

A program was initiated at Grenoble to investigate the freezing dynamics of single-phase $\mathrm{UO}_{2}$ in circular tubes. Thick walled tubes were used to insure an adiabatic boundary conditon. Early experiments were performed in an initially cold tube with gravity-driven flow. Due to accidental conditions in the pouring of the molten $\mathrm{UO}_{2}$, the fuel did not penetrate the test section at all. The fuel entered the inlet cone as a small diameter jet and the melting attack on the steel core walls was severe. The results of these initial tests did not resemble any of the freezing models previously discussed. Another fuel freezing test (Amblard, 1978) was performed with a thickwalled inlet cone. The test section was a $60 \mathrm{~cm}$ long stainless steel tube (I.D. $\left.=6 \mathrm{~mm}, 0 . \mathrm{D}_{.}=14 \mathrm{~mm}\right)$ connected to a $10 \mathrm{~cm}$ long copper tube (I.D. $=6$ $\mathrm{mm}, 0 . \mathrm{D}_{.}=8 \mathrm{~mm}$ ) leading to a copper tank. The initial test section temperature was $750{ }^{\circ} \mathrm{C}$ on a short length of steel and $400{ }^{\circ} \mathrm{C}$ for the remaining length. The copper tube was $40{ }^{\circ} \mathrm{C}$. The inlet pressure was 0.2 $\mathrm{MPa}$. Once the $\mathrm{fl}$ ow was initiated, fuel initially at $2900{ }^{\circ} \mathrm{C}$ penetrated the steel and copper tubes, and $170 \mathrm{gms}$ of $\mathrm{UO}_{2}$ was found in the tank in the form of a solidified foam. It was reported that the freezing rate was conduction limited and the estimated penetration distance (if the tube were semi-infinite in length) would have been approximately $140 \mathrm{~cm}$. It was reported that the calculated penetration distance (according to conduction freezing models) was larger than the $140 \mathrm{~cm}$ estimated from the data. The authors concluded, "nevertheless, these first experiments have shown that when the steel is initially cool $\left(20{ }^{\circ} \mathrm{C}, 400{ }^{\circ} \mathrm{C}\right)$, the heat conduction model is appropriate and the penetration length widely exceeds the axial blanket dimensions." If the initial fuel velocity is assumed to have been approximately $5 \mathrm{~m} / \mathrm{s}$, the penetration distance expected into the steel tube due to conduction freezing from Equation (4.14) would exceed the tube length, resulting in net mass flow from the test section. The total mass displaced is calculated to be $179 \mathrm{gms}$. The calculation for the plugging time and mass displaced from Greene (1978c) predicted a total mass flow of 267 gms in 1.5 seconds. When the amount of fuel needed to fill the tube was subtracted from this, the amount expected in the receiving tank was found to be $101 \mathrm{gms}$, in better agreement with the experimental data. Unfortunately the conditions of these experiments are not considered characteristic of fuel motion and freezing during the transition phase.

More recently a series of fuel freezing studies have been initiated at Sandia known as the TRAN fuel freezing tests. In these experiments, about 44 grams of $\mathrm{UO}_{2}$ is melted in-pile and injected into a circular thick walled tube (diameter $.32 \mathrm{~cm}$, length $130 \mathrm{~cm}$ ). To date four TRAN tests have been reported (McArthur et al., 1981a, b, 1982). Post-test analysis indicates that 
a stable and continuous crust forms on the wall of the tube and there is no evidence of the crust breakup mechanisms that have been proposed previously. Penetration lengths were measured from radiographs that greatly exceed both the bulk or ablation freezing models. Crust penetrations were measured to be in the range $50-70 \mathrm{~cm}$ into the tube with no penetration of fuel out of the tube. In most cases, no substantial steel wall melting was found; blockages were found in the first two tests but were absent in the last two. The crust thicknesses that were measured were found to be consistent with the theory of conduction-controlled crust growth and were found to be continuous and smooth, even in regions where molten steel removal had apparently occurred. These initial results are indeed encouraging and revealing, and a more prototypic series of tests is planned with pin bundle geometry and fuel/steel mixtures which should contribute greatly to an ultimate understanding of transition phase fuel freezing phenomena.

In conjunction with these tests, a parallel analytical modeling effort was carried out by Hayden (1981) to analyze fuel freezing in tube flow. The model combines the assumptions of stable crust growth with the heat transfer mechanisms of the bulk freezing model (Ostensen, 1974a). Using more accurate temperature dependent steel properties to calculate the instantaneous contact temperature between fuel and steel, it was found that substantially higher steel temperature was required for instantaneous melting on contact with fuel, by about $450 \mathrm{~K}$ than previous analyses predicted. This finding would supress instantaneous wall melting and promote stable crust formation, a condition which has been observed in the TRAN fuel freezing tests. The model calculates the distance that molten fuel must travel to lose its sensible heat, $Z_{c}$, then an additional distance that the so-called slurry must travel to lose its latent heat, $Z_{L}$. The sum of these distances, in a fashion analogous to the ablation model, is the total penetration distance of the fuel. The model was used to calculate the penetration distance of thermite in Spencer's freezing tests (Tests 1,3,4,6) and the penetration distance of $\mathrm{UO}_{2}$ in McArthur's TRAN tests (Tests 1,2 ). In all cases, the model tightly bracketed the observed penetration lengths, deviating from the data by at most ten percent. This type of agreement is encouraging and inclusion of additional effects into the model should improve its general applicability to the calculation of fuel penetration in axial blankets.

There has been concern over the possible effects of residual sodium films on the upper subassembly clad upon the flow of molten fuel into the plenum during core blowdown. The concern was that the vaporization of the sodium films by the molten fuel may represent a sufficiently high pressure source to reverse the flow of fuel and drive it back into the molten disrupted core region. Henry, et al. (1976b) performed a set of tests to examine the effects of sodium films on upper plenum injection of fuel. Similar to the thermite freezing tests previously described, a thermite reaction was directed into a 37-pin bundle with sodium films on the pins. The sodium (at $650{ }^{\circ} \mathrm{C}$ ) was drained from the hexcan, and the thermite was ignited. The results of the test with sodium in the bundle essentially were in agreement with the test performed with dry walls. Thermite penetrated half the way into the bundle along the central axis of the bundle. The authors were led to the conclusion that sodium played no major role in determining the behavior and final disposition of the molten thermite and that for this system and flow regime, no pressure driven recompaction should be expected following a hypo- 
thetical core meltdown. Although this conclusion may be valid under the conditions simulated in the experiments, the same questions that were raised about the applicability of thermite freezing tests to transition phase are, likewise, of concern here. It would, therefore, be desirable to investigate the effects of liquid sodium or fuel flow and freezing at lower void fraction and pressure, and in a more representative flow regime.

Currently, a wide variety of freezing models are available to calculate the penetration of molten fuel into axial pin structure, including the bulk freezing, ablation, conduction freezing, distributed heat sink, and thin film models. When compared to the results from non-reactor materials experiments which are more separate effects tests than integral fuel freezing tests, models and corresponding experimental data generally agree well. Data and models of two phase effects as well as simultaneous freezing-melting situations also have been under development. However, when the various models are applied to the analysis of thermite-generated fuel freezing tests, the models only bracket the available data but none seems to offer a comprehensive representation of all the thermite penetration data on its own basis. At this point it appears that the actual physical phenomenon of fuel freezing is probably a composite of all the separate effects previously discussed, a complicated scenario that still defies a verified analytical solution. Presently, distances are best estimated at 50 to $80 \mathrm{~cm}$ into pin structure with approximately 50 to 70 grams of fuel displaced into the bundle (per seven pins). This represents a considerable negative reactivity but does not eliminate that fuel from reentering the molten core at a later time due to melting of the blankets, and strongly suggests core pressurization which could lead to recriticality conditions. It is expected that future TRAN series tests with additional supporting separate effects experiments and analyses will contribute greatly to clarifying the complicated phenomena involved in fuel motion and freezing in axial pin structures during the transition phase. 
○

○ 


\section{TRANSITION PHASE ACCIUENT SEQUENCES}

\subsection{Introduction}

Development of analytical methods for prediction of the initiation phase of the LOF accident has benefited from guidance provided by in-pile integral test programs. Analysis of the transition phase accident sequence has not substantially benefited from such integral experiments. Consequently, hypotheses of the development of the transition phase accident sequence, which begin with initial conditions provided by initiation phase analysis, have been founded upon basic physical principles applied to complex integral phenomena. Guidance has been provided largely by out-of-pile simulation experiments, engineering judgement, and physical intuition. An in-pile experimental program will be required in order to eventually evaluate the hypothesized transition phase accident sequences.

Previous analyses of the transition phase accident sequences, related to the FFTF and CRBR systems, were described in Section 3 of this report. In the discussion of these analyses, various deficiencies in physical models and phenomenology were identified. The objectives of this section are to consider possible transition phase accident sequences, to use mechanistic models based upon the most recent experimental evidence to survey the direction of the accident progression, to identify major uncertainties in the accident progression and to assess their potential impacts.

A fundamental feature of an LMFBR core which is undergoing disruptive processes is the tight coupling between material motions and neutronics characteristics. Analysis of the transition phase, therefore, requires that integral computer codes (e.g., SIMMER, TRANSIT) be employed which compute the neutronic feedback of material relocations. An important feature of these computations is prediction of the energetics involved in any recriticalities. Detailed assessments of the accident sequence using integral computer codes are, however, beyond the scope of this effort. Rather, emphasis is placed on identification of phenomena which would tend to impact on the dynamics of fuel motion and, hence, on possible recriticalities and associated energetics.

Section 5.2 presents a discussion of the transition phase accident sequence. An accident sequence flow chart is presented and various phenomena are discussed which play important roles in influencing the course of events. Quantitative evaluations of various phases of the accident sequence which support the arguments presented in Section 5.2 are found in Appendix A. Section 5.3 summarizes the results of the analysis.

\subsection{Accident Flow Chart and Discussion}

A hypothesized transition phase accident sequence flow chart is presented in Fig. 5.1. It traces the various stages of the accident, highlights the expected major events, and indicates crucial junctions along the accident progression. For discussion purposes, the flow chart has been divided into 

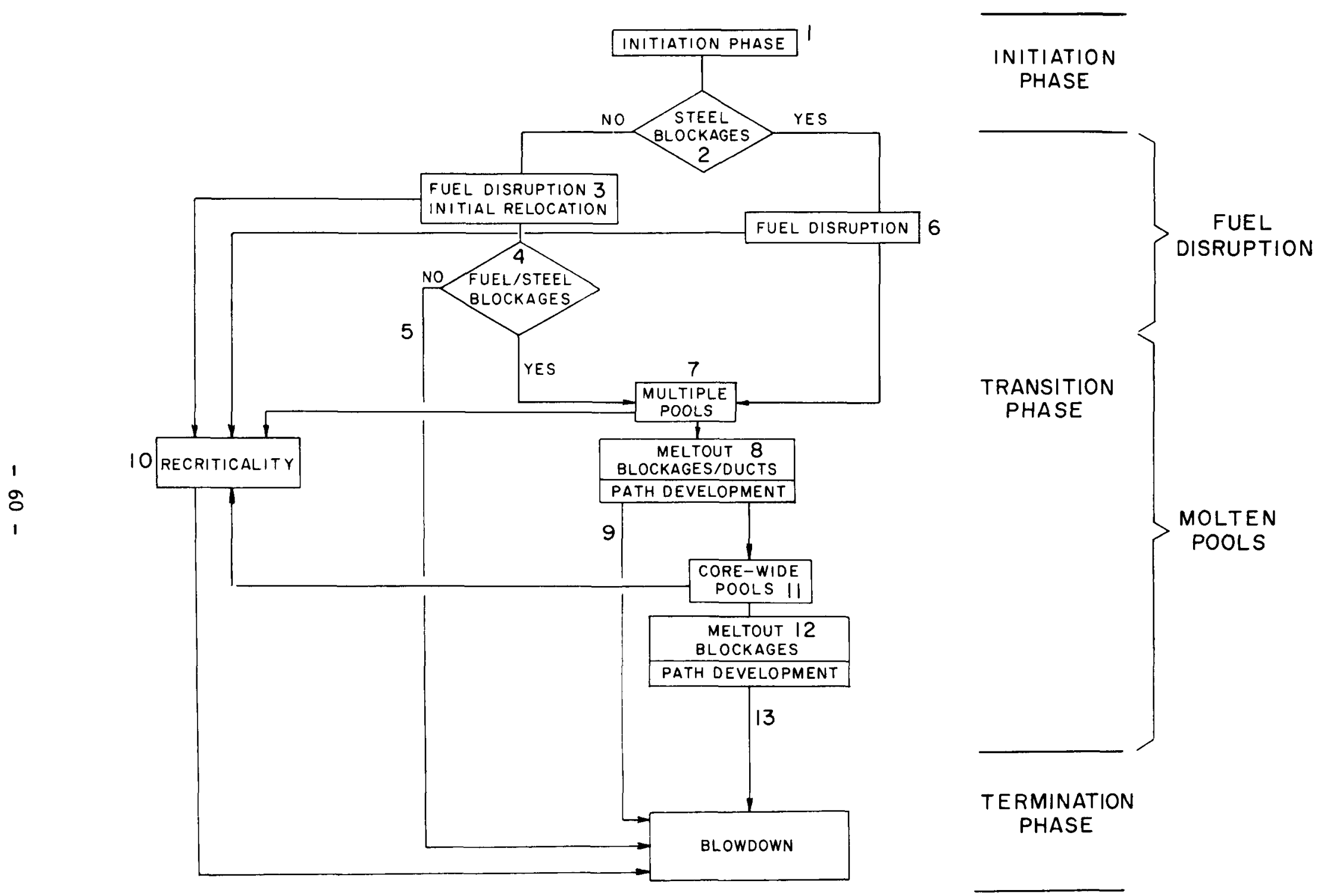

Figure 5.1 - Transition Phase Accident Sequence Paths 
three parts: (i) initiation phase, (ii) transition phase, and (iji) termination phase. The accident may proceed along the paths on the right side of the page to a "benign," nonenergetic blowdown. Alternately, recriticality conditions may develop from any one of a number of circumstances. A number of phenomena are identified below which may lead to recriticality events. It is, however, beyond the scope of this work to estimate the energy releases.

\subsubsection{Initiation Phase}

Analysis of the transition phase requires that conditions at the end of the initiation phase be specified. The details of sodium boiling, voiding and cladding dryout will not be discussed here. It is assumed that the reactor core is devoid of sodium and that clad melting is progressing across the core.

The reactor power level at this juncture in the accident sequence is expected to influence the mode of clad relocation and fuel disruption and relocation. The power level during the ensuing transition phase, however, depends not only on the reactivity history of the initiation phase, but also on the mode and extent of "early" fuel relocation following fuel disruption. Thus, the power level during the transition phase cannot simply be specified without resorting to integral calculations which couple material motions to neutronic behavior. For the purposes of this discussion, however, two cases will be considered. In the first, it is assumed that fuel disruption occurs at "near nominal power" conditions $\left(P / P_{0} \simeq 1\right)$. In the second case, it is assumed that fuel disruption occurs at some "elevated power" $\left(P / P_{0}>10\right)$. Calculations (Jackson, 1974a) suggest that in FFTF the initial fuel disruption would occur at approximately nominal power conditions. In the case of CRBR, on the other hand, it is more likely that fuel disruption would initially occur at a power level significantly above nominal.

Table 5.1 presents the timing of initiation phase events for FFTF and CRBR. The significant point here is that the times available between voiding and clad melting and between clad melting and fuel motion, are seconds at nominal power and tenths of seconds at elevated power levels. These time scales have a bearing on subsequent transition phase phenomena, as discussed below. In the discussion which follows, core-wide incoherencies in events are not considered. The behavior of the system is discussed in terms of a "representative channel."

The flow dynamics of molten cladding may significantly influence the extent of initial fuel relocation upon fuel-pin disruption. If complete steel blockaqes develop (see block 2 in Fig. 5.1) in the cold blanket structure above and below the core, they would temporarily retard the flow of fuel into the pin structure upon pin disruption and prevent early reactivity loss due to axial fuel relocation.

The current state of knowledge of molten steel flow and freezing dynamics is reviewed in Appendix A, Section A.2.1. The evidence suggests that the rate of steel solidification in the cold blanket structure is largely limited by the rate of steel flow to the blankets. Once steel reaches the blankets, 
TABLE 5.1

TIMING OF INITIATION PHASE EVENTS

\begin{tabular}{|c|c|c|}
\hline & $\begin{array}{c}\text { Low Void Coefficient } \\
\text { System (FFTF) } \\
(\mathrm{s})\end{array}$ & $\begin{array}{c}\text { High Void Coefficient } \\
\text { System (CRBR) } \\
\text { (s) }\end{array}$ \\
\hline $\begin{array}{c}\text { Time to sodium boiling* } \\
\text { Time between voiding } \\
\text { and clad melting } \\
\begin{array}{c}\text { Time between clad- } \\
\text { melting and fuel } \\
\text { disruption }\end{array}\end{array}$ & 14 & 10 \\
\hline
\end{tabular}

* Not dependent on void coefficient (Included for completeness) 
freezing is rapid. The extent of steel plug development is a function of (i) the time available for steel flow before fuel disruption, and ( $i i)$ the extent of subassembly spatial incoherency with respect to sodium vapor streaming. Based upon current understanding, it is expected that if the power level is near nominal, thick $(10 \mathrm{~cm})$ blockages would form in the lower axial blanket, and thin (up to several $\mathrm{cm}$ ) blockages would develop in the upper pin structure. These blockages may not be solid, but they are expected to be sufficiently coherent so as to prevent axial relocation of fuel from the core upon pin disruption. The extent of blockages at high power levels during clad melting is less certain, due to the small time between clad melting and fuel disruption. It appears likely that clad relocation would occur, but the spatial coherency of steel blockages is uncertain. In-pile tests with largesize bundles are needed to help evaluate the potential for steel blockages under high power conditions. It is felt that in-pile tests with large-size bundles are needed to substantiate conclusions based upon small-scale simulant experiments and analysis. Until a broader data base is collected, complete steel blockage formation (path 2-6 in Fig. 5.1) should not be precluded from analysis. Its consequences (primarily temporarily retarded fuel relocation upon disruption) should be explored in analysis.

\subsubsection{Transition Phase}

\subsubsection{Fuel Disruption Stage}

Whether or not steel blockages develop, the next stage of the accident takes place as fuel disruption occurs (either block no. 3 or 6 in Fig. 5.1). The core during this phase of the accident is neither fully molten, nor geometrically intact. Uncertainties include the mode(s) of fuel-pin disruption, the extent of fuel dispersal and the state of the material upon disruption, and the physics of transition from fission gas into other modes of fuel dispersion.

It has been suggested (Deitrich, 1977) that at high power (greater than 10 times steady state) fission gas released from fuel as it heats and melts would initially act to disperse the fuel. If sufficient driving pressure is available, then the gas may drive molten fuel into the pin structure region, if steel blockages do not retard the process. The flow of molten fuel into the structure could continue until either the driving pressure is dissipated, or until a flow blockage develops. This optimistic view of fission gas dispersal remains to be demonstrated in future experimental research. If the breakup process is not dispersive, then the paths $3-10$ or $6-10$ in Fig. 5.1 to recriticality would be conceivable. The energetics of recriticality would depend upon the rate of fuel compaction and on the coherence of disruption across the core. If the energetics are insufficient for disassembly, the fuel or steel vapor pressure would eventually drive the molten core material into the pin structure. The extent of penetration of molten fuel, either by fission gas or by steel or fuel vapor, is discussed later in this section.

At steady state power levels, it has been suggested (Deitrich, 1977) that solid fuel swelling would occur initially. Upon melting, the fission gas released could have sufficient time to bubble through the liquid and escape up to the interior of the pin. The gas, then, would not be effective 
in dispersing the fuel, and drainage of fuel may be expected. These arguments remain to be demonstrated in future research into pin failure modes. They suggest, however, that the plausibility of recriticality during the pin disruption stage and the paths 3-10 and 6-10 need to be evaluated. The energetics involved would depend upon core-wide coherency of fuel-pin disruption. If the energetics are mild and disassembly does not occur, then the molten core would continue to heat until fuel or steel vapor pressure supplies the driving force for dispersal. If steel blockages do not exist, then the dispersal process would eject a fuel-steel mixture into the pin structure.

The fission gas dispersal mechanism, if it is at all operative, would dissipate upon separation of the gas. It has been suggested (Fauske, 1975) that steel vaporization would then provide a mechanism which would disperse the fuel. The time scale for development of the steel vapor source is difficult to predict, due to the unknown distribution of fuel and steel. Idealized conduction-limited fuel-steel heat transfer calculations (see Appendix A, Section A.I) suggest that if the steel is at its boiling temperature, steel vaporization sufficient to disperse the fuel may be available. If the steel is subcooled, then several seconds may elapse before the steel begins to vaporize. An understanding of the mechanism involved in development of the steel vapor sources is needed, because of its impact on potential fuel collapse.

The above arguments suggest that fuel collapse may indeed occur during the time period of fuel disruption. The energetics of the resulting recriticalities, however, would be limited due to the incoherency of fuel disruption and to the inherent incoherency of fuel motion provided by the presence of the yet-intact subassembly duct walls. In order to adequately account for these incoherencies in analysis, however, an understanding of the modes and timing of fuel disruption is required, especially under high power conditions, where disruption across the core may take just a fraction of a second.

Fuel motion into the cold axial blanket pin structure is expected during this time period, with either fission gas or steel vapor acting as the driving pressure source (if steel blockages do not impede the flow). The extent of relocation of molten material into the structure before blockage formation is crucial for the ensuing accident analysis, since the potential fuel reactivity loss largely controls the reactivity of the system. The extent of fuel relocation is, however, highly uncertain. Appendix A, Section A.2.2 summarizes the current state of knowledge of fuel flow and freezing dynamics, as applied to molten fuel and steel flow into pin blanket structure. Available thermite data suggest that molten fuel will freeze before penetration through the pin structure region. It is felt, however, that future tests at lower driving pressures ( $10 \mathrm{~atm}$ or less) are required to substantiate this conclusion in application to transition phase conditions. Based upon the existing evidence, however, a direct blowdown of molten fuel to the sodium plenum (path 3-4-5 in Fig. 5.1) is judged un likely.

While the existing data tentatively support the conclusion that molten fuel would not penetrate the entire pin structure upon pin disruption, the extent of penetration before blockage formation is highly uncertain. The mechanisms of molten fuel flow and freezing in channels with melting are not yet understood. At present, therefore, the uncertainties in fuel penetration 
into the blankets must be bracketed in transition phase analyses. Further research is required in order to narrow the uncertainties in fuel relocation to the blanket structures.

\subsubsection{Molten Pool Development - Multiple Pools Stage}

It is likely, as discussed above, that either steel or fuel-steel blockages would prevent blowdown of the molten core to the sodium plena upon pin disruption. As summarized in Table 5.2 under conditions of 1 ow power at the time of fuel disruption, thick coherent lower steel blockages and thinner upper blockages are likely. In this case, upward flow and relocation past incoherent steel blockages is feasible. In the case of high power at disruption, the appearance of coherent steel blockages is not certain. Fuel relocation in both upward and downward directions may occur, until blockages develop. These blockages would temporarily entrap mixtures of molten fuel and steel within initially intact subassembly duct walls (see block no. 7 in Fig. 5.1). The mixtures would be confined axially by the blockages. The major distinction between path 2-3-4-7 (fuel-steel blockages) and path 2-6-7 (steel blockages) is that the presence of steel blockages inhibits the flow of molten fuel upon pin disruption. Consequently, the molten pools which are bounded by steel blockages would contain larger inventories of fuel within the original core volume. Little reactivity loss due to axial fuel relocation would be possible. In the case of fuel-steel blockages, some fuel relocation into the blanket structures would occur before the blockages develop. Since the extent of fuel relocation is uncertain, also uncertain are: (i) the mass of fuel relocated, ( $i i)$ the associated reactivity loss, and ( $i i j$ ) the quantity of fuel still free to move within the molten pools. Analysis of the dynamics of the multiple, subassembly-scale pools requires that research be directed toward reduction of the uncertainty in the extent of fuel relocation prior to plugging.

Following blockage formation, molten pools would be confined within subassembly walls. The steel would be boiling and the boiling fuel-steel mixture would transfer energy to all bounding walls, radially, as well as axially. Hence, melting attacks on the surrounding structure would ensue, growth of the molten core region would take place, and individual subassembly pools would grow larger. Analysis of this phase of the accident requires understanding the dynamics of pool behavior for small, subassembly scale pools, and for progressively larger size systems. During the early portion of this phase of the accident the duct walls would be intact. Later on, steel meltin would occur. This process must be accounted for in analysis of the flow and boiling dynamics. The potential for pool collapse and the rate of collapse must be evaluated.

Boiling pool collapse during this phase of the accident would occur if the vaporization could not be sustained as a result of a number of possible mechanisms: (i) excessive heat losses, ( $i$ ) heat transfer to cold molten steel entering the pool, ( $\left.i i_{i}\right)$ transient sensible heating due to pressurization, (iv) sudden external overpressurization, and (v) fall-in of cold structural material. The first two of the above mechanisms are considered briefly here. Scoping energy balances were performed on single-subassembly boiling pools, first for the case of nonmelting duct walls and second, estimates were 
TABLE 5.2

COMPARISUN OF TRANSITION PHASE EVENTS UNDER LOW AND HIGH POWER CONDITIONS

\begin{tabular}{|c|c|c|}
\hline & Low Power & High Power \\
\hline $\begin{array}{l}\text { Power at Beginning of } \\
\text { Transition Phase }\left(P / P_{0}\right)\end{array}$ & 1 & $>10$ \\
\hline Fuel Disruption Mode & $\begin{array}{l}\text { uncertain } \\
\text { swelling/draining } \\
\text { slumping favored }\end{array}$ & $\begin{array}{l}\text { uncertain } \\
\text { trothing/chunk break- } \\
\text { up favored }\end{array}$ \\
\hline $\begin{array}{l}\text { Time for Core-Wide } \\
\text { Di sruption }\end{array}$ & seconds & $<1$ second \\
\hline Steel Blockages & $\begin{array}{l}\text { likely } \\
\text { thick coherent lower } \\
\text { thin upper }\end{array}$ & less likely \\
\hline Fuel/Steel Blockage & likely & likely \\
\hline $\begin{array}{l}\text { Initial Mass Molten Fuel } \\
\text { in Subassembly Pools }\end{array}$ & $\begin{array}{l}\text { more than high } \\
\text { power case }\end{array}$ & $\begin{array}{l}\text { less than low } \\
\text { power case }\end{array}$ \\
\hline
\end{tabular}


made for the impact of cold duct wall melt-in. These calculations are discussed in Appendix A, Section A.5. Results are described below.

In the case of early pool behavior when duct steel would not be melting into the pool, results show that at decay power, heat losses are predominantly radial. The uncertainty in boiling pool heat transfer behavior precludes a firm conclusion about net energy available for vaporization. If fuel crusts do not exist along the walls of the assembly, the heat loss rates would be so large that no net energy would be available for vaporization. If crusts are stable then calculations suggest that single assembly pools would sustain a net heat loss and vaporization would not be possible. For seven-subassembly pools the uncertainties in boundary heat losses preclude a clear determination of whether vapor production would occur. The uncertainties in pool heat transfer rates must be reduced in order to substantiate pool boilup or collapse under decay heating conditions with no steel melt-in. When, however, duct wall melt-in supplies subcooled steel to subassembly-steel pools, calculations predict that the molten steel would act as an efficient heat sink, and would absorb enough energy to lead to pool collapse. This conclusion is based upon an idealized model of steel melt-in and heat transfer to the boiling mixture. Analytical and experimental development is required in this area of phenomenology to study the basic mechanisms and to enable prediction of pool collapse rates. The above arguments suggest that since pool collapse is likely during duct wall melt-in at decay power levels, recriticality is conceivable during this phase of the accident (path 7-10 in Fig. 5.1). The energetics would depend upon the rate of collapse of individual pools and upon the coherence of collapse across the core.

At full-power conditions $\left(P / P_{0}=1\right)$, the subassembly energy balance calculations of Section 5.3 .5 suggest that if the fuel crusts are stable, then in the absence of wall melt-in, net energy is available for vaporization. The pool is likely to boil, but pressurization effects may limit the vaporization rates. The extent of fuel dispersal then would depend on the vapor generation rate and distribution and on the vapor-liquid slip dynamics. When, later in the pool development, duct wall melt-in occurs at full power, the idealized melt-in model leads to no clear conclusion. The range of uncertainty in heat flux brackets both net heat loss (void collapse) and net heat generation (with vapor generation and boilup).

Under high power level conditions $\left(P / P_{0} \sim 10\right)$, the single-subassembly energy balance suggests that energy would be available for vaporization if stable fuel crusts exist, even during duct wall melt-through. The extent of boilup would depend upon the pressurization rate. Under high power conditions, however, the fuel crust would be submillimeter in thickness. Their stability is subject to doubt.

As the accident progresses through the duct wall melt-out stage, the molten pools would grow and decrease in number. Calculations described in Appendix A, Section A.4 indicate that duct wall melt-through would occur in roughly 10 seconds at decay power levels if fuel crusts are stable, and in a fraction of a second in the absence of crusts. At high power, duct wall melt-through would occur in a few seconds or 1ess. As the pools grow in size, the pool energy balance shifts towards net vaporization and conditions become more favorable to boil-up. The extent of boil-up, however, would depend on the effects of sensible heating. 
Melting of axial blockages would accompany radial growth of the molten pools. The melt-out time for fuel-steel blockages depends upon the composition and subcooling of the blockage prior to remelting. Calculations indicate that at decay power, melt-out of a $10 \mathrm{~cm}$ blockage could occur in approximately 10 seconds for a pure fuel blockage. Up to several tens of seconds would be required for a highly subcooled fuel-steel blockage. Upon melt-out of the upper plug, the remelted fuel would reenter the boiling pool, possibly along with blanket pellets. Open passages would then again be available for fuel ejection. Blockage development may occur again. The upper pin structure has a length of about $1.5 \mathrm{~m}$. Available thermite data (for high pressure fuel ejection) suggest that molten fuel penetration into the pin structure would be in the range of tens of $\mathrm{cm}$. It is likely, therefore, that several cycles of fuel ejection, freezing and remelting would occur before molten fuel would be ejected to the upper plenum. Therefore, the core melt could be contained by blockages for approximately a minute or a few minutes before blowdown to the upper plenum could occur.

It appears, from the above considerations, that a whole-core molten pool would develop before blowdown of large quantities of fuel to the plenum could occur.

\subsubsection{Molten Pool Development - Core-Wide Pool Stage}

As the molten pools grow radially to core-wide scale, fuel motion would tend towards greater coherence. In addition, reactivity effects may be significant, depending on core design. For the homogeneous CRBR core, mixing of fuel from inner and outer enrichment zones would lead to as much as $\$ 14$ worth of reactivity insertion.

The extent of fuel penetration into the axial blankets would be significant in determining the reactivity and power history during this phase of the accident. Figure 5.2 shows the results of a series of CRBR-related criticality calculations (Ludewig, 1979) based upon (i) homogeneously mixed inner and outer enrichment zones, ( $i i)$ material at $3100 \mathrm{~K}$, ( $i i_{i}$ ) control elements mixed with steel and fuel, and (iv) blanket and fission gas plenum structure are intact. The core material is assumed to be homogeneously distributed over a volume which is composed of the original core region and the space between pins in the upper and lower structures. The extent of penetration into the structure is the abscissa in Fig. 5.2. The results indicate that subcriticality could be achieved if fuel is ejected roughly $0.25 \mathrm{~m}$ into each of the upper and lower structures and if the boiling processes keep the fuel uniformly distributed. These calculations, however, also indicate that the system in these configurations is sensitive to relatively small compaction rates. Sensitivities of approximately $\$ 1 / \mathrm{cm}$ are indicated by these results, implying that core-wide coherent motions of only tens of centimeters per second can lead to significant ramp rates. Recently reported SIMMER (Boh1, 1979) calculations have demonstrated strong coupling between whole-core fluid motions and neutronic characteristics. It was speculated that three-dimensional calculations would show that coherent behavior is not as severe as indicated by two-dimensional models. Mechanisms which may mitigate coherent whole-core fluid motions need to be identified. 


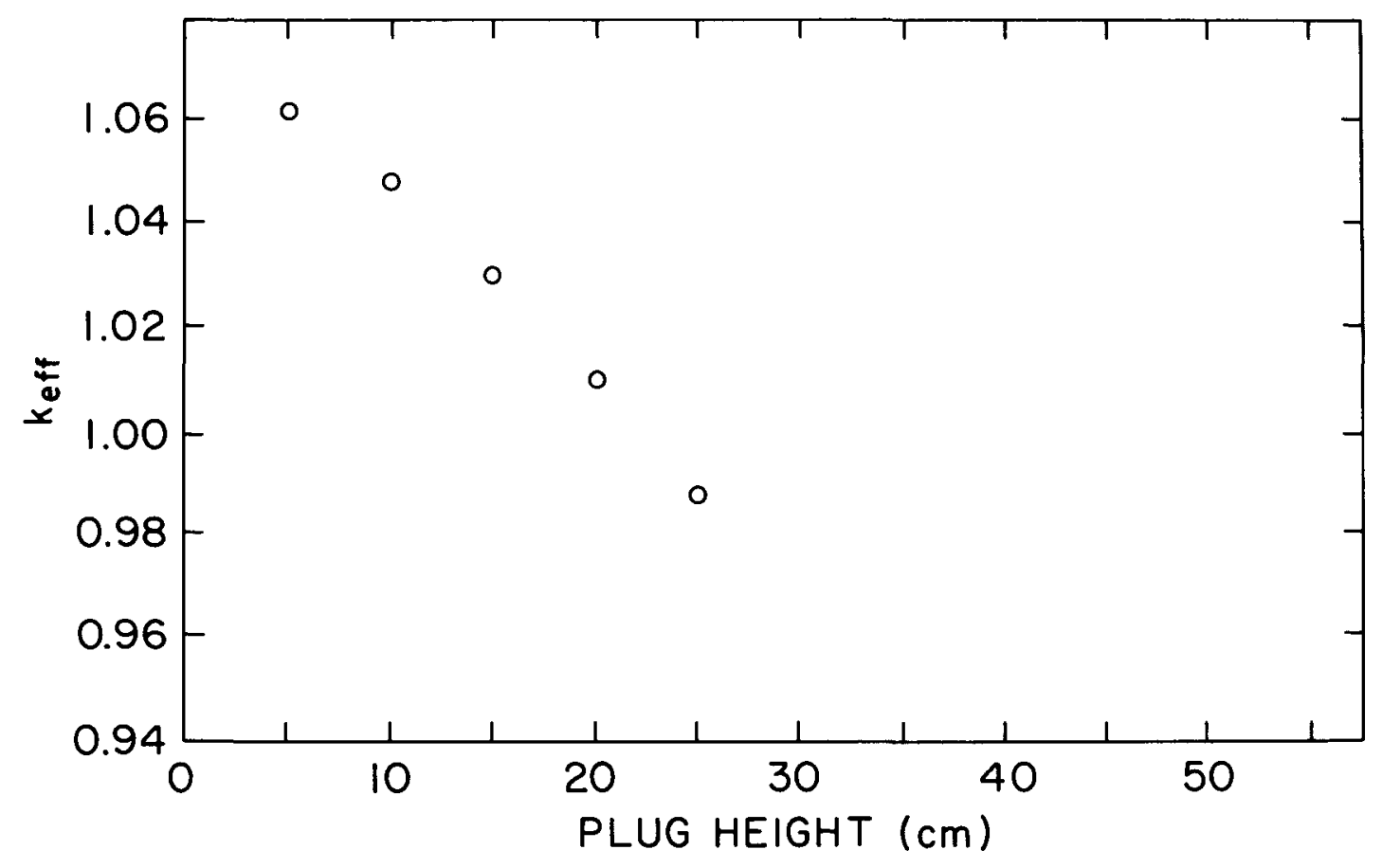

Figure 5.2 - Disrupted Core Criticality Calculation Results (CRBR) 
During the whole-core period of the transition phase sequence, axial blanket structure would likely fall into the underlying pool, together with frozen blockages. The potential exists for mitigation of neutronics events by the blanket material, but is not clear that the entry of the blanket structure would occur early enough to act as a mitigating mechanism.

Energy balances of closed, whole-core pools are described in Appendix A, Section A.6. It is shown that the system would likely be pressurizing and that the magnitude of axial heat sinks would determine the extent of boilup. Quasi-steady calculation results indicate that if steel condensation surfaces are available, then pools can potentially boil up to the limits of the initially available volume, fixed by the axial blockages. The effects of noncondensables and the possibility of fuel liquid films blanketing the upper surfaces precludes determination of the magnitude of condensation. It is not clear, therefore, that the molten pool can be kept fully boiled up to the limits of the core volume. The potential for recriticalities due to pool subsidence cannot be ruled out at this point. It would depend upon the extent of fuel penetration into the blanket structures, the quantity of blanket material mixed in with the pool and the distribution of molten fuel within the available core region occupied by the boiling fuel-steel mixture.

While the potential for recriticality during this phase of accident exists, the rate of fuel compaction has not been considered in this work. Methods for bounding the collapse rates should be developed and evaluated experimentally.

\subsubsection{Termination Phase}

During the whole-core pool stage of the accident, relief paths to the sodium plena would be developed. The molten core components would then be driven by steel or fuel vapor pressure into the sodium plena. A major objective of termination phase analys is is prediction of the rate of core material transport to the upper and lower plena. This calculation would provide the initial conditions for post-accident heat removal evaluations.

Calculations (Kazimi, et al., 1975) indicate that upon development of a subassembly-size relief path to the upper plenum in the CRBR, the molten core would blow down to the plenum in a matter of seconds. This model assumed a homogeneous flow of the two-phase core material through the opening. Recent experimental evidence (Henry, et al., 1980) suggests that vapor-liquid slip effects could be significant, and that a significant fraction of the core material would remain in the core upon completion of the blowdown. The final distribution of core materials at the termination of the transition phase accident progression is, therefore, still an open issue requiring further work.

\subsection{Summary}

The major conclusion suggested by this scoping survey of the transition phase accident sequence is that the concept of "fuel dispersal" cannot be relied upon to rule out the possibility of recriticalities during this stage of 
the accident. The potential for fuel dispersal immediately following fuel disruption to a subcritical configuration has been greatly overestimated in prior transition phase analyses. On the other hand, this work has not attempted to bound the energetics associated with possible recriticality circumstances. It should not be concluded, therefore, that containment-threatening energetics would result from transition phase recriticalities. Rather, this work does suggest that future analytical and experimental research should be directed towards identification of collapse mechanisms and bounding of associated energetics.

The above conclusion is based upon the following major factors:

(i) Experimental evidence developed recently indicates the likelihood that molten fuel would not penetrate the entire pin structure region, even if prior steel blockages did not exist. Blockages may develop which would prevent fuel dispersal to the sodium plenum and early accident temination.

(ii) Fuel dispersal by boil-up of molten fuel by steel vaporization is limited by

(a) the geometry imposed by axial blockages,

(b) sensible heating (pressurization) effects,

(c) boundary heat losses,

(d) nonequilibrium vaporization,

(e) heat transfer to cold steel melted into the pools from the boundaries,

(f) flow regime limitations.

(iii) Fuel disruption has not been shown to be inherently dispersive. The modes of pin disruption are not understood, and the efficiency of fission gas in dispersing fuel is uncertain.

As a result of (i) molten fuel and steel would remain temporarily entrapped in the core region. Molten pools of subassembly scale would grow to whole-core pools. During this process of pool growth, several mechanisms of pool collapse are conceivable and recriticality could occur. The accident progresses from a situation of incoherent fuel motion, imposed by the presence of subassembly duct walls, to progressively greater potential coherence. It appears that the possibility for significant energetics increases as the accident progresses towards the whole-core pool configuration.

Our state of knowledge of the major transition phase phenomenology is incomplete. While the evidence from thermite fuel freezing tests suggests that blockages would develop, the mechanisms are not understood, inconsistencies in interpretation of various experiments are apparent, and uncertainties in the extent of fuel flow prior to blockage development are great. The limitations on the potential for fuel dispersal by boiling steel have been sug- 
gested by only a limited number of experimental studies. Much of the information developed thus far is based upon analytical arguments. The efficiency of fission gas as a dispersal mechanism under transition phase circumstances has not been demonstrated, and a window between fuel disruption and steel vaporization may exist during which fuel collapse may occur. These uncertainties notwithstanding, the thrust of available information is that upon fuel disruption, the molten fuel would not immediately flow to a permanently subcritical configuration. Growing molten pools of fuel and steel are likely to develop and exist until passageways to the sodium plena are developed. During this time, a number of modes of fuel compaction are conceivable. Future work should be directed toward bounding the compaction rates based upon mechanistic modeling and supporting experiments. 


\section{ASSESSMENT OF RESEARCH NEEDS AND PRIORITIES}

In view of the present state of the art of transition phase technology (detailed in Chapter 4) and the various factors affecting the progression of events in an unprotected loss-of-flow accident (detailed in Chapter 5), several areas of further research needs can be identified. The essential areas for further research to define the initial conditions of the transition phase are:

6.1.1 Sodium Voiding Dynamics in Multi-Channels

6.1.2 Clad Relocation Dynamics

6.1.3 Fuel Dispersal Modes

The essential areas for further research to accurately describe the core material behavior during the transition phase are:

6.2.1 Solidification of Fuel-Steel in Pin Bundles

6.2.2 Multi-Component (Fuel-Steel) Pool Thermal and Hydraulic Characteristics

6.2.3 Boiling Pool Collapse Mechanisms

The termination of the accident can be better defined by further investigation of:

\subsubsection{Fuel Two-Phase Blowdown Through Pin Bundles}

A summation of the work needed and issues involved in each of these areas is given in the following paragraphs. The priority level of the areas is given in Table 6.1 .

\subsection{Initial Conditions of the Transition Phase}

\subsubsection{Sodium Voiding Dynamics in Multi-Channels}

Because the presence of sodium in the core at the time of fuel pin failure can substantially increase the potential for mechanical energy generation, an accurate estimate of the rate of sodium voiding from the subassemblies is important. As the LMFBR core designs move to the heterogeneous concepts, better capability to predict the multi-dimensionality of the voiding pattern (incoherencies) becomes important for the large cores. (The large cores will potentially have a high positive net worth of sodium voiding.) Work on models and codes is now in progress at ANL (COMMIX) and MIT (THERMIT). Coupling of these codes to neutronic feedback will be needed. Experimental investigation of voiding pattern under nonsymmetric assembly boundary conditions (to reflect presence of adjacent cold blanket assemblies) 
TABLE 6.1

SUMMARY OF FURTHER RESEARCH NEEDS

\begin{tabular}{|c|c|c|c|c|}
\hline Areas of Significance & Experimental Needs & Issues Involved & Priority & $\begin{array}{c}\text { Role } \\
\text { For Simulant } \\
\text { Expts. }\end{array}$ \\
\hline $\begin{array}{l}\text { 6.1 } \frac{\text { Initial Condition }}{\text { 6.1.1 Sodium Boiling }} \\
\text { Dynamics in Multi- } \\
\text { Channels }\end{array}$ & $\begin{array}{l}\text { Verification of incoherency } \\
\text { effects due to internal } \\
\text { blankets adjacent to the } \\
\text { boiling subassembly }\end{array}$ & $\begin{array}{l}\text { The presence of sodium } \\
\text { in assemblies that enter } \\
\text { in a transient overpower } \\
\text { after Na flow decay. } \\
\text { results in huqe reactivity } \\
\text { additions }\end{array}$ & Low & No \\
\hline $\begin{array}{l}\text { 6.1.2 } \mathrm{Cl} \text { ad Relocation } \\
\text { Dynamics }\end{array}$ & $\begin{array}{l}\text { Multipin clad relocation } \\
\text { experiments with high } \\
\text { power rating under inlet } \\
\text { pressure conditions }\end{array}$ & $\begin{array}{l}\text { For large cores, the addi- } \\
\text { tion of reactivity due to } \\
\text { steel removal from core } \\
\text { may lead to prompt critical } \\
\text { conditions. However, if } \\
\text { fuel melting tollows clad } \\
\text { melting by a fraction of a } \\
\text { second, the relocation } \\
\text { will be minimum }\end{array}$ & Low & No \\
\hline $\begin{array}{l}\text { 6.1.3 Fuel Dispersal } \\
\text { Modes }\end{array}$ & $\begin{array}{l}\text { In-pile disruption tests } \\
\text { with variable power } \\
\text { histories and burnup condi- } \\
\text { tions under loss-of-coolant } \\
\text { flow conditions }\end{array}$ & $\begin{array}{l}\text { If tuel slumping can be } \\
\text { precluded, the potential } \\
\text { for energetic disassembly } \\
\text { following fuel disruption } \\
\text { is reduced. } \\
\text { Fuel and steel vapor role } \\
\text { in initial fuel motion } \\
\text { need to be quantified }\end{array}$ & $\mathrm{High}$ & No \\
\hline $\begin{array}{l}\text { 6.2 } \text { Transition Phase } \\
\text { 6.2.1 Sol idification of } \\
\text { Fuel-Steel In Pin } \\
\text { Bundles }\end{array}$ & $\begin{array}{l}\text { Solidification of fuel in } \\
\text { steel pin structures for } \\
\text { low ( }-5 \mathrm{~atm}) \text { driving pres- } \\
\text { sure conditions and for } \\
\text { controlled void fraction } \\
\text { in the flow. Separate } \\
\text { effect tests of wall } \\
\text { melting, crust stability } \\
\text { and void effects }\end{array}$ & $\begin{array}{l}\text { Steel wall melt entrain- } \\
\text { ment and void fraction } \\
\text { content are two proposed } \\
\text { mechanisms for limiting } \\
\text { the penetration length of } \\
\text { fuel ejected into struc- } \\
\text { tures. This limitation } \\
\text { leads to a much higher } \\
\text { potential for recriti- } \\
\text { cality during transition } \\
\text { phase }\end{array}$ & High & $\begin{array}{c}\text { Yes } \\
\text { (tor separate } \\
\text { effects) }\end{array}$ \\
\hline
\end{tabular}


TABLE 6.1 (Continued)

\begin{tabular}{|c|c|c|c|c|}
\hline $\begin{array}{l}\text { 6.2.2 Mult i-Component } \\
\text { (Fuel Steel) } \\
\text { Pool Thermal } \\
\text { and Hydrodynamic } \\
\text { Chracteristics }\end{array}$ & $\begin{array}{l}\text { Several phenomena need to } \\
\text { be quantified: } \\
\text { 1. Heat transfer from } \\
\text { a two-component } \\
\text { system to the } \\
\text { boundaries } \\
\text { 2. The effect of } \\
\text { melting boundary } \\
\text { on heat transfer; } \\
\text { axially upwards and } \\
\text { laterally sideward } \\
\text { 3. Transient behavior } \\
\text { under conditions of } \\
\text { cold component addi- } \\
\text { tion to pool } \\
\text { 4. Heat transfer be- } \\
\text { tween two components } \\
\text { 5. Crust stability at } \\
\text { boundaries } \\
\text { 6. Effect of closed } \\
\text { pool conditions or } \\
\text { void distributions }\end{array}$ & $\begin{array}{l}\text { Net vapor generation } \\
\text { rate within the pool is } \\
\text { required to sustain a } \\
\text { boiled-up pool. The } \\
\text { vapor generation rate } \\
\text { will depend on the heat } \\
\text { transfer rate from pool to } \\
\text { boundaries and under non- } \\
\text { equilibrium conditions, } \\
\text { trom fuel to steel. If } \\
\text { the vapor generation is } \\
\text { pronibited by any of the } \\
\text { separate effects, recriti- } \\
\text { cality will result }\end{array}$ & High & Yes \\
\hline $\begin{aligned} 6.2 .3 & \text { Boiling Pool } \\
& \text { Collapse Mechanisms }\end{aligned}$ & $\begin{array}{l}\text { Scoping studies are needed to } \\
\text { define the rate at which a } \\
\text { boiling pool can be collapsed } \\
\text { under pressure transients } \\
\text { the influence of the rate of } \\
\text { pressure change on the void- } \\
\text { ing pattern. Noncoherency } \\
\text { effects in pools, both for } \\
\text { boiling up and collapsing. } \\
\text { Single component and two- } \\
\text { component fluids are to be } \\
\text { tested }\end{array}$ & $\begin{array}{l}\text { The response of a boiling } \\
\text { pool to a pressure transient } \\
\text { has been suggested to be } \\
\text { limited by bubble transport } \\
\text { rate. If consideration also } \\
\text { occurs, the pool collapse } \\
\text { may be fast, and hence } \\
\text { the neutronic response may } \\
\text { lead to large power bursts. } \\
\text { Noncoherent pool behavior is } \\
\text { a limiting factor that needs } \\
\text { to be scoped in simple stu- } \\
\text { dies }\end{array}$ & Medi um & Yes \\
\hline
\end{tabular}


TABLE 6.1 (Continued)

\begin{tabular}{|c|c|c|c|c|}
\hline $\begin{aligned} 6.3 .1 & \text { Termination Phase } \\
6.3 .1 & \text { Fue1 Two-Phase } \\
& \text { Bl owd own Through } \\
& \text { Fuel Pin Bundles }\end{aligned}$ & $\begin{array}{l}\text { Experiments on phase } \\
\text { separation during blow- } \\
\text { down within a pin bundle } \\
\text { geometry with wire wraps } \\
\text { are needed. Both high } \\
\text { pressure and low pressure } \\
\text { driving conditions are to } \\
\text { be tested }\end{array}$ & $\begin{array}{l}\text { The rapidity and extent } \\
\text { of fuel removal from the } \\
\text { core through the structures } \\
\text { above the core is a control- } \\
\text { ling factor in determining } \\
\text { the degree to which neutronic } \\
\text { shutdown will be established } \\
\text { following the blowd own }\end{array}$ & Low & Yes \\
\hline
\end{tabular}


is needed. It is expected that the amount of sodium in the optimally designed heterogeneous core at the time of gross fuel failure will be less than what is predicted by the SAS3A calculation for the CRBR homogeneous core.

\subsubsection{Clad Relocation Dynamics}

Since clad motion reactivity is a significant contribution to the severity of the LOF induced power transient, clad relocation should be properiy modeled. All analyses and experiments to date indicate that the clad motion is not expected to be coherent. In low void coefficient cores, significant clad relocation and blockage formation at the core extremities will take place. Only a short time will exist between clad melting and fuel motion initiation in large void coefficient cores. This will limit the net relocation of clad that may be realized prior to fuel motion. Transient clad relocation experiments with inlet pressure conditions at high levels of power (2-10 times nominal power) are lacking. These experiments will be needed to confirm the expected behavior. The range of conditions under which substantial clad motion may precede fuel pin failure should be assessed with the current multi-channel codes for clad motion.

\subsubsection{Fuel Dispersal Modes}

For a large core, it is expected that fuel motion will follow clad motion by a fraction of a second. Therefore, at the time of initiation of fuel motion, all the fuel will be in contact with the clad. Current evidence suggests that at power levels of the order of ten times the nominal power level, the initial fuel motion will be dispersive (see Chapter 2). This is the case expected (from LOF analyses of CRBR) for intermediate and large cores. Based on fuel-to-steel heat transfer by conduction, it can be shown that if the steel temperature is at its boiling point, steel vaporization may be rapid enough to govern fuel motion within tens of milliseconds. If the steel temperature is below its boiling point, steel vapor generation may take an additional half a second to start. If fuel-to-steel heat transfer is assumed more efficient due to convective effects, less time would be required to generate steel vapor. Thus, if dispersive fuel motion is achieved initially by fission gas or fuel vapor effect, it is expected that steel vapor generation will sustain the dispersive motion within one second. This fuel-to-steel heat transfer will not cause fuel temperature drop below the steel boiling point at power levels near nominal power. At decay power levels, cold steel may lead to fuel collapse.

The above discussion leads to the conclusion that further understanding in the following areas is important:

(i) Initial fuel disruption modes need to be better understood.

(ii) Fuel-to-steel heat transfer, including transient effects when fuel dispersal is initiated with the cladding still surrounding the fuel pellets. 
Experimental investigation of the above discussed two areas is of a nature that necessitates in-pile experiments. The voiding dynamics and fuel dispersal modes are of high priority. The area of clad relocation dynamics is of a low priority.

\subsection{Material Behavior During the Transition Phase \\ 6.2.1 Solidification of Fuel-Steel in Pin Bundles}

The ability of the molten core materials to penetrate through the above core pin structure is a key question with regard to achievement of a shutdown condition in the reactor core following the loss-of-flow accident. Should the materials readily penetrate through the structure, the possibility exists for early shutdown. The evidence to date from fuel and thermite freezing experiments and non-reactor material experiments is that considerable molten fuel and steel may be removed from the core but not penetrate through the upper pin structure. The mechanism for solidification is not clearly understood. Modeling of the thermite experiments on the basis of single phase indicates that neither conduction controlled solidification nor bulk freezing accurately predicts the ANL results. It can be speculated therefore that the presence of void, wall-melting, and fuel crust stability play important roles in determining the penetrations for the fuel.

Two types of experiments are called for. One kind involves experiments with fuel materials that have a quantifiable range of void fractions, including no voids at all. The other kind of experiment involves development of better understanding of separate effects on the freezing process. Three separate effects can be identified as:

(i) Frozen crust stability

(ii) Wall melting

(iii) Void fraction

The crust stability under various flow and wall conditions needs to be resolved in view of contradictory statements and evidence originating at different laboratories (see Section 4.4). If reactor accident conditions do lead to an unstable fuel crust, the fuel penetrations into the pin bundle structures will be severely more limited than if a stable crust is to isolate the fuel flow from the wall.

The wall melting effect is also important if it would lead to either crust instability or crust gliding on a frictionless surface. The conditions leading to such effects need to be understood.

As for the void fraction effects, BNL experiments with non-reactor materials have indicated that the void leads to a more rapid solidification process. The effect of the void presence on the solidification process in the presence of wall melting should be investigated. The effects of flow driving pressure on the degree of mixing between the solidifying fluid and the melting wall are of particular interest. 


\subsubsection{Multi-Component (Fuel-Steel) Pool Thermal and Hydrodynamic Character- istics}

Thermal and hydrodynamic conditions in a pool of molten fuel and steel that will form in the core under the unprotected LOF condition will influence the stability and/or collapse of the pool, which dictates the reactivity condition in the pool. SIMMER II calculations indicate large neutronic bursts are possible (Bohl, et al., 1979). Therefore, mechanistic models are to be employed in the analyses to reduce the uncertainty margins in the analysis. Particularly, the absence of multi-component boiling pool experiments has led to inclusion of bounding assumptions about pool behavior. Defensible mechanistic analysis of transition phase sequence of events requires that better understanding be established for a number of key phenomena. These phenomena, in most cases, can be easily investigated by non-reactor materials:

(i) Heat transfer from a two-component pool to the boundary. The experiments on single component heat transfer have shown a strong dependence on flow regime. No model was generated for the boundary heat transfer under conditions of a renewable boundary layer as may be the case for a vigorously boiling pool. The effect of the interaction between the two components on the heat transfer at the boundary is needed.

(ii) The effect of the melting boundaries on the heat transfer has not been established. The molten layer will hamper heat transfer at the boundaries unless it was continually removed due to pool turbulence or hydrodynamic instabilities in the molten layer.

(iii) The stability of fuel crust at the boundaries. Such a crust will act to significantly reduce the heat transfer than will otherwise be possible at the pool boundaries. The conditions leading to crust breakup need to be defined.

(iv) The transient pool behavior due to cold component addition needs to be quantified. Thus, the liquid-liquid heat transfer rate between the fuel and steel under various conditions of void fraction and initial steel subcooling needs to be defined. The coherency with which the pool will respond to local introduction of cold liquid also needs to be defined.

(v) Bottling up the pool is expected to lead to significant pressures inside the pool. The effect of this pressurization on pool void distribution (and associated flow regime) needs to be quantified.

\subsubsection{Boiling Pool Collapse Mechanisms}

Mechanisms leading to pool collapse have been discussed in chapter 5 . To date, no experimental information has been generated on the collapse rate of a volume boiling pool. Several theoretical arguments have been presented for a slow rate of pool collapse, including vapor bubble motion and bubble 
condensation rate. However, in general, these arguments have been based on behavior of an adiabatic two-phase system (e.g., air/water) under mildly varying conditions and steady-state conditions. The degree of uncertainty in the behavior has not been quantified. It is concluded that the dynamics of the collapse of volume boiling pools need to be investigated on a scoping basis using simulation fluids.

The investigation of noncoherent pool behavior under local pressure pulses is needed. The influence of the rate of pressure change on the pattern of voiding should be investigated for both single-component and twocomponent systems.

\subsection{Termination Phase}

\subsubsection{Fuel Two-Pnase Blowdown Through Pin Bundles}

The termination of the accident will eventually occur via removal of fuel from the core region through the upper pin bundle structures. The interaction of the structure with the highly voided fuel has yet to be quantified. Particularly, the phase separation that may occur due to droplet impaction on the wall and the resulting resistance to flow should be addressed. Both high and low driving pressures for these tests should be pursued as there is no evidence that transition phase will or will not end via a large neutronic burst. 


\section{SUMMARY AND CONCLUSIONS}

A loss-of-flow accident without scram in a LMFBR would lead to core-wide fuel disruption. If, in the initiation phase of the accident, the reactor is not driven to an early disassembly, then the ensuing accident sequence may be characterized by a more gradual progression of fuel disruption and fuel meltdown. This process could lead to a growing molten core configuration as subassenibly duct walls melt and individual molten "pools" coalesce. This period of fuel disruption and meltdown, accompanied by growth of the molten core region, has been labeled the "transition phase" of the loss-of-flow accident.

The technology of thermal hydraulic aspects of the transition phase accident sequence has been reviewed. In particular:

(i) Previous analyses of the transition phase accident sequence have been reviewed.

(ii) The current understanding of major thermal hydraulic aspects of transition phase phenomenology has been assessed.

(iii) A scoping analysis of the transition phase accident sequence has been presented.

(iv) Major transition phase issues have been defined, and research needs have been identified.

The major conclusions resulting from this technology assessment are presented below, first pertinent to accident analysis and, second, relevant to transition phase phenomenology.

\subsection{Accident Analysis}

- The likelinood that a LOF accident would develop a transition phase accident path is design-dependent. Previous analyses of the LOF accident in the case of FFTF, a low void coefficient system, suggested the likelihood of a transition phase path. The likelihood of a transition phase path for the homogeneous-core CRBR is an unresolved issue.

- Transition phase recriticality events cannot be ruled out on the basis of fuel dispersal immediately following fuel disruption. The mechanisms of fuel-pin disruption are poorly understood. The period of transition from intact geometry to a molten fuel configuration cannot be characterized at this time. Fuel collapse during this period, therefore, cannot be ruled out.

- Early termination of the transition phase accident progression by fuel blowdown to the sodium plena is unlikely. Material freezing in the subassembly blanket structure is the major factor in preventing blowdown. 
- Steel relocation and subsequent blockage formation is likely under low power level conditions, where sufficient time is available. Fuel dispersal would be impeded until the steel blockages melt out. Subsequently, molten fuel and steel would be ejected into the blankets. At high power levels, fuel and steel relocation would occur and nearly simultaneously molten fuel and steel would be ejected into the blankets. In both cases, blockages would likely occur and would impede further fuel relocation. Available evidence suggests that the molten material would not penetrate the entire flow path to the sodium plena. Further relocation would have to await blockage melt-out.

- Entrapped molten pool configurations are likely to exist during portions of the accident sequence. The issue of molten pool compaction during these portions of the accident cannot be avoided. Blockages are likely to confine molten pools of fuel and steel to the core region for some period of time during the accident. These pools would experience several stages:

- Single-subassembly stage, characterized by large heat losses to yet-intact subassembly walls.

- Steel melt-in stage, with potentially large heat transfer to cold molten duct wall steel.

- Large core-wide pools characterized by low surface to volume ratio and relatively low heat losses.

- The transition phase accident path is likely to progress from a stage of spatially incoherent fuel motion, while duct walls are still intact, to that of coherent core-wide fuel motion. Power transients, moreover, can provide a source of core-wide coherency to fuel motion whether or not duct walls are present.

Potentially large quantities of molten fuel would be available within the core region. The potential for coherent core-wide fuel motion implies that recriticality energetics must be carefully considered during this phase of the accident. Estimation of such energetics is beyond the scope of this work.

\subsection{Transition Phase Phenomenology}

- Fuel Relocation and Freezing

Experimental and analytical investigations of the past few years suggest that the mode of molten fluid freezing in pin bundle geometry is dependent upon wall melting conditions. If the walls are non-melting, then the evidence suggests that the rate of molten fluid freezing is limited by conduction heat transfer through the frozen solid layer. It has also been noted that entrained voids and particulates can influence the freezing rate under non-melting wall conditions. 
Under conditions of relting walls expected during the tlow of molten fuel through subassembly pin structure, the freezing rate depends upon whether the frozen solid layer, or crust, is stable or not. If it is stable and effectively insulates the flowing fluid trom the steel heat sink, then the freezing rate is conduction limited, as described abuve. Under these conditions riolten fuel would be expected to penetrate distances exceeding the length of the pin structure.

Siriuldtion experiments using thermite rilxtures suggest that molten fuel would penetrate $20-40 \mathrm{~cm}$ into pin structure flow channels betore treezing terminates the flow. These experiments, moreover, indicate that the driving pressure and mixture void content have little influence on the extent of penetration.

The mechanisms of freezing of molten fuel and steel mixtures within pin structure are not yet understood. A number of matheriatical riodels have been proposed, however. These models, which combine assumptions of unstable fuel crusts and heat transfer from molten tuel directly to molten steel, appear to characterize the thermite data most closely.

Fundamental uncertainties remain:

- the basic mechanisris of molten fuel freezing in blanket structure,

- criteria for fuel crust stability,

- the adequacy of thermite as a molten fuel-steel simulant,

- the effects of suspended particulate and entrained voids,

- the effect of driving pressure,

- the influence of geometry,

- the effect of mass of molten flurd avallable for ejection.

- Dynamics of Volume Borling Pools

- Hydrodynamic Characteristics of One-Component Steady State Systems.

The steady state behavior of single-component volume boiling pools has been studied in a number of simulation experiments. The available evidence suggests:

(1) The pool-average vold behavior of volume boiling systems can be adequately characterized by one-dimensional driftflux models. Avallable data for void distribution do not agree with the same models. 
(ii) The bubbly flow regime is stable to greater vapor velocities (by approximately a factor of four) than predicted by available transition criteria.

(iii) The churn flow regime is the dominant regime at vapor fluxes corresponding to decay heating power levels. Dispersed flow is not to be expected under these conditions.

- Multicomponent, Transient Void Dynamics.

Little information is available on the dynamics of volume boiling multi-component systems under steady state or transient conditions. Unresolved issues include:

(i) distribution of, and possible separation of, the vaporproducing steel from the heat generating fuel,

(ii) interaction of boiling fluid with the entraining cold steel from duct wall melt-in,

(iji) void dynamics models and flow regime transition criteria.

- Boundary Heat Transfer Phenomena.

Correlations for local heat transfer to bounding vertical walls of boiling systems have been developed. The mechanism of heat transfer is flow regime dependent. In bubbly flow, the mechanism has been identified as boundary layer flow driven by bubble rise induced fluid circulation. The correlations, originally developed for post-accident heat removal conditions, must be extrapolated to transition phase conditions. Only limited data for churn-turbulent pools are available, and the heat transfer mechanism is as yet not understood. 


\section{ACKNOWLENGEMENTS}

The authors would like to thank Dr. N. Abuaf for his assistance in the preparation of this report.

Special appreciation is due to Mrs. Nancy Yerry, Ms. Marisa Canner and Mrs. Jean Muller for their skills and patience in typing the initial version of this report. In addition, special appreciation is due to Mrs. Ann Fort, Ms. Linda Hanlon and Mrs. Laura Zaharatos for their skill and patience in preparing this manuscript for final publication. 


\section{REFERENCES}

Angerer, G., "Computation Studies of Cladding Relocation Dynamics During Liquid Metal Fast Breeder Reactor Transient Undercooling Accidents," Nuclear Technology, 36(3), pp. 305-313 (1977).

Angerer, G., and D. Woll, "Simulation of Cladding Relocation in the TREAT Experiment R-5 with the CMOT Code," presented at Specialists Workshop on Predictive Analysis of Material Dynamics in LMFBR Safety Experiments," LA-7938-C, Los Alamos, NM (1979).

Bankoff, S. G. and A. Ganguli, "Crust Behavior in Simultaneous Melting and Freezing on a Submerged Flat Plate," 18th National Heat Transfer Conference, San Diego, CA (1979).

Bari, R. A., et al., "Material Relocation and Recriticality Assessment for the Loss-of-Heat-Sink Accident in the LMFBR," Brookhaven National Laboratory, BNL-NUREG-23432 (1977).

Bel1, C. R., "A Calibration of the SIMMER-II Boilup Capability," Trans. Am. Nucl. Soc., 39, pp. 662-663 (1981).

Bober, M., J. Singer and K. Wagner, "Spectral Reflectivity and Emissivity Measurements of Solid and Liquid $\mathrm{UO}_{2}$ at $458,514.5$, and $647 \mathrm{~nm}$ as a Function of Polarization and Angle of Incidence," KFK 3023 (1980).

Bohl, W. R., et al., "An Analysis of Transient Undercooling and Transient Overpower Accident Without Scram in the Clinch River Breeder Reactor," ANL/RAS-75-29 (1975).

Bohl, W. R., J. E. Cahalan and D. R. Ferguson, "An Analysis of the Unprotected Loss-of-Flow Accident in the Clinch River Breeder Reactor with an Endof-Equilibrium Cycle Core," ANL/RAS-77-15 (1977).

Bohl, W. R., "Some Recriticality Studies with SIMMER I I," Presented at International Meeting on Fast Reactor Safety Technology, Seattle, WA (1979a).

Bohl, W. R., "A SIMMER-II Analysis of the R-7 TREAT Test," presented at Specialists' Workshop on Predictive Analysis of Material Dynamics in LMFBR Safety Experiments, Los Alamos, NM (1979b).

Chawla, T. C., S. H. Chan, R. C. Borg and D. L. Graff, "Heat Transfer From Vertical/Inclined Boundaries of Heat-Generating Boiling Pools Pertaining to Transition Phase and PAHR," ANL/RAS-81-17 (1981).

Chen, W. L., M. Ishii and M. A. Grolmes, "The Parametric Effects of Varied Channel Pressure Drop on the Molten Cladding Motion," ANL-76-84 (1976).

Cheung, F. B. and L. Baker, Jr., "Transient Freezing of Liquids in Tube Flow," Nucl. Sci. Engr., 60, pp. 1-9 (1976). 


\section{REFERENCES (Cont'd)}

Chun, M. H., J. J. Barry, M. S. Kazimi, T. Ginsberg and 0. C. Jones, Jr., "Solidification Dynamics of Flowing Fluids," BNL-NUREG-24616 (1977).

Dhir, V. K., J. N. Castle, I. Catton, W. E. Kastenberg and J. B. Doshi, "Role of Wall Heat Transfer and Other System Variables on Fuel Compaction and Recriticality," Proc. Intern. Meeting Fast Reactor Safety and Related Physics, CONF-761001, pp. 1172-1182 (1976).

Dhir, V. K., J. N. Castle and I. Catton, "Role of Taylor Instability on SubI imation of a Horizontal Slab of Dry Ice," J. Heat Transfer, 99 (3), pp. $411-418(1977)$.

Dickerman, C. E., A. B. Rothman, A. E. Klickman, B. W. Spencer and A. DeVolpi, "Status and Summary of TREAT In-Pile Experiments on LMFBR Response to Hypothetical Core Disruptive Accidents," in Thermal and Hydraulic Aspects of Nuclear Reactor Safety, V. 2, The American Society of Mechanical Engineers (1977).

Deitrich, L. W. and R. W. Ostensen, "An Assessment of Fission Gas Driven Fuel Disruption and Dispersal in a Hypothetical LMFBR Loss-of-Flow Accident," ANL/RAS-77-4 (1977).

DiMonte, M. and T. G. Theofanous, "Cladding Relocation Dynamics: Incoherency Effects," Trans. Am. Nuc1. Soc., 22, p. 405 (1975).

Dukler, A. E. and Y. Taitel, "Flow Regime Transitions for Upward Gas-Liquid Flow: A Preliminary Approach Through Physical Modeling," NUREG-0162 (1977).

Dunn, F. E., et al., "The SAS-3A LMFBR Accident Analysis Computer Code," ANL/RAS-77-15 (1975).

Eisenhawer, S. W., D. 0. Lee, M. L. Corradini, R. W. Ostensen and F. Gonzalez, "A Study of Heat Transfer From a Flowing Liquid to a Melting Wall," Proceedings International Meeting on Fast Reactor Safety Technology, Seattle, WA, pp. 2081-2092 (1979).

Eisenhawer, S. W., D. 0. Lee, M. L. Corradini and R. W. Ostensen, "On the Physics of Fuel Streaming and Freezing in Fast Reactor Core Disruptive Accidents," SAND80-0484 (1981).

Epstein, M., "Transient Behavior of a Volume-Heated Boiling Pool," ASME Winter Meeting, Paper No. 75-WA/HT-31 (1975).

Epstein, M., "The Growth and Decay of a Frozen Layer in Forced Flow," Int. J. Heat Mass Transfer, 19, pp. 1281-1288 (1976a).

Epstein, M., M. A. Grolmes, R. E. Henry and H. K. Fauske, "Transient Freezing of a Flowing Ceramic Fuel in a Steel Channel," Nucl. Sci. Engr., 61, pp. 310-323 (1976b). 


\section{REFERENCES (Cont'd)}

Epstein, M., R. E. Henry, M. A. Grolmes, H. K. Fauske, G. T. Goldfuss, D. J. Quinn and R. L. Roth, "Analytical and Experimental Studies of Transient Fuel Freezing," Proc. Intern. Meeting Fast Reactor Safety and Related Physics, CONF-761001, p. 1788 (1976c).

Epstein, M., "Melting, Boiling, and Freezing: The Transition Phase in Fast Reactor Safety Analysis," in Thermal and Hydraulic Aspects of Nuclear Reactor Safety, Vol. 2, The American Society of Mechanical Engineers (1977a).

Epstein, M., A. Yim and F. B. Cheung, "Freezing-Controlled Penetration of a Saturated Liquid into a Cold Tube," J. Heat Transfer, 99 (2), pp. 233-238 (1977b).

Epstein, M. and G. M. Hauser, "Freezing of an Advancing Tube Flow," J. Heat Transfer, 99 (4), pp. 687-689 (1977c).

Epstein, M., "Stability of a Submerged Frozen Crust," J. Heat Transfer, 99 (4), pp. 527-532 (1977d).

Epstein, M., M. J. Swedish, J. H. Linehan, G. A. Lambert, G. M. Hauser and L. J. Stachyra, "Simultaneous Melting and Freezing in the Impingement Region of a Liquid Jet," ASME Winter Annual Meeting, San Francisco, CA (1978).

Epstein, M., L. J. Stachyra and G. A. Lambert, "Solidification in a Rod Bundle," Trans. Am. Nucl. Soc., 33, pp. 513-514 (1979).

Farahat, M., R. E. Henry and J. Santori, "Fuel Dispersal Experiments with Simulant Fluids," Proc. Intern. Meeting on Fast Reactor Safety and Related Physics, CONF-761001, p. 1707 (1976).

Fauske, H. K., "Boiling Flow Regime Maps in LMFBR HCDA Analysis," Trans. Am. Nuc 1. Soc., 22, pp. 385-386 (1975).

Fauske, H. K., "Liquid Metal Fast Breeder Reactor Safety: An Overview Including Implications of Alternate Fuel Cycles," in Thermal and Hydraulic Aspects of Nuclear Reactor Safety, Vol. 2, The American Society of Mechanical Engineers (1977a).

Fauske, H. K., "Assessment of Accident Energetics in LMFBR Core Disruptive Accidents," Nucl. Engr. and Design, 42, pp. 19-29 (1977b).

Westinghouse-Hanford, "FFTF Final Safety Analysis Report," HEDL-TI-75001, App. A, (1975).

Gabor, J. D., L. Baker, Jr., J. C. Cassulo and G. A. Mansouri, "Heat Transfer from Heat Generating Pools," ASME-AIChE National Heat Transfer Conference, St. Louis, MO (1976). 


\section{REFERENCES (Cont'd)}

Ganguli, A. and S. G. Bankoff, "Crust Behavior in Simultaneous Melting and Freezing on a Submerged Flat Plate," Northwestern University, C00-2554-7 (1978).

Ginsberg, T., "Role of Condensation in Dispersion of Closed Boiling $\mathrm{UO}_{2}$ Systems," Trans. Am. Nuc1. Soc., 26, pp. 363-364 (1977a).

Ginsberg, T., 0. C. Jones, Jr., C. E. Schwarz and J. C. Chen, "Observations of Flow Characteristics of Volume-Heated Boiling Pools," BNL-NUREG-24270 (1977b).

Ginsberg, T., 0. C. Jones, Jr. and J. C. Chen, "Volume-Heated Boiling Pool Flow Behavior and Application to Transition Phase Accident Conditions," BNL-NUREG-24984, ENS/ANS Topical Meeting on Nuclear Power Reactor Safety, Brussels, Belgium (1978).

Ginsberg, T., 0. C. Jones, Jr. and J. C. Chen, "Flow Dynamics of Volume Heated Boiling Pools," ASME Paper No. 79-HT-102, 18th National Heat Transfer Conference, San Diego, CA (1979).

Ginsberg, T., 0. C. Jones, Jr. and J. C. Chen, "Flow Behavior of VolumeHeated Boiling Pools: Implications With Respect to Transition Phase ACcident Conditions", Nuclear Technology, 46 (1979b).

Ginsberg, T., "Gas Injection Simulations of Aspects of Boiling Pool Flow Dynamics and Comparison With Previous Volume Boiling Studies," Trans. Am. Nuc l. Soc., 39, pp. 654-655 (1981).

Greene, G. A., 0. C. Jones, Jr. and C. E. Schwarz, "Thermo-Fluid Mechanics of Volume-Heated Boiling Pools," Third PAHR Information Exchange, Argonne National Laboratory, ANL 78-10 (BNL-NUREG-50759) (1977a).

Greene, G. A., 0. C. Jones, Jr. and M. S. Kazimi, "Effects of Non-Condensable Void Fraction on Freezing of Flowing Fluids," Trans. Am. Nucl. Soc., 27, pp. 546-547 (1977b).

Greene, G. A., 0. C. Jones, Jr., M. S. Kazimi, T. Ginsberg and J. J. Barry, "Analysis and Measurement of Solidification Dynamics of Flowing TwoPhase Non-Condensable Mixtures," Trans. Am. Nucl. Soc., 28, pp. 465-466 (1978a).

Greene, G. A., 0. C. Jones, Jr., W. J. Leonhardt and M. S. Kazimi, "Transient Fuel Solidification and Relocation from Core During Transition Phase Conditions," Trans. Am. Nucl. Soc., 30, pp. 451-452 (1978b).

Greene, G. A., 0. C. Jones, Jr., M. S. Kazimi, J. J. Barry and G. A. Zimmer, "Two-Phase Transient Solidification Dynamics of Flowing Fluids with NonCondensable Vapors," BNL-NUREG-24486R (1978C). 


\section{REFERENCES (Cont'd)}

Greene, G. A., 0. C. Jones, Jr., C. E. Schwarz and N. Abuaf, "Heat Removal Characteristics of Volume-Heated Boiling Pools with Inclined Boundaries," BNL-NUREG-51157 (1979a).

Greene, G. A., 0. C. Jones, Jr., N. Abuaf and C. E. Schwarz, "Heat Removal Characteristics of Volume-Heated Boiling Pools with Inclined Boundaries in Bubbly Flow Regime," ASME Paper No. 79-HT-99, 18th National Heat Transfer Conference, San Di ego, CA (1979b).

Greene, G. A. and S. M. Reilly, "Boiling Inception in Volume-Heated Liquids," Trans. Am. Nucl. Soc., 38, pp. 394-395 (1981).

Gustavson, W. R., J. C. Chen and M. S. Kazimi, "Heat Transfer and Fluid Dynamic Characteristics of Internally Heated Boiling Pools," BNL-NUREG21856 (1977).

Hakim, S. J., "Transit-Hydro: A Code for Analysis of the Transition Phase in LMFBR Accidents," Proc. Intern. Meeting on Fast Reactor Safety Technology, Seattle, WA., pp. 160-170 (1979).

Hayden, N. K., "An Analytical Model of Freezing Liquid Penetration in Tube Flow," Trans. Am. Nucl. Soc., 39, pp. 671-672 (1981).

Henry, R. E., W. C. Jeans, D. J. Quinn and E. A. Spleha, "Cladding Relocation Experiments," Proc. Intern. Meeting on Fast Reactor Safety and Related Physics, Vol. 4, CONF-76100I, pp. 1691-1696 (1976a).

Henry, R. E., G. T. Goldfuss, J. J. Heiberger, D. J. Quinn, R. L. Roth, E. A. Spleha and I. 0. Winsch, "Upper Plenum Injection Tests No. I and No. 2," ANL/RAS-76-4 (1976b).

Henry, R. E. and J. L. Smith, "Blowdown of Boiling Pools with Internal Heat Generation," Proc. Intern. Meeting on Fast Reactor Safety Technology, Seattle, WA, pp. 1776-1785 (1979).

Ishii, M. and M. A. Grolmes, "Inception Criteria for Droplet Entrainment in Two-Phase Concurrent Film Flow," AIChE J., 21, pp. 308-318 (1975).

Ishii, M., W. L. Chen and T. M. Kuzay, "Molten Clad Motion Model for Fast Reactor Loss-of-Flow Accidents," Nuc1. Sci. Engr., 60, p. 424 (1976).

Ishij, M., W. L. Chen and T. M. Kuzay, "Comparison of the Predictions from Multichannel Clad Relocation Model to Available In-Pile Experimental Data," presented at Specialists' Workshop on Predictive Analysis of Material Dynamics in LMFBR Safety Experiments, Los Alamos, NM (1979).

Jackson, J.F., R. W. Ostensen and R. J. Henninger, "Report on the Core Disruptive Phase on an Unprotected Flow-Coastdown Accident in the FTR," ANL/RAS-74-16 (1974a). 


\section{REFERENCES (Cont'd)}

Jackson, J. F., et al., "Trends in LMFBR Hypothetical-Accident Analysis," Proc. of the Fast Reactor Safety Meeting, CONF-740401-P3 (1974b).

Kazimi, M. S., Private Communication (1979).

Kazimi, M. S., R. Gasser and T. Ginsberg, "Preliminary Studies on the Dynamics of Post-Accident Fuel Relocation in the LMFBR," BNL-20334 (1975).

Kim, C. S., R. A. Blomquist, J. Haley, R. Land, J. Fischer, M. G. Chasanov and L. Leibowitz, "Measurement of Thermal Diffusivity of Molten $\mathrm{UO}_{2}$," Proc. Seventh Symposium on Thermal Properties, ASME (1977).

Koontz, F. A., Jr., "Volumetric Boiling: A Fundamental Study of the Phenomena Pertaining to LMFBR Safety," M. Sc. Dissertation, Nuclear Engineering Department, Purdue University (1977).

Kraft, T. E., et al., "Simulation of an Unprotected Loss-of-Flow Accident with a 37-Pin Bundle in the Sodium Loop Safety Facility," presented at ANS Topical Meeting on Fast Reactor Safety Technology, Seattle, WA (1979).

Kutateladze, S. S. and V. N. Moskicheva, "Hydrodynamics of a Two-Component Layer as Related to the Theory of Crises in the Process of Boiling," Sov. Phys. Tech. Phys. 4 (7), 103701040 (1960a).

Kutateladze, S. S. and M. A. Styrikovich, "Hydraulics of Gas-Liquid Systems," Ed., L. A. Vitman, NP-tr-550, Chapter 7 (1960b).

Lee, D. 0., S. W. Eisenhawer, M. L. Corradini and R. W. Ostensen, "Forced Convection Melting Heat Transfer in a Tube for a Two Component System," AIChE Symposium Series, 75, pp. 55-68 (1979).

Leung, J. C. M., G. A. Lambert and L. J. Stachyra, "Transition to Dispersed Flow in a Stagnant Pool With Gas Injection," Trans. Am. Nucl. Soc., 38, pp. 397-399 (1981).

Ludewig, H., Personal Communication, Brookhaven National Laboratory (1978).

Luk, A. C. H., "Simulation of Boiling Pools with Internal Heat Sources by Gas Injection," M. S. Thesis, Northwestern University (1976).

Luk, A. C. H., A. Ganguli and S. G. Bankoff, "Simulation of Boiling Pools with Internal Heat Sources By Gas Injection," Northwestern University Report, C00-2554-6 (1977).

Marrotte, G. and T. G. Theofanous, "Fundamental Aspects of Molten $\mathrm{Clad}$ Relocation," PNE-78-129, Purdue University (1978).

Marrotte, G. and T. G. Theofanous, "Fundamental Aspects of Molten Clad Relocation," Presented at Specialists' Workshop on Predictive Analysis of Material Dynamics in LMFBR Safety Experiments, Los Al amos, NM (1979). 


\section{REFERENCES (Cont'd)}

Martin, F. J., T. Grambihler and G. Hultgren, "FUMO-T: A Fuel Motion Transient Code for Analysis of Fully-Developed LMFBR Transition Phase Conditions," HEDL-TME 78-63, Hanford Engineering Development Laboratory, Rich1 and, WA (1979).

Martin, F. J., "Bottled Transition Phase Analysis - Preliminary Report," HEDL-TME 78-64, Hanford Engineering Development Laboratory, Richland, WA (1980).

McArthur, D. A., S. F. Duliere and D. J. Sasmor, "Post-Test Analysis of TRAN-1 and TRAN-2 Final Fuel Distributions," Trans. Am. Nucl. Soc., 39, pp. 676-678 (1981a).

McArthur, D. A., R. W. Ostensen and N. K. Hayden, "In-Core Transition Phase Fuel Freezing Experiment TRAN-1," Trans. Am. Nucl. Soc., 38, pp. 393-394 (1981b).

McArthur, D. A. and N. K. Hayden, "Preliminary Results of the First Four TRAN Fuel Freezing Experiments," Trans. Am. Nucl. Soc., 41, pp. 381-382 (1982).

Meyer, J. F., L. Lois, J. L. Carter and T. P. Speis, "An Analysis and Evaluation of the $\mathrm{Cl}$ inch River Breeder Reactor Core Disruptive Accident Energetics," NUREG-0122 (1977).

Muraoka, J., R. T. Toyooka and G. 0. Hultgren, "FuMO-A Fuel Motion Code for LMFBR Transition Phase Analys is," HEDL-TME-75-132 (1975).

Orth, K. W., M. Epstein, J. H. Linehan, G. A. Lambert and L. J. Stachyra, "Hydrodynamic Aspects of Volumetric Boiling," Trans. Am. Nucl. Soc., 33, pp. 545-546 (1979).

Orth, K. W., M. Epstein, J. H. Linehand, G. A. Lambert and L. J. Stachyra, "Hydrodynamic Aspects of Volume Boiling," ANL-RAS 80-6 (1980).

Ostensen, R. W. and J. J. Jackson, "Dynamic Behavior of a Partially Molten LMFBR Core," Trans. Am. Nucl. Soc., 18, p. 220 (1974a).

Ostensen, R. W., R. E. Henry, J. F. Jackson, G. T. Goldfuss, W. H. Gunther and N. E. Parker, "Fuel Fl ow and Freezing in the Upper Subassembly Structure Following an LMFBR Disassembly," Trans. Am. Nucl. Soc., 18, pp. 214-215 (1974b).

Ostensen, R. W., R. J. Henninger and J. J. Jackson, "The Transition Phase in LMFBR Hypothetical Accidents," Proc. Intern. Meeting on Fast Reactor Safety and Related Physics, CONF-761001, p. 895 (1976).

Ostensen, R. W., "Effect of Thermal Stress on Oxide Crusts," Trans. Am. Nucl. Soc., 27, p. 662 (1977).

Ostensen, R. W., W. F. Murphy, B. J. Wrona, L. W. Dietrich and J. C. Florek, "Intrusion of Molten Steel into Cracks in Solid Fuel in a TransientUndercooling Accident in a Liquid-Metal Fast Breeder Reactor," Nuclear Technology, 36(2), pp. 200-214 (1977). 


\section{REFERENCES (Cont'd)}

Ostensen, R. W., personal communication (1980).

Petrie, D. J., M. Epstein, J. H. Linehan, G. A. Lambert and L. J. Stachyra, "Solidification in Two-Phase Flow," Trans. Am. Nucl. Soc., 34, pp. 554-556 (1980).

Prather, W. and T. G. Theofanous, Cladding Relocation Dynamics," PNE-76-121, Purdue Univ. (1976).

Sha, W. T., H. M. Domanus, R. C. Schmitt, J. J. Oras and E. I. H. Lin, "COMMIX-1, A Three Dimensional Transient Single Phase Component Computer Program for Thermal-Hydraulic Analysis," ANL-77-96, NUREG-0145 (1978).

Sienicki, J. J. and B. W. Spencer, "A Study of Phenomenological Fuel Freezing Models and Comparison with the Results of Reactor Material Experiments Peformed with Pin Bundles," ANL/RAS 81-29 (1981).

Sienicki, J. J. and B. W. Spencer, "An Extended Material Motion Model for Thermite Fuel Freezing Tests," Trans. Am. Nucl. Soc., 38, pp. 391-392 (1981).

Sienicki, J. J. and B. W. Spencer, "The Effects of Flowing Fuel Particulate on Bulk Freezing Model Predictions," ANL/RAS 82-4 (1982).

Sienicki, J. J. and B. W. Spencer, "Two-Phase Flow Effects on Freezing and Plugging of Molten Fuel," Trans. Am. Nucl. Soc., 38, pp. 392-393 (1981).

Smith, L. L., "SIMMER-II: A Computer Program for LMFBR Disrupted Core Analysis," Los Alamos Scientific Laboratory Report, NUREG/CR-0453, LA-7515-M (1978).

Smith, R. C. and C. R. Bell, "SIMMER-II Simulation of Thermite Freezing and Plugging Experiments," Trans. Am. Nuc1. Soc., 39, pp. 668-670 (1981).

Spencer, B. W., M. A. Grolmes, R. E. Holtz, F. J. Testa and N. A. Kramer, "Summary and Evaluation of R-Series Loss-of-Flow Safety Tests in TREAT," Proc. Intern. Meeting on Fast Reactor Safety and Related Physics, CONF761001 , Vol. 4, pp. 1647-1657 (1976).

Spencer, B. W., R. L. Roth, G. T. Goldfuss and R. W. Henry, Results of Fuel Freezing Tests with Simulated CRBR-Type Fuel Pins," Trans. Am. Nucl. Soc., 30, pp. 446-447 (1978).

Spencer, B. W., G. T. Goldfuss, R. E. Henry, D. J. Quinn and R. L. Roth, "Reactor Material Fuel Freezing Experiments Using Small-Bundle, CRBR-Type Pins," ANL/RAS-79-11 (1979).

Stein, R. P., J. C. Hesson and W. H. Gunther, "Studies of Heat Removal from Heat Generating Boiling Pools," ANS Fast Reactor Safety Conference, CONF740401 , pp. 865-880 (1974). 


\section{REFERENCES (Cont'd)}

Stein, R. P., L. Baker, W. H. Gunther and C. Cook, "Heat Transfer from Heat Generating Molten $\mathrm{UO}_{2}$ : Interpretations of the Available Experimental Data," 18th National Heat Transfer Conference, Paper No. 9-HT-115, San Diego, CA (1979).

Stevenson, M. G., et al., "Report on the Analysis of the Initiating Phase of a Loss-of-Flow (Without Scram) Accident in the FTR," ANL/RAS-74-24 (1974).

Swedish, M. J., M. Epstein, J. H. Linehan, G. A. Lambert, G. M. Hauser and L. J. Stachyra, "Surface Ablation in the Impingement Region of a Liquid Jet," Trans. Am. Nucl. Soc., 28, pp. 446-447 (1978).

Theofanous, T. G., M. DiMonte and P. D. Patel, "Incoherency Effects in $\mathrm{Cl}$ ad Relocation Dynamics for LMFBR CDA Analyses," Nucl. Engr. Design, 36, p. 59 (1976a).

Theofanous, T. G., W. Prather, M. Chen, T. P. Speis and L. Lois, "Cladding Relocation Dynamics - The Physics and Accident Evolution Implications," Proc. Intern. Meeting on Fast Reactor Safety and Related Physics, Vol. 4, CONF-761001, p. 1697 (1976b).

Theofanous, T. G., "Multiphase Transients with Coolant and Core Materials in LMFBR Core Disruptive Accident Energetics Evaluation," NUREG/CR-0224 (1978).

Wallis, G. B., "Some Hydrodynamic Aspects of Two-Phase Flow and Boiling," 1961 Intern. Heat Transfer Conference, Boulder, C0, P. 319 (1961).

Wallis, G. B., One-Dimensional Two-Phase Flow, McGraw-Hill Book Co., New York (1969).

Yim, A., M. Epstein, S. G. Bankoff and G. A. Lambert, "Freezing of a Flowing Liquid Inside a Melting Tube," Trans. Am. Nucl. Soc., 27, pp. 501-502 (1977).

Yim, A., M. Epstein, S. G. Bankoff, G. A. Lambert and G. M. Hauser, "Freezing-Melting Heat Transfer in Tube Flow," Int. J. Heat Mass Transfer, 21 (1978).

Zuber, N. and J. Hench, "Steady-State and Transient Void Fraction of Bubbling Systems and Their Operating Limits: Part I: Steady State Operation," General Electric Report, 62GL100 (1963). 


\section{A.1 Fuel Disruption and Steel Vapor Source Development}

The sequence of transition phase events between the onset of fuel disruption and development of subassembly pools of boiling fuel and steel is highly speculative. The modes of fuel disruption are not known. While the initial fuel dispersal may be driven by fission gas, this mechanism would eventually dissipate. Alternate driving pressures would develop. In the absence of energetic excursions, steel vaporization has been proposed as a potential source of fuel dispersal. If eneryetic dispersion occurs, the fuel vapor provides the driving force for dispersal. What follows is a discussion of the case which would occur in the absence of energetic excursions.

For cores characterized by large void coefficients, fuel motion is expected to follow clad motion by a fraction of a second. It is expected, therefore, that at the time of initiation of fuel motion the clad would be still largely in contact with the fuel. For low void coefficient cores, some clad would be relocated prior to fuel motion. Some steel, however, is still expected to remain in contact with the fuel at the time of disruption. As fuel motion occurs, the fuel and steel eventually mix and lose their well defined geometry. Under these disordered conditions, prediction of the heat transfer from the fuel to the steel, and consequentiy, the onset and rate of steel vaporization becomes tenuous. It is expected, however, that during this time period, the fuel-steel heat transfer would be limited by the interfacial contact area between the fuel and steel and by the conductivity of the fuel.

A lower bound on the fuel-steel heat transfer during this time period was computed assuming that the heat transfer from fuel to steel is identical to its magnitude while the fuel was still intact. Using this assumption, a steel vaporization rate is computed.

The effectiveness of the steel vapor in dispersing the fuel depends on the momentum exchange between the vapor and the molten fuel. The geonetric structure of the components during this stage of the accident is unknown. It is not possible, therefore, to compute the extent of fuel dispersion by the steel vapor with any precision. The approach taken was to assume that the extent of dispersion may be estimated using steady-state void dynamics (see Section 4.2). The steel vaporization rate is computed as the superficial vapor velocity ratio $j_{g_{\infty}} / U_{\infty}$. Figure 4.1 was then used to estimate the steel vapor fraction. This gives an estimate of the extent of dispersion of the fuel by the steel vapor.

The rate of steel vaporization is yiven by

$$
Q_{s}=\frac{(h A)_{f-s}\left(T_{f}-T_{s}\right)}{\left(\rho_{v} h_{f g}\right)_{s}}
$$


and the dimensionless superficial vapor velocity at the top of the molten region is

$$
\frac{j_{g \infty}}{U_{\infty}}=\frac{Q_{S} / A_{F L O W}}{U_{\infty}}
$$

The fuel-steel heat transfer area is taken as the geometrically intact contact area

$$
A_{f S}=\pi D L
$$

The limiting heat transfer coefficient is taken as that of conduction in the fuel estimated by

$$
h_{f s}=\frac{2 k_{f}}{D}
$$

The total flow area is taken as twice the area occupied by the intact fuel. The dimensionless steel vapor flux is then,

$$
\frac{j_{g o}}{U_{\infty}}=\frac{8 k_{f} L\left(T_{f}-T_{s}\right)}{D^{2}\left(\rho_{v} h_{f g}\right)_{s}}
$$

Using selected property values with $D=6 \mathrm{~mm}$ and $L=1 \mathrm{~m}$, the resulting values of $j_{y_{\infty} / U_{\infty}}$ are presented in Table A.1. Comparison of the computed steel vapor flux $j_{g_{\infty}} / U_{\infty}$ with Fig. 4.1 indicates that they are sufficient in magnitude to disperse the molten fuel to void fractions of at least 0.5 . This result was arrived at in spite of assumptions which probably greatly ninimize the computed steel vapor flux.

If the steel is initially subcooled, some time would be required to bring the steel to its saturation temperature. The fuel-steel heat transfer model described above, i.e., limited by conduction in the fuel and the geometrically intact fuel-steel contact area was used to compute the time delay to steel boiling. It is found that if the fuel-steel temperature difference is $100 \mathrm{~K}$, then the rate of steel temperature rise is approximately $25 \mathrm{~K} / \mathrm{s}$. So, if the steel is $100 \mathrm{~K}$ subcooled, then four seconds would be required to bring the steel to its boiling point. This time can obviously be less if the steel is initially closer to the boiling point. The point is that there may be a several-second time delay following fuel melting required to bring the steel to its boiling point. If this is the case, then during this time period steel vapor would not be available as a dispersal mechanism. If fission gas is no longer available to disperse the fuel, then gravity-driven fuel collapse is suggested. If a neutronic excursion occurs, the fuel vapor would probably disperse the fuel and provide a mechanism for rapid mixing of fuel and steel. Upon termination of the excursion, steel vaporization would be available for fuel dispersal. 
Table A.1

Computed Dimensionless Steel Vapor Generation Rates

\begin{tabular}{|c|c|c|}
\hline $\begin{array}{l}\text { Pressure } \\
\text { (bar) }\end{array}$ & TFuel $\underset{(K)}{-}$ Steel & $j_{g{ }^{\infty}} / U_{\infty}$ \\
\hline 1 & 100 & 158.0 \\
\hline 1 & 10 & 15.8 \\
\hline 10 & 100 & 25.0 \\
\hline 10 & 10 & 2.5 \\
\hline
\end{tabular}


The above calculational results suggest that following fuel disruption, several seconds may be required to bring the steel to its boiling temperature. Once this occurs, however, there would potentially be sufficient steel vaporization to provide a mechanism for fuel dispersion. The steel could disperse the molten fuel to at least twice its fully dense volume.

\section{A.2 Molten Fuel and Steel Relocation and Blockage Development}

\section{A.2.1 Clad Relocation}

Following clad melting, steel relocation will occur due to two effects: (i) gravity drainage, and (ii) flooding by sodium vapor streaming past the molten cladding. These processes would deposit molten steel into the blanket or reflector regions. Refreezing of the molten steel on the relatively cold cladding could occur, thereby temporarily retarding further relocation of molten fuel and steel.

The freezing of molten steel on cold cladding is limited by conduction heat transfer through the growing layer, and by the rate of flow of molten steel to the cold structure. Since the steel conductivity is relatively large, the freezing rate is limited by the steel flow dynamics. Flooding of molten steel by sodium vapor leads to upward relocation of steel and subsequent freezing. The closing of passages for sodium vapor flow then leads to drainage of the steel into the lower blanket structure. The extent to which the above processes occur depends on the time available between clad melting and fuel relocation.

In the case of low void coefficient cores, the power level at clad melting is approximately nominal $\left(P / P_{O}=1\right)$. Seconds would be available for clad relocation. The data available from TREAT and SLSF tests indicate that steel blockages developed in both upper and lower structures. In the 7-pin TREAT tests, the upper blockages were only several $\mathrm{mm}$ thick. The lower blockages and lower structures were $2 \mathrm{~cm}$ and $5 \mathrm{~cm}$, respectively. While the blockages were not coherent, i.e., some vapor flow could be sustained, they were sufficiently coherent as to prevent relocation of molten fuel beyond the blockage locations. These results suggest that steel blockages would develop in low void coefficient cores and would temporarily retard relocation of molten fuel away from the core region.

In the case of high void coefficient cores, the power level at clad melting would be at least ten times nominal $\left(P / P_{0}=10\right)$. The time available before fuel disruption would only be tenths of seconds. It is not clear that sufficient time would be available for relocation of sufficient steel to the cold structure to form blockages. Experimental data are not available.

\section{A.2.2 Molten Fuel-Steel Mixture Relocation}

Molten fuel-steel mixtures would be ejected from the core region into the upper and lower pin structure if steel blockages do not obstruct the flow passages. The extent of fuel removal from the core region following fuel disruption governs, to a large extent, the neutronic state of the core. 
Prediction of the extent of fuel penetration in, or beyond, the axial pin structure is crucial to the transition phase accident sequence.

The mechanism of freezing of two-phase molten fuel-steel mixtures within pin structure is uncertain. Section 4.4 surimarizes the available models and assumptions which have been proposed to characterize the freezing process. Table 4.3 sumarizes the available experimental data pertinent to freezing of flowing $\mathrm{UO}_{2}$ mixtures in duct and bundle geometry. The major conclusion to be drawn from Section 4.4 is that models based upon fuel conduction-limited freezing with stable fuel crust growth greatly overestimate the observed therritite penetration distances in pin structure. While the details of the freezing mechanisms involved are not understood, it is clear that assuraptions involving a combination of unstable fuel crust yrowth, wall melting and ablation lead to models which give reasonable agreement with the observations. A definitive model for fuel relocation and freezing in bundle geometry, however, has yet to be developed.

The pin bundle data of Table 4.3 are all characterized by high source pressure $(25-66 \mathrm{~atm})$. The data involved ejected molten fuel milasses of 0.5 and $2.0 \mathrm{~kg}$. The $0.5 \mathrm{~kg}$ experiments simulate conditions where molten core material from a single subassembly is ejected through its associated pin structure. The $2.0 \mathrm{~kg}$ experiments simulate conditions where larger masses of molten material are ejected through the pin structure.

The experimental datd suggest that if molten fuel and steel at approximately $3000^{\circ} \mathrm{C}$ from a single subassembly are ejected through the associated pin structure, and if the clad temperature is between 400 and $900^{\circ} \mathrm{C}$, the material would penetrate in the range of $20-40 \mathrm{~cm}$ before freezing. This is taken as the best estimate of molten fuel and steel penetration in pin structure. It is recognized, however, that a mechanistic understanding of the experinental results is not at hand.

The above conclusions are based upon high source pressure experiments. Low-pressure tests have since been executed at ANL, with apparently sinilar results (Spencer, 1979).

\section{A.3 Blockage Melt-Through}

Consider a complete blockaye in the upper pin structure. The time required to melt such a blockage depends upon

(i) plug composition, void content, geometry, and subcooling,

(ii) heat transfer mechanism which supplies energy to the pluy from the lower surface,

(iii) heat removal mechanisns, and

(iv) internal heat generation rate.

The characteristics of the blockages delineated in (i) depend upon the mechanisms of blockages formation, about which little is known. The available 
evidence (Spencer, 1979) however, points to a strong role of entrained steel in the mechanism of blockage development. The extent of entrained steel influences the time to melt the blockage. Two blockage models are used below to estimate the time to melt the blockage. First, a pure fuel blockage is assumed. Second, a fuel-steel blockage is considered.

\section{A.3.1 Fuel Blockages}

Assume that the blockage is pure fuel with no void content. Further, assume heat losses from the blockage are negligible. A lumped parameter energy balance on the melting plug is

$$
\Delta t\left(Q^{\prime \prime} ' V+q^{\prime \prime} A\right)=\left(c_{f} \Delta T_{s u b}+h_{s_{f}}\right) \rho_{f} V
$$

and, therefore,

$$
\Delta t=\rho_{f}\left(\frac{c_{f} T_{s u b}+h_{f s}}{Q_{0}^{1 ! 1}}\right)\left(\frac{1}{\frac{P_{P_{0}}}{P_{0}}+\frac{q^{\prime \prime}}{Q_{0}^{1 !} H}}\right)
$$

The mechanism of heat transfer from a boiling mixture to the upper surface of the blockage has not been previously studied. If the fluid is vigorously boiling, then molten fluid would intermittently wash the surface of the blockages. It is conceivable that a liquid film would continually adhere to the surface, but would be agitated by the fluid being thrust upward by the boiling process. Correlations for this mode of heat transfer are unavailable. The best that can be done at this point is to attempt to bound the heat transfer rate.

The heat flux to the vertical boundaries of the molten fuel-steel boiling system (see Section A.5.1) has been estimated to be in the range $10^{6}$ $10^{7} \mathrm{~W} / \mathrm{m}^{2}$. It can be shown that if $q^{\prime \prime}<10^{6} \mathrm{~W} / \mathrm{m}^{2}$, then the heat flux term in Eq. (A.7) is negligible for cases of practical interest. So, Eg. (A.7) is plotted in Fig. A.l with $q^{\prime \prime}$ treated parametrically up to $10 \mathrm{~W} / \mathrm{m}^{2}$. It seems unlikely to be more than an order of magnitude greater than the vertical heat flux. The results presented in Fig. A.l assume that the fuel is initially at its melting temperature. If the blockage occurs as a result of fuel freezing due to transfer of heat to the cladding, small subcooling appears a reasonable assumption. However, subcooling as large as $500 \mathrm{~K}$ would only increase the melting time of Fig. A.l by a factor of two.

\section{A.3.2 Fuel-Steel Blockages}

It is assumed that steel is entrained in a continuous fuel medium and acts as a heat sink which freezes the fuel to form the blockage. Since fuel is the continuous medium, it is assumed that the fuel volume fraction is 


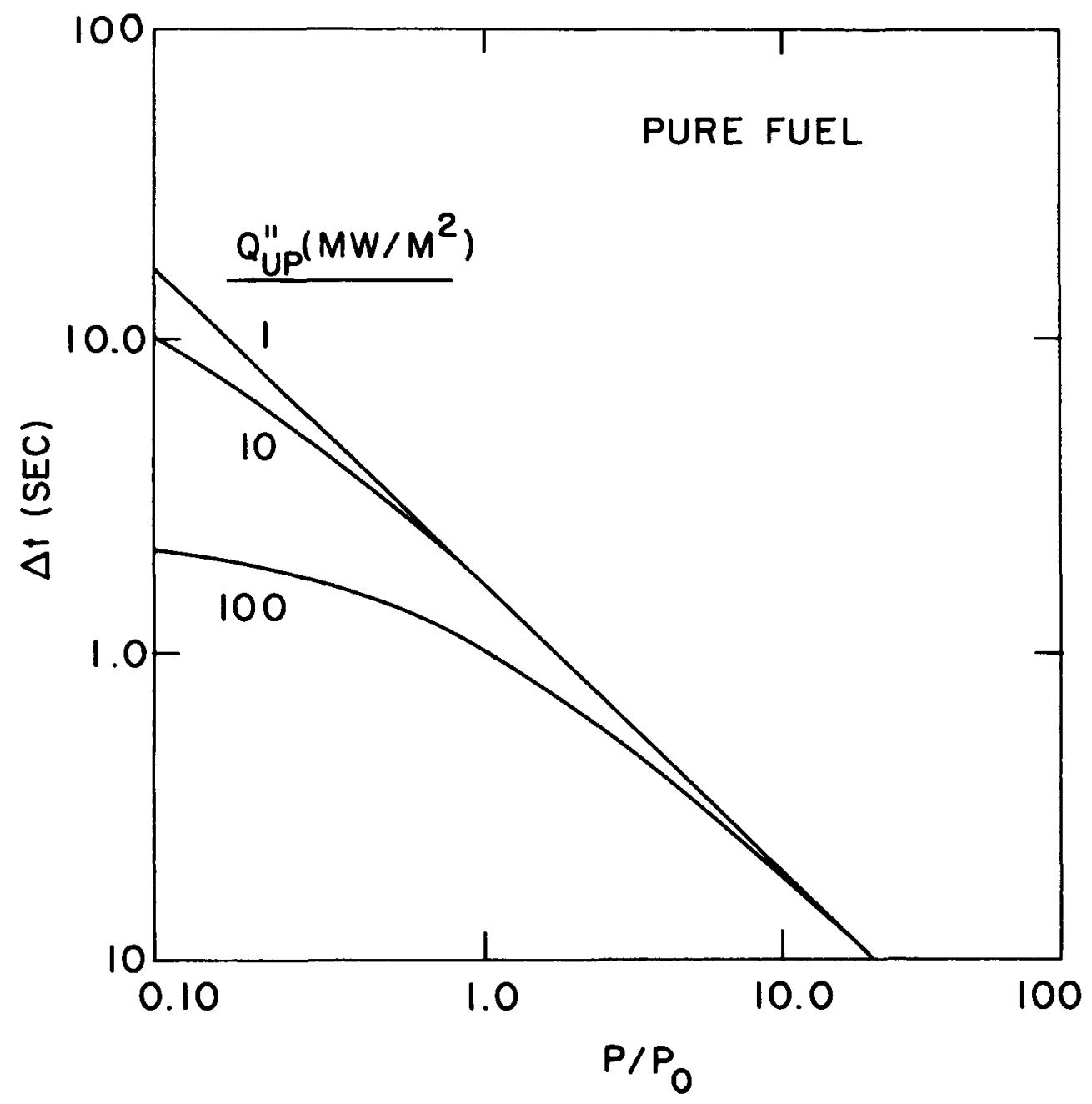

Figure A.1 - Melting Time of Pure Fuel Blockage, Thickness $=0.1 \mathrm{~m}$, Zero Subcooling

$-101-$ 
greater than 0.5. Following entrainment, it is assumed that fuel and steel temperatures equilibrate, at which point the fuel freezes. Melting of the fuel-steel blockage (steel is liquid) ensues. It is assumed that the fuel and steel mixture heat up in thermodynamic equilibrium until the fuel is fully molten.

Assume that $V_{f}$ and $V_{s}$ are the volumes of fuel and steel in the blockage, and that $T_{f}$ and $T_{s}$ are the initial fuel and steel temperatures prior to blockage formation. Upon equilibration to form the blockage, the temperature, $T$, of the blockaye is computed by an energy balance on the fuelsteel system:

$$
\rho_{f} V_{f}\left[c_{f}\left(T_{f}-T\right)+h_{s f}\right]=\rho_{s} V_{s} c_{s}\left(T-T_{s}\right)
$$

The blockaye temperature is, therefore,

$$
T=\left(T_{f}+\frac{h_{s}}{c_{f}}+R T_{s}\right) /(1+R)
$$

where

$$
R \equiv \frac{\rho_{s} V_{s} c_{s}}{\rho_{f} V_{f} c_{f}}
$$

The minimum volume fraction of steel which would freeze the fuel just to its freezing temperature is obtained from $\mathrm{Eq}$. (A.9) by setting $\mathrm{T}=\mathrm{T}_{\mathrm{m}}\left(\mathrm{UO}_{2}\right)$. For this condition, it is found that $V_{S} / V_{f}=0.29$, or $V_{S} / V=0.22$.

If the fuel volume fraction is 0.5 and the molten fuel temperature is $3200 \mathrm{~K}$, it is found from Eq. (A.9) that the blockage temperature would be $T=2575 \mathrm{~K}$, and the subcooling $\Delta T=T-T_{m}\left(U 0_{2}\right)=598 \mathrm{~K}$. This extent of blockage subcooling is quite large. It is used as an upper estimate of subcooling for calculations of blockage melting time.

Assume as discussed above that the plug forms due to mixing of fuel and cold steel at its melting temperature. Fuel and steel heat up in equilibrium until the fuel melts. The initial blockage temperature is T. A lumped parameter energy balance in the fuel and steel is

$$
\Delta t\left(Q^{\prime \prime \prime} V_{f}+q^{\prime \prime} A\right)=\left[c_{f}\left(T-T_{m, U O_{2}}\right)+h_{s_{f}}\right] \rho_{f} V_{f}+c_{s}\left(T-T_{m, s}\right) \rho_{s} V_{s}
$$


and the melting time is

$$
\Delta t=\frac{\rho_{f}\left(c_{f} \Delta T+h_{s_{f}}\right)}{Q_{0}^{\prime \prime \prime}}\left[\frac{1+R}{\frac{P}{p_{0}}+\frac{q^{\prime \prime} V}{Q^{\prime \prime \prime} V_{f} H}}\right]
$$

where $R$ is defined in Eq. (A.10).

The blockage melting time is computed for the two conditions just described above:

(i) $V_{S} / V_{f}=0.29$ and $\Delta T=0$, corresponding to just enough steel entrainment to freeze the fuel.

(ii) $V_{S} / V_{f}=1.0$ and $\Delta T=598 \mathrm{~K}$, corresponding to an upper limit on steel entrainment and subcooling, consistent with the assumption of a continuous fuel blockage.

The results of these two cases are presented in Figs. A.2 and A.3.

For the first case, little significant difference from the pure fuel calculation (Fig. A.l) is observed. For the second case, the large subcooling and large amount of sensible heat absorbed by the steel increases the estimate of blockage melting time to approximately one minute at decay levels of 10 percent, and to the order of ten seconds at full power. It is felt that these numbers represent an upper estimate of the meltout times.

\section{A.3.3 Summary}

Based upon the set of calculations presented above, it is judged that fuel, or fuel-steel blockage meltout times would be in the range 5-20 seconds at decay power level. At full power, several seconds would be required, and at ten times full power less than a second would be required for blockage meltout.

\section{A.4 Duct Wall Melt-Through}

Consider a section of a stainless steel hexagonal duct wall. It is assumed that a solid fuel crust separates the steel from the molten boiling mixture of fuel and steel. The heat flux from the pool to the crust is $\mathrm{qp}_{\mathrm{p}}$. The flux to the steel is $q_{s}$. It is assumed that the heat flux to the crust can be approximated by quasi-steady heat transfer. The heat flux to the steel is approximated by

$$
q_{s}^{\prime \prime}=\left[q_{p}^{\prime \prime 2}+2 k_{f} \Delta T_{c} q^{\prime \prime \prime}\right]^{1 / 2}
$$




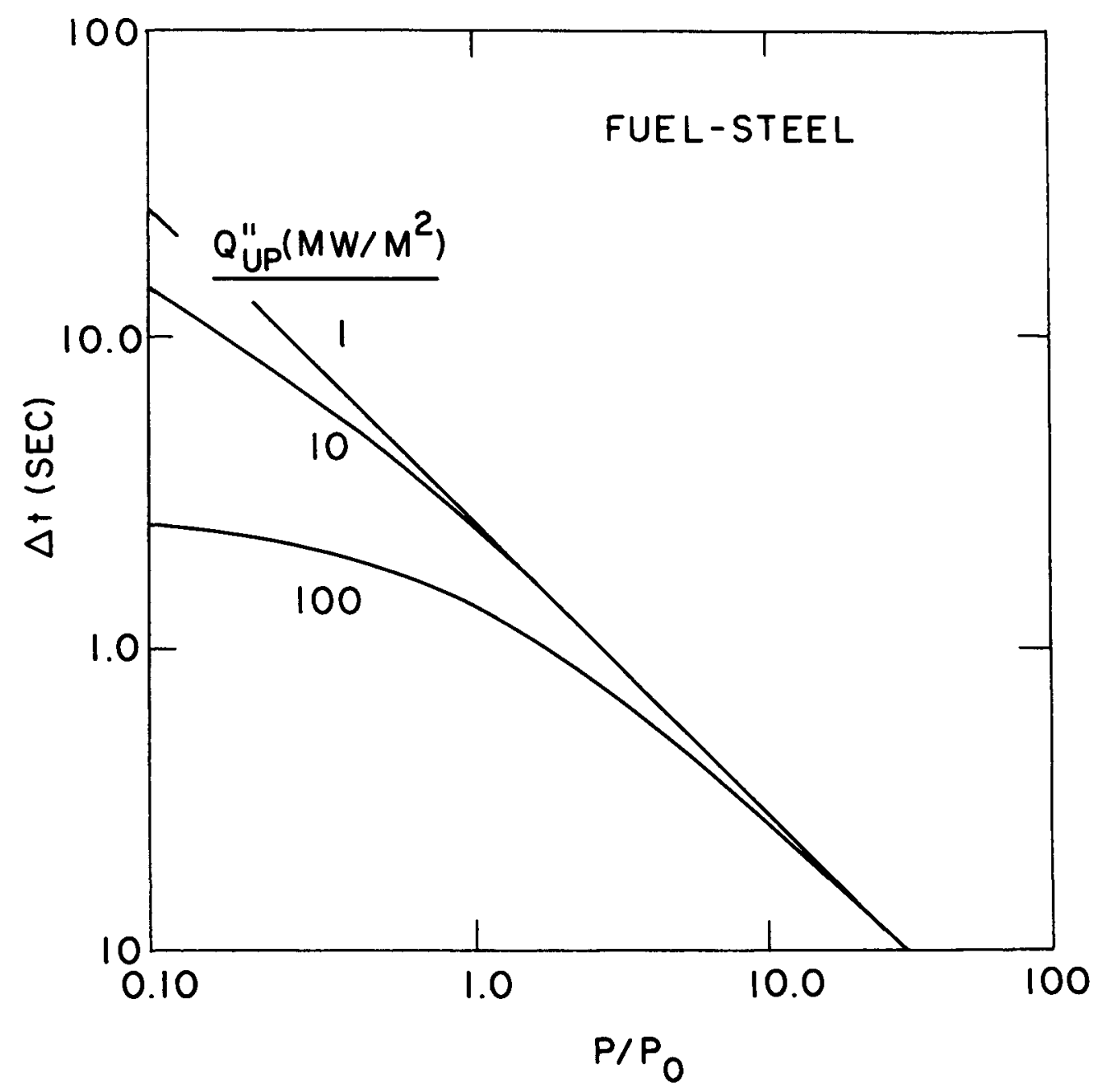

Figure A.2 - Melting Time of Fuel-Steel Blockage,

Thickness $=0.1 \mathrm{~m}$, Zero Subcooling, $V_{S} / V_{F}=0.29$ 


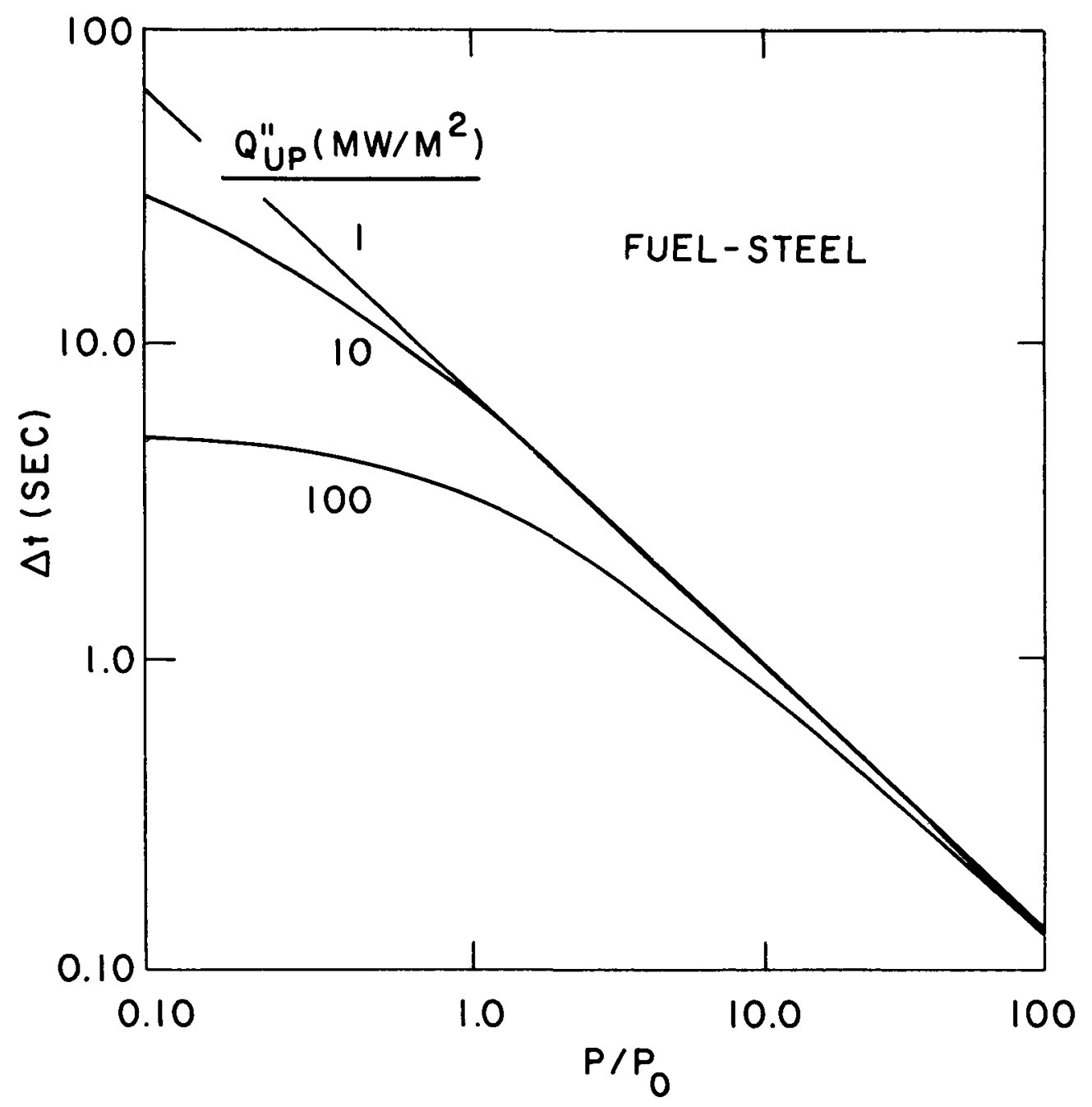

Figure A.3 - Melting Time of Fuel-Steel Blockage, Thickness $=0.1 \mathrm{~m}$, Subcooling $=528 \mathrm{~K}, V_{\mathrm{S}} / V_{\mathrm{F}}=1.0$ 
where the temperature difference across the crust is $\Delta T_{C}$. The steady state crust thickness is

$$
\delta=\frac{1}{Q^{\prime \prime \prime}}\left[\sqrt{q_{p}^{\prime \prime 2}+2 Q^{\prime \prime \prime} k_{f} \Delta T_{c}}-q_{p}^{\prime \prime}\right]
$$

The heat flux on the pool-side is

$$
q_{p}^{\prime \prime}=h\left(T_{p o o r}-T_{m, \cup O_{2}}\right)
$$

The coefficient $h$ is determined by the mechanisms of heat transfer from the boiling mixtures of fuel and steel to the boundaries of the container. Figure 4.2 presents the boiling pool data obtained from single-component boiling pool experiments. The correlations shown in Fig. 4.2 were used to estimate the heat transfer to the duct wall. It is assumed that the boiled-up pool height is $1 \mathrm{~m}$ and the void fraction is 0.5 . For the bubbly flow regime, it has been suggested (Greene, 1979b) that the mechanism of heat transfer is due to bubble-circulation enhanced boundary layer flow. The thermal properties of the boundary layer should be used in the correlation of Fig. 4.2. If it is assumed that the boundary layer is pure fuel, then the product $\mathrm{Gr} * \mathrm{Pr}$ is approximately $1.2 \times 1013$. The Nusselt number, $\mathrm{Nu}=\mathrm{hL} / \mathrm{k}$, is approximately 5000 . Using fuel properties, it is found that $h=14.5 \mathrm{~kW} / \mathrm{m}^{2} \mathrm{~K}$. Preliminary data indicate that churn-turbulent flow heat transfer is a factor of two higher than for bubbly flow. It is noted that if the effective fuel-steel mixture conductivity is used to account for the possibly enhanced heat transfer due to the presence of steel, and is given by,

$$
\frac{k}{k_{f}}=\left[1+\frac{\gamma\left(k_{s}-k_{f}\right)}{\left(1-\gamma^{1 / 3}\right) k_{s}+\gamma^{1 / 3} k_{f}}\right]
$$

For a steel mass fraction of 0.5 , it is found that $k=3 k_{f}$. This factor of three combines with the factor of two due to flow regime effects to give a factor of six possible variation in the heat transfer coefficient. In addition, the temperature difference in Eq. (A.15) may be as much as several hundred degrees Kelvin. The duct melt-out times were, therefore, computed parametrically, with the heat flux treated as a variable.

The results are presented in Fig. A.4. The calculations indicate that duct walls will melt through in several seconds at decay heating levels, and at approximately one second at higher power. The upper value of $8 \mathrm{~s}$ corresponds to a condition of $h=14.5 \mathrm{~kW} / \mathrm{m}^{2} \mathrm{~K}$ and $\Delta T=100 \mathrm{~K}$. Crust thicknesses corresponding to the conditions of these calculations are presented in Fig. A.5. The stability of the submillimeter crusts is doubtful. Even higher heat transfer rates and shorter melt-out times are conceivable if the crusts are indeed unstable. 


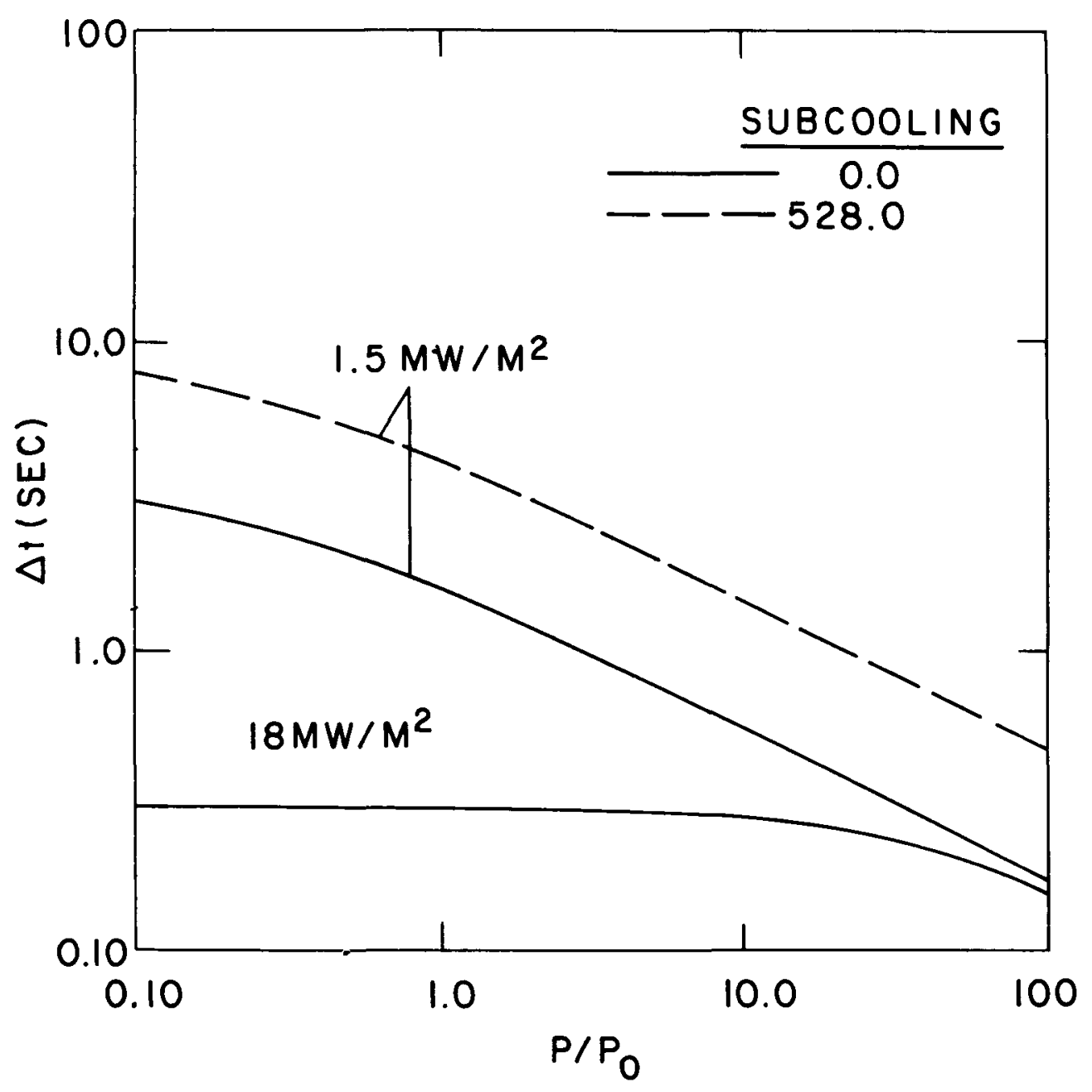

Figure A.4 - Duct Wall Melting Time 


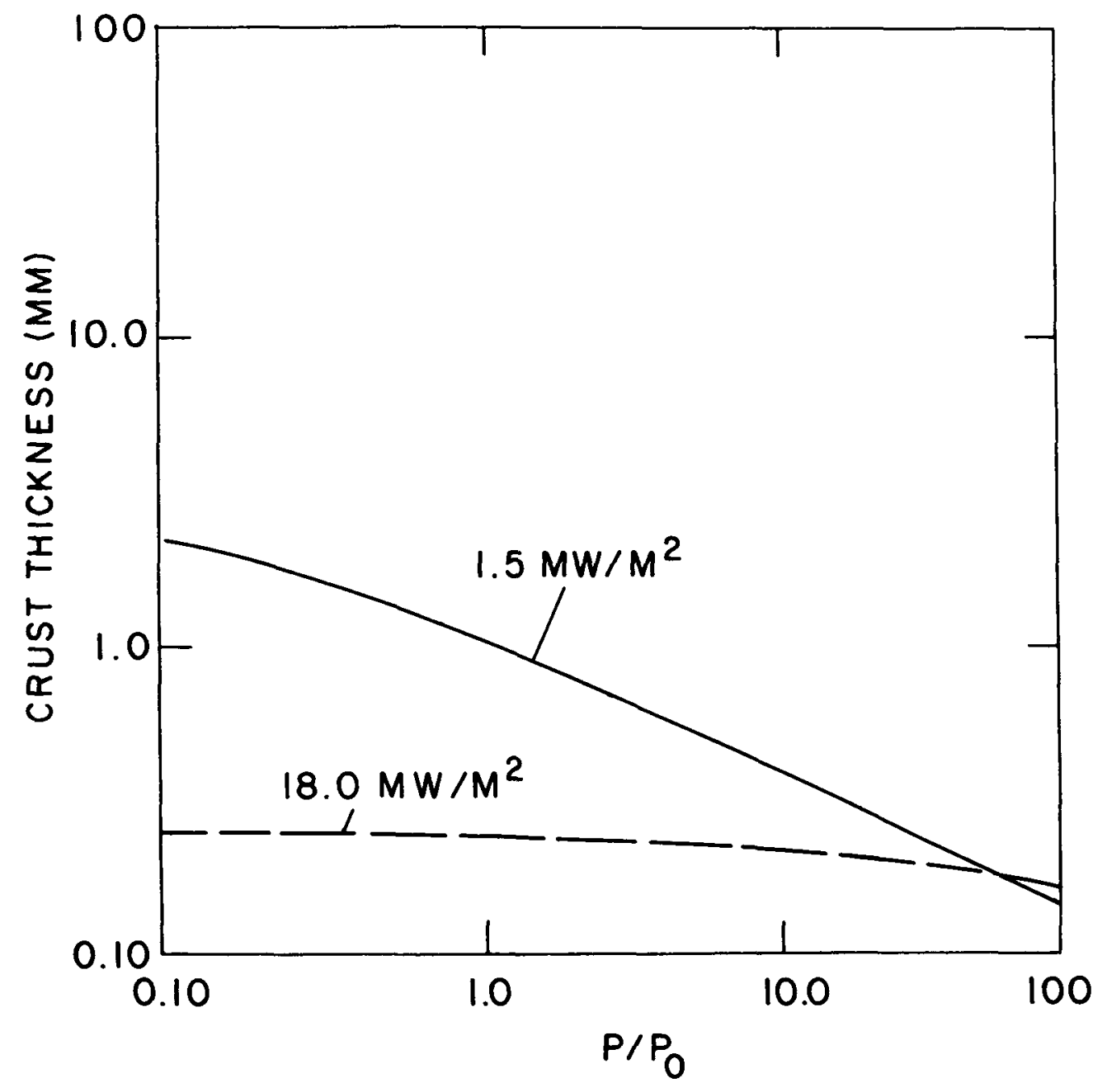

Figure A.5 $-\mathrm{UO}_{2}$ Crust Thickness 


\section{A.5 Small-Scale Pool Energy Balances}

It is likely that boiling pools of molten steel and fuel would develop during the transition phase as a result of blockage formation by refrozen fuel and/or steel. In the early stages of the transition phase, these pools would be contained within intact individual subassembly ducts. As the accident progresses, duct wall melting would occur, subcooled steel would enter the pools and would likely act as a distributed heat sink. The pools would grow from subassembly scale to core-wide scales. They would attack the axial boundaries, blockages would remelt and would permit some outflow of fuel and steel before refreezing would take place. The core power level during this time period is likely to vary between decay heating levels to possibly large power levels many times steady state.

Analysis of the transient dynamics of boiling pool behavior is beyond the scope of the present work. Since the neutronics characteristics of the collection of boiling pools depend on the extent of pool boilup, it is of interest to discuss basic pool energy balances. If a system energy balance indicates a net heat loss, then pool collapse is suggested. If, on the other hand, an energy balance indicates net heat generation, then pool boiling is possible, although system pressurization effects would limit the magnitude of vapor generation and, hence, pool boilup and fuel dispersal.

In principle, energy balances must be done on a local differential basis. This is not done here. Instead, global energy balances are approximated, and attention is directed towards phenomenological uncertainties which may impact the transition phase accident sequence.

Pool energy balances are here considered for two circumstances. The first case is directed to the early part of the transition phase where pools are contained in subassembly ducts which are not yet melting into the pool. The second case considers molten pools into which the duct walls are melting.

\section{A.5.1 Nonmelting Duct Walls: Small Scale Pools}

Consider a molten pool of fuel and steel which is confined to a single subassembly. Assume that the axial extent of the pool is $1 \mathrm{~m}$, with complete blockages at its axial extremities. For an average core linear power of 23 $\mathrm{kW} / \mathrm{m}$ (typical of CRBR), the power generated by a single subassembly is 4.9 Mw. It is assumed that the molten pool is boiling and occupies the entire volume of the $1 \mathrm{~m}$ high available region. In subassembly scale pools, the heat losses to the vertical walls clearly overshadow the losses to upper and lower surfaces. The area for heat transfer from the pool to the duct wall is approximately $0.35 \mathrm{~m}^{2}$. As in Section A.4, the boiling pool heat flux is assumed to be in the range of $1.5-18 \mathrm{MW} / \mathrm{m}^{2}$. The ratio of heat lost to heat generated in a single subassembly pool is presented in Fig. A.6. Also presented in Fig. A.6 are the results for a pool of $0.30 \mathrm{~m}$ in diameter, which approximates a seven-subassembly pool. The heat transfer area is approximately $0.94 \mathrm{~m}$.

Figure A.6 demonstrates that at decay power, $P / P_{0}=0.10$ single subassembly pool would experience a net heat loss and boiling, therefore, 


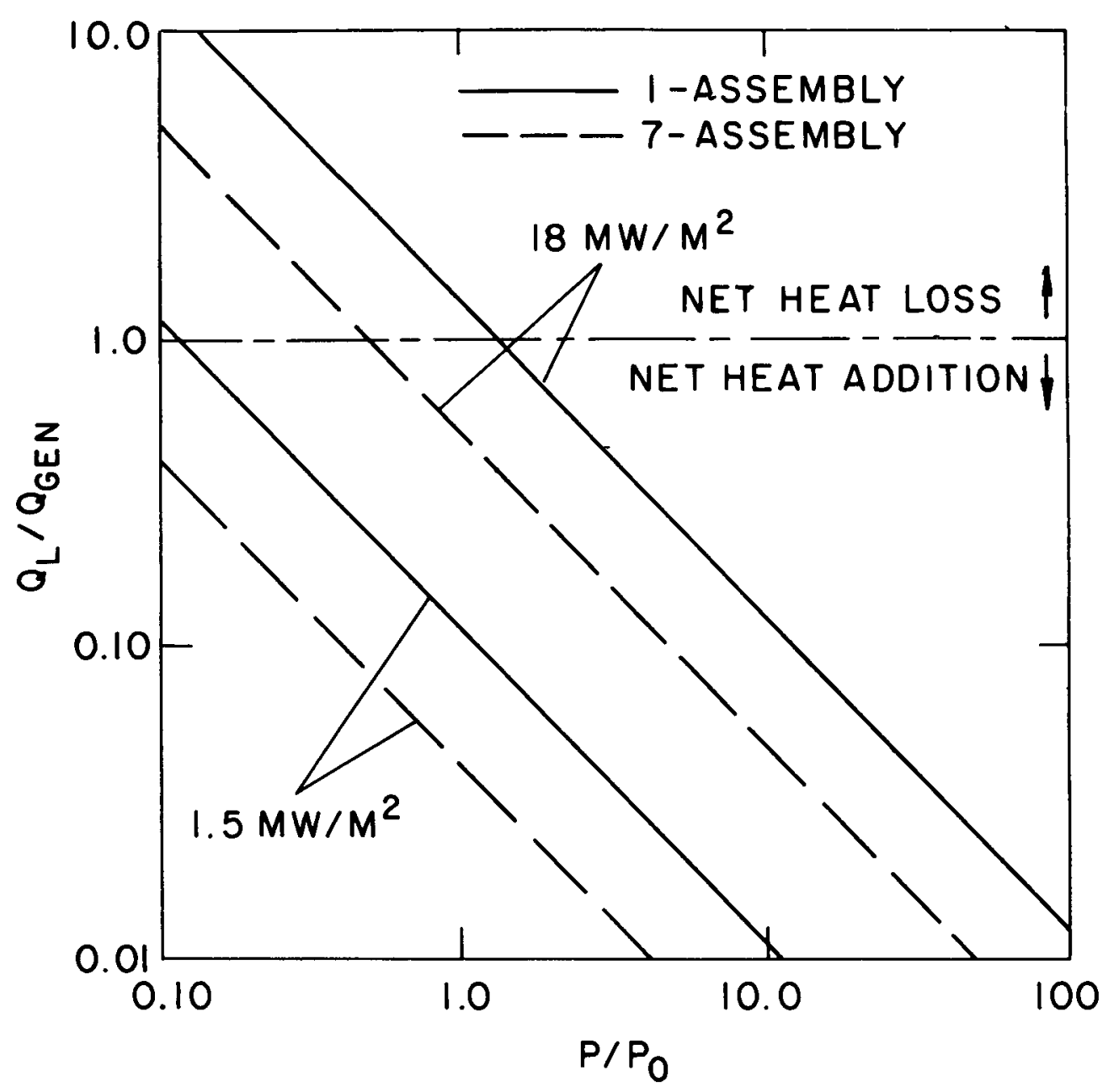

Figure A.6 - Boiling Fuel-Steel Pool Heat Losses 
could not be sustained. The results indicate that at decay power, $P / P_{0}=$ 0.10 , the uncertainty in heat flux precludes a definitive conclusion about whether or not seven-subassembly pools would generate more heat than they lose. At higher power levels, $P / P_{0}>1$, both single- and seven-assembly pools would generate more heat than they 1 ose.

Since systems with net heat loss cannot sustain net vapor generation, these fuel-steel mixture systems would tend to be nonboiling and in a fully compacted configuration. The systems characterized by net heat addition, and, hence, net vapor generation, would be pressurizing. While the vapor generated can sustain a boiled-up fuel-steel configuration, a good deal of the available energy would be consumed in sensible heating with only a fraction available for vapor generation (Dhir, et al., 1976). The vapor generation rate would have to be determined by a system energy balance which accounts for sensible heating effects.

The above discussion suggests that the uncertainties in boundary heat loss estimates must be reduced in order to accurately characterize the boiling behavior of small scale subassembly pools, with no melt-in of subcooled steel, especially at decay heating levels.

\section{A.5.2 Melting Duct Walls: Small-Scale Pools}

Subassembly duct wall melt-in may have a significant influence on boiling pool energy balances (Jackson, et al., 1977a). The melting steel would enter the pool approximately $1500 \mathrm{~K}$ subcooled and could, therefore, act as a strong distributed heat sink which would absorb energy from the boiling system. The rate of heat transfer from the boiling steel mixture to the subcooled steel depends upon the rate of melting, upon the geometry of the cold steel and upon the mechanism of heat transfer to the liquid. The melt-in heat transfer process cannot, at present, be predicted from first principles, and relevant experimental data are not available.

The mode of duct wall steel flow into the pool is unclear. Fuel crusts inhibit the melt-in process. When the duct walls lose their integrity, however, it is expected that a large fraction of the steel would then mix with the boiling mixture. The only factor that is clear is that the heat transfer from the pool to the duct wall controls the rate of steel melting.

In order to estimate the possible impact of the cold molten steel on the pool boiling behavior, the following model was adopted: it is assumed that the duct-wall steel is at its melting temperature as it flows into the pool. As it enters the pool at a rate $m_{s}$, the steel instantaneously equilibrates thermodynamically with the pool contents. The rate of flow of molten fluid into the pool is limited only by the rate of steel melting which, in turn, is assumed proportional to the rate of heat transfer to the boundaries, i.e.,

$$
\dot{m}_{s}=Q_{b} / h_{f s}
$$


A lumped-parameter energy balance on the molten fuel component of the pool is

$$
\frac{d}{d t} m_{f} h_{f}=Q_{G E N}-Q_{b f}-q_{f s}
$$

and for the molten steel the balance equation is

$$
\frac{d}{d t} m_{s} h_{s}=-Q_{b s}+q_{f s}+\dot{m}_{s} h^{*}
$$

Adding Eqs. (A.18) and (A.19), the resulting mixture energy balance is

$$
m_{s} \frac{d h_{s}}{d t}+m_{f} \frac{d h_{f}}{d t}=Q_{G E N}-Q_{b}+\dot{m}_{s}\left(h^{*}-h_{s}\right)
$$

where the net heat transfer to the boundary is $Q_{b}=Q_{b s}+Q_{b f}$. It is assumed that the fuel and steel are in thermodynamic equilibrium, and that the rate of steel melt-in is given by Eq. (A.17). The resulting mixture energy equation is

$$
\left(m_{s} c_{s}+m_{f} c_{f}\right) \frac{d T}{d t}=Q_{G E N}-Q_{b}\left[1+\frac{h_{s}-h^{*}}{h_{f s}}\right]
$$

Equation (A.21) implies that the effect of melt-in and entrainment of the duct walls is to enhance the pool heat losses by the quantity

$$
E=\frac{h_{s}-h^{*}}{h_{f s}}=\frac{c_{s}\left(T_{s}-T_{m, s}\right)}{h_{f s}}
$$

If the pool temperature is $3200 \mathrm{~K}$, then $\mathrm{E}=4.5$. Thus, the highly subcooled steel can potentially act as a heat sink of nearly five times the strength of the boundary losses. Obviously, there are reasons to believe that the heat absorption characteristics of the steel would not be as great as indicated above. Mechanistic arguments are, however, at present difficult to justify. The potential indicated by the above model, however, indicates that future work must be directed towards quantification of the basic mechanisms involved in melting and entrainment of structural steel into boiling fuel-steel mixtures.

The heat balance calculation of Fig. A.6 taken together with Eq. (A.22), implies that during the duct-wall melt-in stage, the potential for fuel collapse at decay heat levels is significant for single-subassembly pool. This situation is less clear for seven-subassembly scale pools. At full power conditions, the uncertainties in heat flux preclude firm conclusions on the 
potential of heat generation for the case of single-subassembly pools. It seems likely that seven-subassembly pools (or greater) would be characterized by net heat addition to the pool at full power. At greater than full power conditions, even single-assembly pools would generate more heat than it would lose, and vaporization could be sustained. The potential for fuel dispersal, therefore, would exist under these conditions.

\section{A.6 Whole-Core Energy Balance}

In order to perform a global energy balance on a core-wide pool, heat transfer correlations for the upward, downward, and sideward heat fluxes are required. It is assumed that the pool is closed at the top. The mechanisms of heat transfer to the vertical boundaries are assumed identical to those described in section A.5. The upward heat transfer rate is appoximated by the lateral component. The same heat transfer uncertainties apply. The range of heat flux used in that section is al so used here, i.e., q" $=1.5-18$ $\mathrm{MW} / \mathrm{m}^{2}$ with stable fuel crusts. Heat transfer in the downward direction is estimated by using the correlation suggested by Baker, et al . (1977)

$$
\frac{q_{D}^{\prime \prime}}{\left(k_{f} \Delta T_{D} Q^{\prime \prime \prime}\right)^{1 / 2}}=5.32(1-\alpha)
$$

which applies to systems with vapor fluxes greater than $6.3 \mathrm{~cm} / \mathrm{s}$. Application of this correlation involves several uncertainties:

(i) If the fuel crust is unstable and if heat is transferred to a layer of melting steel, then a "film-boiling" type of heat transfer mechanism suggested by Dhir (1977) may be applicable.

(ii) The vapor fluxes of interest in transition phase analysis are considerably greater than the $50 \mathrm{~cm} / \mathrm{s}$ upper limit of the laboratory experiments which led to Eq. (A.23).

(iii) The fluid conductivity can be greater than that of pure fuel, due to the presence of stainless steel.

These uncertainties were considered in the estimates of pool heat loss.

It was assumed that both the pool radius and the pool height are $1 \mathrm{~m}$. The calculation results are summarized in Table A.2. Two calculation results are presented for each power level, representing low and high estimates of the heat transfer rates.

The results, which are insensitive to power level, indicate that if the whole-core pools transfer heat to boundaries covered by stable fuel crusts, then heat losses are a small fraction of the heat generated for full power conditions or greater. Vapor production and, hence dispersal by boilup, can be sustained. Pressurization and sensible heating, however, must be considered in computing the vapor generation rate. Only under decay heating could the heat losses approach the heat generated. 


\section{Table A.2}

\section{Results of Whole-Core Energy Balances}

\begin{tabular}{|c|c|c|c|c|c|c|}
\hline$P / P_{0}$ & $\begin{array}{c}P \\
(M W)\end{array}$ & $\begin{array}{l}Q_{\text {SIDE }} \\
(-M W)\end{array}$ & $\begin{array}{r}\text { QUP } \\
\text { (MW) }\end{array}$ & $\begin{array}{l}\mathrm{Q}_{\mathrm{BOT}} \\
(\mathrm{MW})\end{array}$ & $\begin{array}{l}Q_{\text {TOT }} \\
\text { (MW) }\end{array}$ & \\
\hline 0.1 & 97.5 & $\begin{array}{r}9.4 \\
112.5\end{array}$ & $\begin{array}{r}4.7 \\
56.6\end{array}$ & $\begin{array}{l}1.6 \\
4.1\end{array}$ & $\begin{array}{r}15.7 \\
173.2\end{array}$ & $\begin{array}{l}\text { LOW } \\
\text { HIGH }\end{array}$ \\
\hline 1.0 & 975.0 & $\begin{array}{r}9.4 \\
112.5\end{array}$ & $\begin{array}{r}4.7 \\
56.6\end{array}$ & $\begin{array}{r}5.0 \\
12.3\end{array}$ & $\begin{array}{r}19.1 \\
181.4\end{array}$ & $\begin{array}{l}\text { LOW } \\
\text { HIGH }\end{array}$ \\
\hline 10.0 & 9750.0 & $\begin{array}{r}9.4 \\
112.5\end{array}$ & $\begin{array}{r}9.5 \\
56.6\end{array}$ & $\begin{array}{l}16.0 \\
39.0\end{array}$ & $\begin{array}{r}34.9 \\
208.0\end{array}$ & $\begin{array}{l}\text { LOW } \\
\text { HIGH }\end{array}$ \\
\hline
\end{tabular}

